Linköping Studies in Science and Technology

Thesis No 1822

\title{
Pulse-Width Modulated RF Transmitters
}

\author{
Muhammad Fahim Ul Haque
}

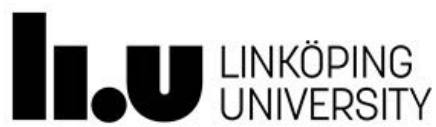

Division of Computer Engineering

Department of Electrical Engineering

Linköping University

SE-581 83 Linköping, Sweden

Linköping 2017 
Linköping Studies in Science and Technology

Thesis No 1822

Muhammad Fahim Ul Haque

muhammad.fahim.ul.haque@liu.se

www.da.isy.liu.se

Division of Computer Engineering

Department of Electrical Engineering

Linköping University

SE-581 83 Linköping, Sweden

Copyright (C) 2017 Muhammad Fahim Ul Haque, unless otherwise noted.

All rights reserved.

ISBN 978-91-7685-598-0

ISSN 0345-7524

IEEE holds the copyright for Papers B, E, and F.

Printed by LiU-Tryck, Linköping, Sweden 2017 
To my mother, father, and uncle (mamoo), 



\section{Abstract}

The market for wireless portable devices has grown significantly over the recent years. Wireless devices with ever-increased functionality require high rate data transmission and reduced costs. High data rate is achieved through communication standards such as LTE and WLAN, which generate signals with high peak-to-average-power ratio (PAPR), hence requiring a power amplifier (PA) that can handle a large dynamic range signal. To keep the costs low, modern CMOS processes allow the integration of the digital, analog and radio functions on to a single chip. However, the design of PAs with large dynamic range and high efficiency is challenging due to the low voltage headroom.

To prolong the battery life, the PAs have to be power-efficient as they consume a sizable percentage of the total power. For LTE and WLAN, traditional transmitters operate the PA at back-off power, below their peak efficiency, whereas pulse-width modulation (PWM) transmitters use the PA at their peak power, resulting in a higher efficiency. PWM transmitters can use both linear and SMPAs where the latter are more power efficient and easy to implement in nanometer CMOS. The PWM transmitters have a higher efficiency but suffer from image and aliasing distortion, resulting in a lower dynamic range, amplitude and phase resolution.

This thesis studies several new transmitter architectures to improve the dynamic range, amplitude and phase resolution of PWM transmitters with relaxed filtering requirements. The architectures are suited for fully integrated CMOS solutions, in particular for portable applications.

The first transmitter (MAF-PWMT) eliminates aliasing and image distortions while allowing the use of SMPAs by combining RF-PWM and band-limited PWM. The transmitter can be implemented using all-digital techniques and exhibits an improved linearity and spectral performance. The approach is validated using a Class-D PA based transmitter where an improvement of $10.2 \mathrm{~dB}$ in the dynamic range compared to a PWM transmitter for a $1.4 \mathrm{MHz}$ of LTE signal is achieved.

The second transmitter (AC-PWMT) compensates for aliasing distortion by combining PWM and outphasing. It can be used with switch-mode PAs (SMPAs) or linear PAs at peak power. The proposed transmitter shows better linearity, improved spectral performance and increased dynamic range as it does not suffer from AM-AM distortion of the PAs and aliasing distortion due to digital PWM. The idea is validated using push-pull PAs and the proposed transmitter shows an improvement of $9 \mathrm{~dB}$ in the dynamic range as compared 
to a PWM transmitter using digital pulse-width modulation for a $1.4 \mathrm{MHz} \mathrm{LTE}$ signal.

The third transmitter (MD-PWMT) is an all-digital implementation of the second transmitter. The PWM is implemented using a Field Programmable Gate Array (FPGA) core, and outphasing is implemented as pulse-position modulation using FPGA transceivers, which drive two class-D PAs. The digital implementation offers the flexibility to adapt the transmitter for multi-standard and multi-band signals. From the measurement results, an improvement of $5 \mathrm{~dB}$ in the dynamic range is observed as compared to an all-digital PWM transmitter for a $1.4 \mathrm{MHz}$ LTE signal.

The fourth transmitter (EP-PWMT) improves the phase linearity of an all-digital PWM transmitter using PWM and asymmetric outphasing. The transmitter uses PWM to encode the amplitude, and outphasing for enhanced phase control thus doubling the phase resolution. The measurement setup uses Class-D PAs to amplify a $1.4 \mathrm{MHz}$ LTE up-link signal. An improvement of $2.8 \mathrm{~dB}$ in the adjacent channel leakage ratio is observed whereas the EVM is reduced by $3.3 \%$ as compared to an all-digital PWM transmitter.

The fifth transmitter (CRF-ML-PWMT) combines multilevel and RF-PWM, whereas the sixth transmitter (CRF-MP-PMWT) combines multiphase PWM and RF-PWM. Both transmitters have smaller chip area as compared to the conventional multiphase and multilevel PWM transmitters, as a combiner is not required. The proposed transmitters also show better dynamic range and improved amplitude resolution as compared to conventional RF-PWM transmitters.

The solutions presented in this thesis aims to enhance the performance and simplify the digital implementation of PWM-based RF transmitters. 


\section{Populärvetenskaplig sammanfattning}

Marknaden för trådlösa bärbara enheter har vuxit betydligt under de senaste åren. Ständigt ökad funktionalitet kräver högre dataöverföringshastigheter till allt lägre pris. Hög hastighet uppnås genom kommunikationsstandarder som LTE och WLAN där signaler med höga topp-till-medeleffektförhållande (PAPR) används, som därför kräver en effektförstärkare (PA) som kan hantera signaler med stort dynamiskt område. För att hålla låg kostnad vill man använda moderna CMOS-processer där digitala, analoga och radiodelar kan integreras på ett enda chip. Att konstruera integrerade effektförstärkare i CMOS med stort dynamiskt område och hög energieffektivitet är en utmaning på grund av den låga spänningen som modern CMOS använder.

För att förlänga batteriets livslängd måste en effektförstärkare ha hög verkningsgrad eftersom den förbrukar en betydande andel av en sändares energi. I konventionella sändare för LTE och WLAN används effektförstärkare med reducerad maximal (avbackad) effekt för att nå linjaritet, vilket sänker verkningsgraden. Genom att använda pulsbreddsmodulering (PWM) kan istället effektförstärkaren användas vid sin toppeffekt, vilket ger hög verkningsgrad. PWM-baserade sändare kan använda linjära effektförstärkare men också reläkopplade (switchar, switched-mode PA, SMPA) förstärkare som har hög verkningsgrad och är lätta att konstruera i modern CMOS. PWM-sändarna lider dock av effekter som uppkommer när signaler flyttas i frekvens och digitaliseras, vilket resulterar i ett lägre dynamiskt område och lägre amplitud- och fasupplösning.

I denna avhandling studeras ett flertal nya sändararkitekturer för att förbättra det dynamiska området, amplitud- och fasupplösning i PWM-sändare. Arkitekturerna är lämpade för fullt integrerade CMOS-realiseringar, i synnerhet för bärbara tillämpningar i t.ex. mobiltelefoner.

Sex olika sändararkitekturer har studerats som på olika sätt förbättrar frekvenseffekter, minskar behovet av filtrering, förbättrar verkningsgraden genom att använda switchade förstärkare eller linjära förstärkare vid toppeffekt, använder kretsblock med ren digital teknik, samt har flexibilitet att anpassa sändare för flera olika standarder och olika frekvensband. Genom simuleringar med ett flertal olika verktyg och mätningar på chip och kommersiella förstärkare har de olika koncepten validerats och förbättringar mätts upp.

De sändararkitekturer som presenteras i denna avhandling syftar till att förbättra prestanda och förenkla de digitala realiseringarna i CMOS av PWMbaserade RF-sändare. 



\section{Acknowledgments}

All praise is due on to Allah, the Compassionate, the most Merciful, the most Glorious, who gave me physical strength, mental capability, a loving family, skillful teachers, supporting friends and the opportunity to contribute to the ever evolving vast body of knowledge. Peace and blessing be upon the Holy Prophet Muhammad (Peace be upon Him), the last Prophet of Allah, whose life is the glorious model for humanity and who exhorted his follower to seek knowledge.

I would like to express my sincere and deepest gratitude towards the following people:

- My supervisor Adj. Prof. Ted Johansson for his guidance, patience and ever helping attitude. My research studies started under his supervision, he played the major role in improving my research and academic writing skills. It was an immense pleasure to work and learn from you. I would like to thank him for his untiring efforts and dedication towards my Ph.D. supervision.

- My co-supervisors Prof. Dake Liu and Prof. Qamar Ul Wahab for giving me the opportunity to pursue Ph.D. studies at Linköping University and introducing me to the area of RF switch-mode power amplifier.

- Assoc. Prof. Oscar Gustafsson for encouraging me to complete my research goals. I thank him for his support especially in the final year of my research studies.

- Assoc. Prof Tomas Sevensson for his guidance and help throughout my PhD. I am thankful to him, for supporting me during the low times of my research studies.

- A very special thanks to Amir Islam, for his regular advice that inculcated in me spirituality, humbleness, balanced thinking, and straight forwardness.

- Doktorand Muhammad Touqir Pasha for an excellent collaboration in research studies. It was a very nice experience to work with him. I thank him for improving my writing skills.

- Dr. Jahanzeb Ahmad of Intel programmable solutions group for collaboration on "Modified All digital PWM transmitters". 
- Doktorand Saima Athar, for her support during my PhD studies. She helped and guided me like a younger brother. I would also like thank her for teaching me the basics of cooking.

- Dr. Nadeem Afzal, Dr. Fahad Qureshi and Ali Saeed for all their support and help during my early days in Linköping which helped me to settle in this city.

- ISY administrators Gunnel Hässsler, Susanna von Sehlen and Ylva Jernling for helping out with the administrative tasks.

- Arta Alvandpour for his help in setting up the chip design tools and for arranging the test equipment.

- Anders Nilsson for his help with the office computer and equipment. He also helped me in preparing the PCBs for measurements.

- All the teachers who played an important part in my learning. Few of them who had a profound impact on me Prof. Abdul Rauf Khan, Prof. Saad Qazi, Prof. Abdul Qadir, Prof Zainab Zaidi, Prof. Atila Alvandpour, Prof. Håkan Johansson, Assoc. Prof. Kent Palmkvist, Assoc. Prof. Jerzy Dabrowski, Assoc. Prof. Mikael Olofsson, Assoc. Prof. Muhammad Imran Aslam, Assoc. Prof. Shehzad Hasan, Asst. Prof. Muhammad Asad Arfeen, Asst. Prof. Saneeha Ahmed, Asst. Prof. Amir Zeb, Asst. Prof. Shahzad Siddiqi and Dr Mehnaz.

- The former and current colleagues at Computer Engineering division, Linköping university for their help, support and creating a friendly environment. I would specially give my gratitude to Assoc. Prof. Mario Garrido, Dr. Andeas Karlssson, Dr. Muhammad Irfan Kazim, Dr. Ameya Bhide, Dr. Hashim Raza Khan, Dr. Fahad Qazi, Dr. Zaka Ullah, Dr. Muhammad Abbas, Dr. Shakila Bint Riaz, Doctorand Petter Källström, Doctorand Carl Ingemarsson and Doctrand Erik Bertilsson.

- My friends outside Linköping for morally supporting me and remembering me in prayers. I especially thank Moosa Kaleem, Dr. Tahir Malik, Masroor Ali, Muhammad Fahim, Abbas Zaidi, Waqas Saeed, Dr Ahmad Ahsan Nawaz, Noman Ahmed, Zeeshan Malik and Rahul Anil Nadgouda.

- My current and former corridor mates for create a very friendly environment for living. I would specially give my gratitude to Matti Lundgren, 
Hampus Billing, Li-Yu Chen, Erica Stigell, Fedrik Källgren, Nasir Zaman, Ishtiaq Hussain, Abdus Sami, Karthikeyen Srinivasan and Nandu.

- Finally a special thanks to my family

- My Mother, Quaisar Perveen for her sacrifices, immense love, and support. She played a pivotal part in my upbringing. Throughout her life she supported me and prayed for me.

- My uncle Dr. Muhammad Sami Hyder for all his love, support and guidance. He motivated me to pursue higher studies. He always backed my decisions regarding my career. He acted both as a fatherly figure and a friend throughout my life.

- My father Muhammad Nasim Ul Haque for all his love, support and guidance. He gave me room to make my independent decisions and supported me on them. He always guided throughout my life.

- My sister Humera Nasim for her love, moral support and prayers.

- My brothers and cousins Muhammad Rizwan Ul Haque, Muhammad Nauman Hyder and Muhammad Zeeshan Hyder for their love.

I always thank Allah to bless me such a loving and supporting family.

- To all those not listed here, I thank you for enriching my life.

Muhammad Fahim Ul Haque January 17, 2017, Linköping Sweden 



\section{Preface}

This Ph.D thesis is based on the work presented in the following publications.

- Paper A M. F. Ul Haque, M. T. Pasha, T. Johansson, "A Power efficient aliasing-free PWM transmitter", submitted to IEEE Transactions on Microwave Theory and Technique.

- Paper B M. F. Ul Haque, M. T. Pasha, T. Johansson, "Aliasing-Compensated Polar PWM Transmitter," accepted for publication in IEEE Transactions on Circuits and Systems II: Express Briefs, Sep 2016.

- Paper C M. T. Pasha, M.F. Ul Haque, T. Johansson, "A modified alldigital polar PWM transmitter", submitted to IEEE Transactions on Circuits and Systems I.

- Paper D M. F. Ul Haque, M. T. Pasha, T. Johansson, "An all-digital PWM transmitter with enhanced phase resolution", submitted to IEEE Microwave and Wireless Components Letters.

- Paper E M. F. Ul Haque, T. Johansson and D. Liu, "Combined RF and multilevel PWM switch mode power amplifier," presented at NORCHIP, Vilnius, 2013.

- Paper F M. F. Ul. Haque, T. Johansson and D. Liu, "Combined RF and multiphase PWM transmitter," presented at European Conference on Circuit Theory and Design (ECCTD), Trondheim, 2015.

The following publications are not included in this thesis. The work of these publications partially overlaps with the appended papers or is out of the scope of this thesis. 
- M. F. Ul Haque, T. Johansson, "Power efficient and large dynamic range RF-PWM transmitter," Swedish Microwave Days - Giga Hertz and Antenna EMB Symposium, March 2016, Linköping, p. 34, 2016.

- M. F. Ul Haque, T. Johansson, "Modified band-limited pulse-width modulated polar transmitter," presented at ISMOT, Dresden, July 2015.

- M. F. Ul Haque, T. Johansson and D. Liu, "Power efficient band-limited pulse-width modulated transmitter," presented at Swedish System on Chip Conference, May 4-5 2015, Göteborg.

- M. F. Ul Haque, T. Johansson and D. Liu, "Modified multilevel PWM switch mode power amplifier," presented at Swedish System on Chip Conference, Vadstena, May 12-13, 2014. 
Contents

$\begin{array}{ll}\text { Background } & 1\end{array}$

1 Introduction 3

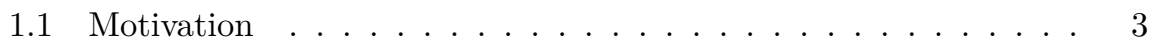

1.2 Organization of Thesis . . . . . . . . . . . . . . 5

1.3 Wireless Transmitter . . . . . . . . . . . . . . . . 6

1.3.1 Direct Conversion Transmitter . . . . . . . . . . . 6

1.3.2 Heterodyne Transmitter . . . . . . . . . . . . 6

1.4 Performance Parameters for Wireless Transmitters . . . . . . . . 7

1.4.1 Output Power . . . . . . . . . . . . . . 8

1.4.2 Type of Modulated Signal . . . . . . . . . . . . 8

1.4 .3 Efficiency ................... . . . 9

1.4 .4 Linearity . . . . . . . . . . . . . . . . . 9

1.5 RF Power Amplifier . . . . . . . . . . . . . . . . . . . . . . . 10

1.5.1 Linear PAs . . . . . . . . . . . . . . . 11

1.5 .2 Switch-Mode PA . . . . . . . . . . . . . . 13

1.6 Fabrication Technology for RF PAs . . . . . . . . . . . . . . . 16

2 Transmitter Architectures for Linearization of Power-Efficient $\begin{array}{ll}\text { Amplifiers } & 19\end{array}$

2.1 Polar Modulation . . . . . . . . . . . . . . . . . . . . . 19

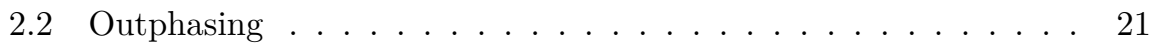

2.2 .1 Outphasing Issues . . . . . . . . . . . . . . 22

2.3 Pulse-Width Modulation . . . . . . . . . . . . . . . . 26

3 Pulse-Width Modulation Based Transmitter 27

3.1 Radio-Frequency PWM Transmitter . . . . . . . . . . . . . 27

3.2 Polar PWM Transmitter . . . . . . . . . . . . . . . . . . . . . . 29 
3.2 .1 Concept . . . . . . . . . . . . . . . . . . . . 29

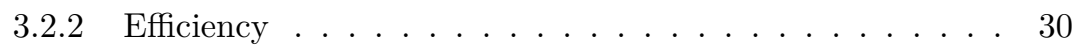

3.2 .3 Polar PWT Transmitter Issue . . . . . . . . . . . . . . . 33

4 Polar PWM Transmitters with Reduce Image and Aliasing Distortion 41

4.1 Image-Distortion Free Polar PWM Transmitter . . . . . . . . . . 42

4.1 .1 Exploiting Image Gap . . . . . . . . . . . . . . . . . 42

4.1 .2 Elimination of Image Distortion _. . . . . . . . . . . . . 42

4.2 Aliasing-Free PWM Transmitter . . . . . . . . . . . . . . . 44

4.2 .1 Concept . . . . . . . . . . . . . . . . . . 44

4.2 .2 Efficiency . . . . . . . . . . . . . . . . 46

4.3 Combined RF and AF-PWM Transmitter . . . . . . . . . . 49

4.4 Aliasing-Compensated PWM Transmitter . . . . . . . . . . 51

4.5 Simulation Results . . . . . . . . . . . . . . . . . . . . 52

4.6 Enhanced Phase Resolution All-Digital PWM Transmitter . . . . 54

5 Polar PWM Transmitters with

Relaxed Band-Pass Filtering $\quad \mathbf{5 7}$

5.1 Multi-Level PWM Transmitter . . . . . . . . . . . . . . 57

5.1 .1 Concept . . . . . . . . . . . . . . . 57

5.1 .2 Efficiency . . . . . . . . . . . . . . . . . . . . 59

5.2 Multi-Phase PWM Transmitter . . . . . . . . . . . . . . . . . 61

5.2 .1 Concept . . . . . . . . . . . . . . . . 61

5.2 .2 Efficiency . . . . . . . . . . . . . . . . . 63

5.3 Combined RF and ML-PWM Transmitter . . . . . . . . . 63

5.4 Combined RF and MP-PWM Transmitter . . . . . . . . . . . 65

6 Conclusions and Future Trends $\quad 67$

$\begin{array}{ll}\text { References } & 71\end{array}$

$\begin{array}{lr}\text { Publications } & 79\end{array}$

A A Power-Efficient Aliasing-Free PWM Transmitter $\quad 81$

B Aliasing-Compensated Polar PWM Transmitter 91

C A Modified All-Digital Polar PWM Transmitter 99 
D An All-digital PWM Transmitter with Enhanced Phase Resolution

E Combined RF and Multilevel PWM Switch Mode Power Amplifier

F Combined RF and multiphase PWM Transmitter 



\section{Background}





\section{Chapter 1}

\section{Introduction}

\subsection{Motivation}

Wireless communication technology is continuously evolving and has become an integral part of daily life. High data rate applications like high definition video streaming and online gaming place high demands on modern wireless communication systems. The demand for wireless communications has increased exponentially in the previous years and is set to further increase with the advent of remote healthcare, internet of things, autonomous cars and virtual reality applications.

The wireless operators aim to reduce the operating costs for their networks by using energy-efficient radio base stations (RBS). The power amplifiers (PAs) consume the major power of an RBS, so using power-efficient PAs would result in a lower power consumption hence reducing the operation cost. Low-efficiency PAs not only increase the power consumption but the heat generated from them contributes to long-term reliability issues. From a user's viewpoint, lowefficiency PAs lead to a shorter battery life and the excessive heat dissipation poses a challenge to the efforts of making wireless devices more portable.

Typically, CMOS has been the technology of choice for implementing digital circuits due to low cost and high levels of integration. The analog and RF circuits have typically been designed using silicon bipolar devices and GaAs due to their performance characteristics. However, due to the rapid scaling of CMOS process, the transition frequency of CMOS devices has been pushed beyond 100 $\mathrm{GHz}$ and gradually the CMOS implementations of RF circuits have become 
popular. To reduce the cost and achieve a full radio system-on-chip (SoC), it is desirable to integrate both the digital baseband and the PAs on a single chip. As the PA is the highest power-consuming component in a transceiver, its power efficiency is an important requirement. A power-efficient PA not only prolongs the battery life but also dissipates less heat thus lowering packaging costs, increasing reliability and allowing for further integration.

To increase the bandwidth utilization, modern wireless standards use complex modulation with multiplexing schemes like quadrature amplitude modulation (QAM) and orthogonal frequency division multiplexing (OFDM). These schemes generate high peak to average power ratio (PAPR) signals which place strict linearity requirements, forcing the use of linear PAs at back-off at which their efficiency drops drastically, thus decreasing the average efficiency of transmitter. Switch-mode PAs (SMPAs) are an attractive alternative as they can operate at zero losses, ideally resulting in highly efficient transmitters. However, they can only be used with constant-envelope signals and require schemes for the translation of non-constant envelope to constant-envelope signals.

Pulse-Width Modulation (PWM) was originally introduced in audio amplifiers to increase the efficiency by replacing the conventional linear amplifiers with SMPAs. The results encouraged the use of PWM for RF applications where it is used to encode the amplitude information. The PWM can be used at RF and baseband frequencies, each with its own advantages and trade-offs.

For the transmitters using PMW at RF frequencies (RF-PWM) [1], the harmonics appear at integer multiples of the carrier frequency thus relaxing the band-pass filtering requirements. However, at higher carrier frequencies the RFPWM based transmitters have a lower dynamic range due to pulse-swallowing, which is related to limited switching frequency of the circuit.

Transmitters using PWM at baseband (polar PWM or carrier-based PWM) [2] do not suffer from pulse swallowing as the modulation is done at IF, which is up-converted to an RF signal with a fixed duty cycle. However, since the harmonics appear at multiples of IF frequencies a higher order band-pass filtering is required. In addition, the infinite bandwidth of the PWM also introduces image and aliasing distortion, thus deteriorating the transmitter linearity.

This thesis aims to relax the filtering requirements and enhance the linearity of polar PWM transmitters. The focus has been to use all-digital techniques to develop multi-standard flexible transmitters. In total, six transmitters have been developed that compensate for aliasing and image distortions and simplify the design requirements. 


\subsection{Organization of Thesis}

This thesis is divided into two sections. The background section provides a brief overview to the target research area and is composed of the following chapters:

- Chapter 1 discusses the wireless transmitter, the performance parameters for transmitters, major classes of power amplifiers and fabrication technology for RF PAs.

- Chapter 2 discusses transmitter architectures that allow power-efficient amplification of non-zero PAPR signals.

- Chapter 3 discusses the PWM transmitter and its issues.

- Chapter 4 discusses variants of PWM transmitters that reduce image and aliasing distortion. This chapter also includes a brief overview of the proposed transmitters presented in Paper A-D.

- Chapter 5 discusses PWM transmitters that have relaxed filtering requirements and high amplitude resolution. This chapter also includes a brief overview of the proposed transmitters presented in Paper E and F.

The publications section collects the papers that are a result of the thesis. A brief overview of each of the papers is given as:

- Paper A presents a transmitter that combines band-limited PWM and RF PWMT to reduce aliasing distortion while achieving an efficiency comparable to a PWM based transmitter. The paper also discusses an all-digital implementation of the transmitter.

- Paper B combines PWM and outphasing to reduce the image and amplitude aliasing distortions while achieving efficiency comparable to a PWM based transmitter.

- Paper $\mathbf{C}$ is about an all-digital implementation of the aliasing-compensated PWM transmitter.

- Paper D combines PWM and asymmetric outphasing to improve phase resolution of all-digital PWM transmitters.

- Paper E combines multilevel PWM and RF PWM to achieve higher amplitude resolution, better efficiency and smaller chip area.

- Paper F combines multiphase PWM and RF PWM to relax final filtering requirements and to reduce the chip area. 


\subsection{Wireless Transmitter}

The wireless transmitter processes, up-converts and amplifies the information signal to the desired carrier frequency and power. The two major architectures of conventional transmitters are the direct conversion transmitter and the heterodyne transmitter.

\subsubsection{Direct Conversion Transmitter}

The block diagram of the direct conversion transmitter for digital communication is shown in Fig. 1.1. The transmitter separates the digital baseband signal into quadrature components $I(n)$ and $Q(n)$, which are then converted into analog signals $I(t)$ and $Q(t)$ using a digital to analog convertor (DAC). These signals are then mixed with quadrature phase-shifted carriers to generate quadrature up-converted signals at a transmit frequency $\left(\omega_{T}\right)$, as given in (1.1). These signals are combined to generate an amplitude and phase modulated carrier, expressed in (1.2). This modulated signal is then amplified to a desired power and finally filtered to generate the transmitted signal. The filtering is done to suppress the out-of-band leakage, which occurs due to non-idealities of the transmitter. The major issues of the transmitter are I/Q mismatch, carrier leakage, oscillator pulling, mixer non-linearity and PA non-linearity. [3, 4]

$$
\begin{gathered}
v_{1}(t)=I(t) \cos \left(\omega_{T} t\right) \\
v_{2}(t)=Q(t) \sin \left(\omega_{T} t\right) \\
v(t)=I(t) \cos \left(\omega_{T} t\right)-Q(t) \sin \left(\omega_{T} t\right)=a(t) \cos \left(\omega_{T} t+\phi(t)\right)
\end{gathered}
$$

where

$a(t)$ is the Amplitude

$\phi(t)$ is the Phase

\subsubsection{Heterodyne Transmitter}

As contrast to the direct-conversion transmitter, the heterodyne transmitter performs two up-conversions in order to transmit the information at the desired frequency. The block diagram of the heterodyne transmitter for digital communication is shown in Fig. 1.2. The transmitter separates the baseband signal into quadrature components, which are up-converted to intermediate frequency $\left(\omega_{1}\right)$ and then combined to generate an amplitude and phase modulated signal at 


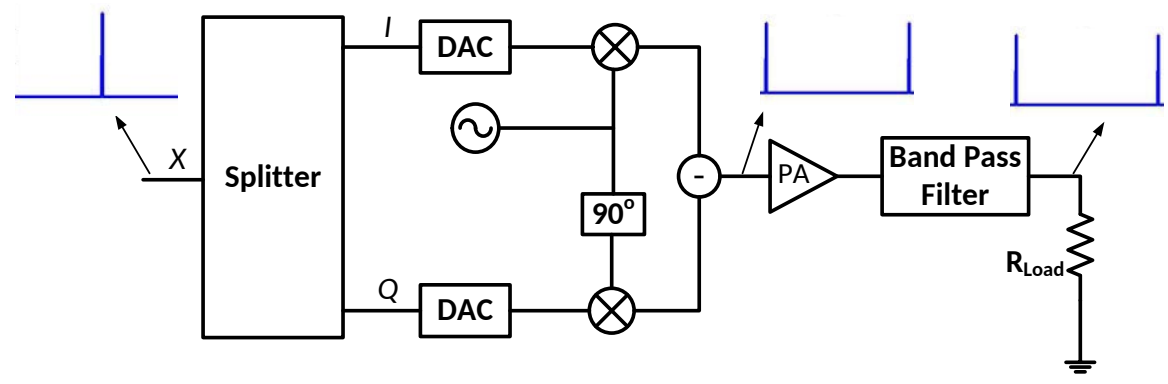

Figure 1.1: Block diagram of a direct conversion transmitter.

$\left(\omega_{1}\right)$, which is given as (1.3). This signal is again up-converted to translate the information to the transmit frequency $\left(\omega_{T}\right)$, which is given as (1.4). The two up-conversions are performed to reduce the effect of oscillator pulling. The signal is then amplified and filtered to generate the transmitted signal. The major issues of this type of transmitters are carrier leakage and mixing spurs. $[3,4]$

$$
\begin{gathered}
v_{1 M i x}(t)=a(t) \cos \left(\omega_{1} t+\phi(t)\right) \\
v_{2 M i x}(t)=\frac{1}{2} a(t)\left\{\cos \left(\left(\omega_{1}+\omega_{2}\right) t+\phi(t)\right)+\cos \left(\left(\omega_{2}-\omega_{1}\right) t+\phi(t)\right)\right\}
\end{gathered}
$$

where

$\omega_{T}=\omega_{1}+\omega_{2}$

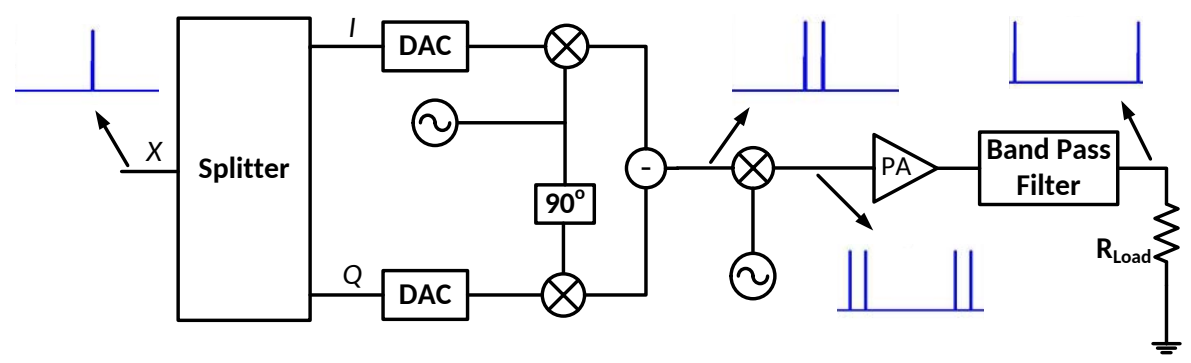

Figure 1.2: Block diagram of a heterodyne transmitter.

\subsection{Performance Parameters for Wireless Transmitters}

The performance of a transmitter is usually characterized by its output power, type of modulated signal, efficiency and linearity. Next each of these parameters are described briefly. 


\subsubsection{Output Power}

Output power is the power delivered to the antenna at desired frequency band and is usually guided by the type of the end-user application. The PA is the major block that determines the output power of the transmitter. It must be noted that due to subsystem imperfections, mismatch and PA characteristics, the transmitter might leak power outside the desired transmission band. A band-pass filter is used to attenuate these leakage power.

\subsubsection{Type of Modulated Signal}

There are two type of modulated signals in general: a constant-envelope modulated signal and a non-constant envelope modulated signal, as shown in Fig. 1.3. The constant-envelope signals are generated by modulation schemes like M-PSK, FSK and GMSK used in GSM cellular networks. The advantage of constantenvelope signals is that they are not corrupted by the PA non-linearity. The non-constant envelope signals are generated by modulation schemes like ASK, M-QAM or a combination of M-QAM and OFDM, which is used in standards like 802.11, LTE, etc. The advantage of non-constant envelope modulation is bandwidth efficiency. However, these signals are prone to PA non-linearity. [5]

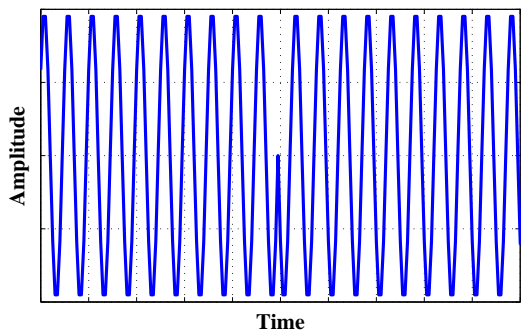

(a)

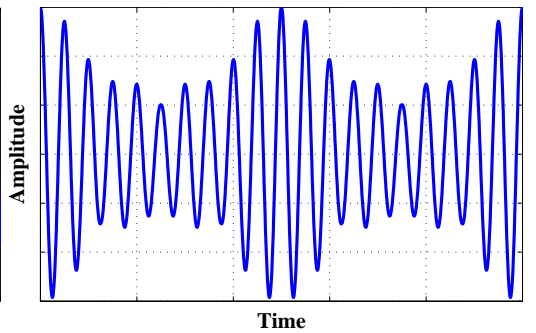

(b)

Figure 1.3: (a) Constant-envelope signal, (b) Non-constant envelope signal.

The PAPR determines the amount of envelope variation in the non-constant envelope signal and is defined as the ratio of peak output power $\left(P_{\text {peak }}\right)$ to average output power $\left(P_{a v g}\right)$, which is given as

$$
P A P R_{d B}=10 \log _{10}\left(\frac{P_{p e a k}}{P_{a v g}}\right)
$$




\subsubsection{Efficiency}

As the transmitter consumes most of the power of a transceiver, the efficiency of the transmitter determines the battery life in case of portable devices and the energy cost in case of RBS.

Two measure of efficiency i.e, drain efficiency $(D E)$ and power added efficiency $(P A E)$ are interchangeably used when characterizing transmitter. The drain efficiency [5-7] is ratio the transmitter's output power $P_{\text {out }}$ to the consumed DC power $P_{d c}$ and is given as

$$
D E=\frac{P_{\text {out }}}{P_{d c}}
$$

The power added efficiency [5-7] is ratio of the difference between output power and input power $P_{i n}$ to the dc power consumption and is given as

$$
P A E=\frac{P_{\text {out }}-P_{\text {in }}}{P_{d c}}
$$

\subsubsection{Linearity}

The linearity of a transmitter is important for the accuracy of the transmitted signal. In case of constant-envelope signals, phase linearity is an important parameter, whereas for non-constant envelope signals both phase and amplitude linearity are important. The two common parameters to measure the linearity of the transmitter are adjacent channel leakage ratio (ACLR) and error vector magnitude (EVM).

The ACLR $[5,7]$ is the ratio of the average powers in the transmission band to the adjacent bands. Fig. 1.4 shows the the measured spectrum and measured ACLR for a 1.4 MHz LTE up-link signal.

The EVM [5, 7] determines the error between the measured transmit signal (in case of transmitter) and the reference signal. It is defined as the ratio of the error vector $\left(V_{\text {error }}\right)$ to the reference signal vector $\left(V_{\text {ref }}\right)$. The EVM is either expressed in percentage as given in (1.8) or in $\mathrm{dB}$ as in (1.9).

$$
\begin{aligned}
& \operatorname{EVM}(\%)=\left(\frac{V_{\text {error }}}{V_{\text {ref }}}\right) \times 100 \\
& E V M(d B)=20 \log \left(\frac{V_{\text {error }}}{V_{\text {ref }}}\right)
\end{aligned}
$$

where error vector and reference vector are determined from the I/Q constellation plot as shown in Fig. 1.5 


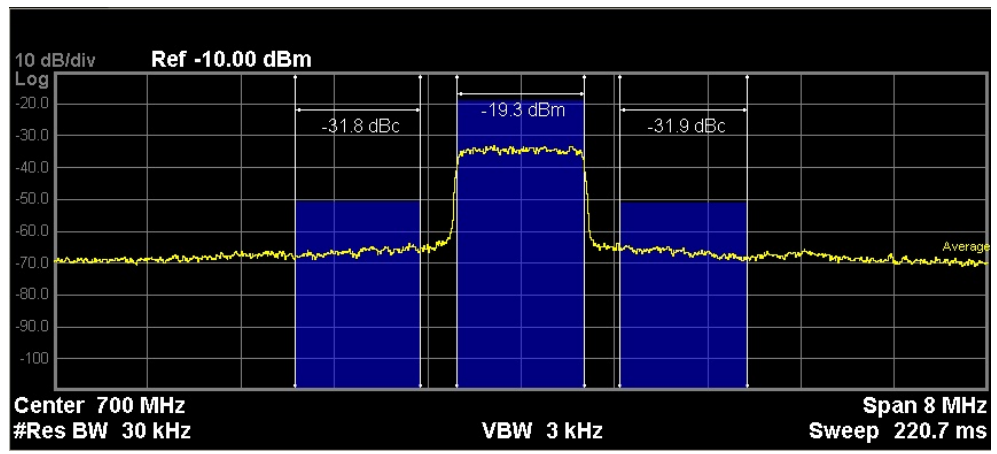

Figure 1.4: Measured spectrum and ACLR for 1.4 MHz LTE up-link signal.

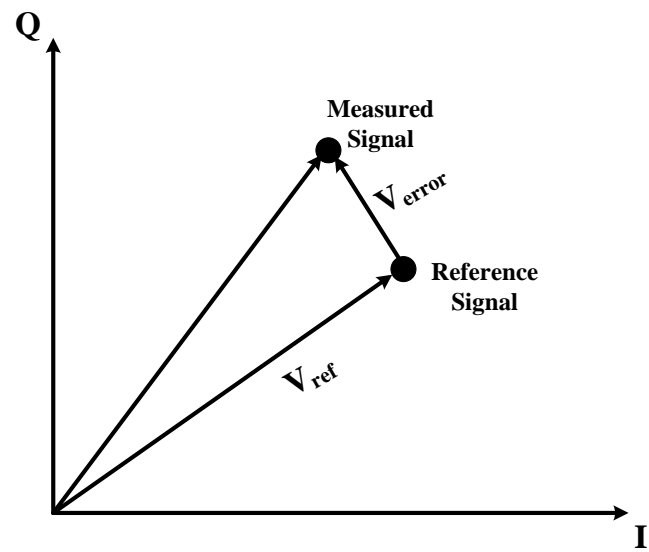

Figure 1.5: EVM measurement from I/Q constellation plot.

\subsection{RF Power Amplifier}

The type of PA used in the transmitter has a profound effect on the performance of the transmitter. Each type of PA has different performance characteristics and it is usually up to the designer to select the most suitable type of PA for the target application. The PAs are broadly classified into two categories: linear PAs and switch mode PAs. 


\subsubsection{Linear PAs}

These PAs are also called classical PAs, and use devices as a controlled current source. The general schematic of a linear PA is shown in Fig. 1.6 and based on the transistor biasing they are categorized in to three major classes, namely Class A, B, C and the subclass AB. [6, 8, 9]

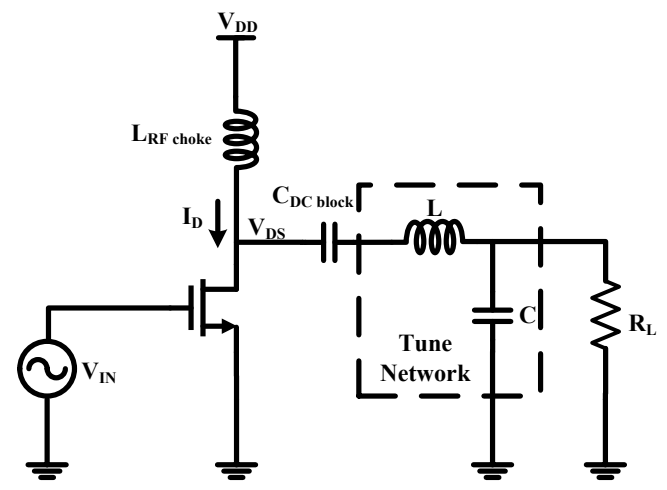

Figure 1.6: Linear PAs schematic.

\subsubsection{Class A}

Class A PAs $[10,11]$ are normally used for applications that require very high linearity. Class A PAs adjust the quiescent point (Q-point) of the transistor such that it does not turn off throughout the input signal cycle. The typical waveforms for the drain voltage and current are shown in Fig. 1.7. These PAs have the best linearity and the lowest efficiency among all PA classes. The peak efficiency of an ideal Class A PA is $50 \%$ at peak power which decreases as the output power reduces below the peak values. The normalized power output capability is the measure of device stress and defined as the ratio of the output power to the product of maximum drain voltage and current for the device (higher is better) [12]. In case of class A PA it is 0.125 .

\subsubsection{Class $B$}

For Class B PAs the Q-point is adjusted such that the device is turned off during half of the input cycle period. The typical waveforms for the drain voltage and current are shown in Fig.1.8. Due to the simultaneous occurrence of drain voltage and current for only half the period, Class B PAs have a higher efficiency and lower linearity as compared to Class A PAs. These PAs require high quality 


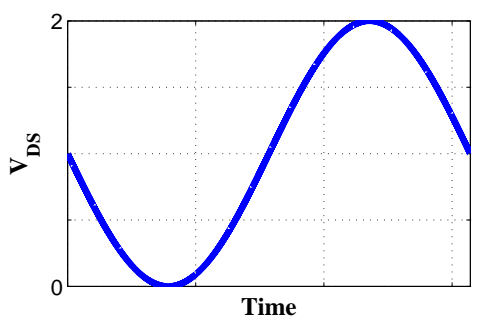

(a)

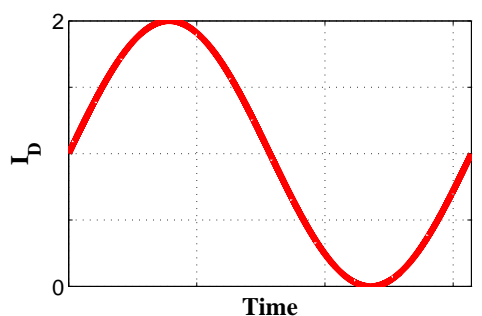

(b)

Figure 1.7: Class A waveform for (a) drain voltage, (b) drain current.

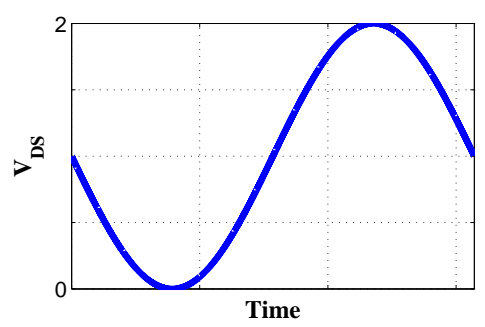

(a)

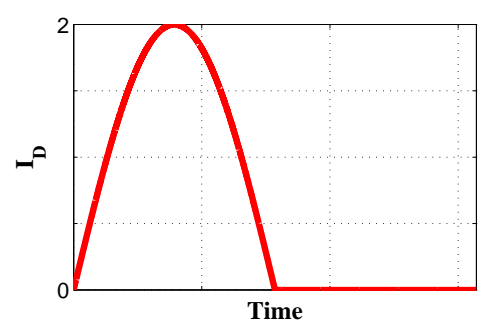

(b)

Figure 1.8: Class B waveform for (a) drain voltage, (b) drain current.

factor tuned network such that the harmonics due to clipped sine wave are filtered to generate a sine wave. The peak efficiency of an ideal Class B PA is $78.5 \%$ and normalized power output capability is 0.125 . [11-13]

\subsubsection{Class $C$}

In Class C PAs the Q-point is biased such that the transistor is active for less than half of the input signal period. As a result the efficiency is improved but with reduced power and degraded linearity. The typical waveforms for the drain voltage and current are shown in Fig.1.9. Ideal Class C PAs efficiency depend on conduction angle, in case of $150^{\circ}$ conduction angle, it achieves $85 \%$ efficiency. [11-13]

\subsubsection{Class $A B$}

The Q-point for Class AB PAs is biased such that the transistor is turned on for more than half of the input clock period unlike Class-B PAs but not for the 


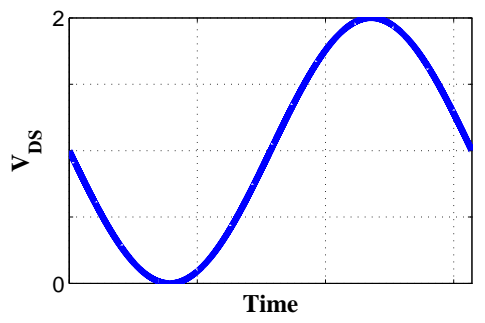

(a)

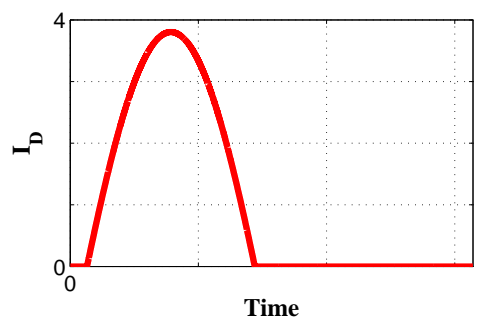

(b)

Figure 1.9: Class $\mathrm{C}$ waveform for (a) drain voltage, (b) drain current.

entire input cycle like Class-A PAs. This amplifier is compromise between class A and class B PAs and achieves higher linearity and efficiency as compared to Class B and Class A PAs respectively. [8, 14-16]

\subsubsection{Switch-Mode PA}

SMPAs use devices as switches that are either in the on or off state. They have higher efficiency as compared to linear PAs. However, they can only amplify constant-envelope signals. They are categorized in three major classes, namely Class D, E and F. [8, 9]

\subsubsection{Class D}

Class D PAs [17-19] use transistors in a switching configuration to generate a square drain-voltage waveform, which is filtered to generate a sinusoid of fundamental frequency at the output. A typical inverter-based Class D implementation is shown in Fig. 1.10 and the corresponding waveforms for the drain voltage and current are shown in Fig. 1.11. Since the voltage and current have a complimentary relation the ideal Class D PA can achieve $100 \%$ efficiency. However, due to finite switching speeds of the output stage the drain voltage and current regions overlap, causing losses. The normalized power output capability of Class D PAs is 0.32. [12, 20, 21]

\subsubsection{Class E}

Class E PAs [22-24] use a tuning network to reduce the losses due to finite switching speed of the transistor. The tuning network for the Class E PA is 


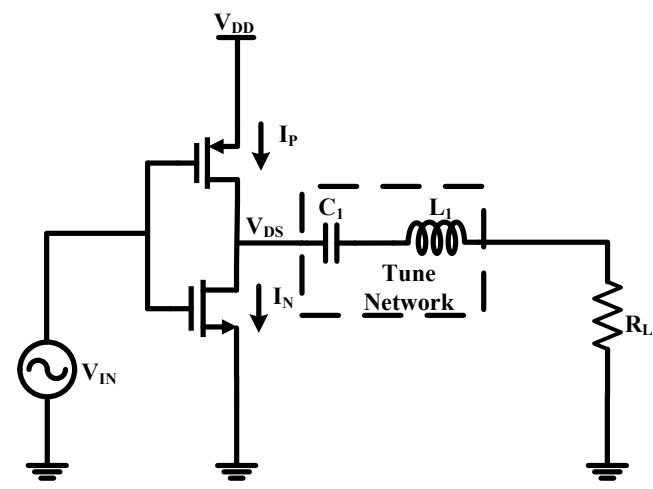

Figure 1.10: Schematic of a Class D PAs.

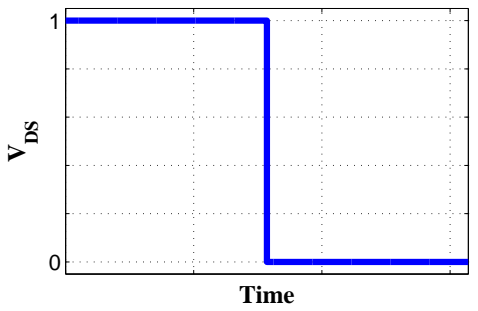

(a)

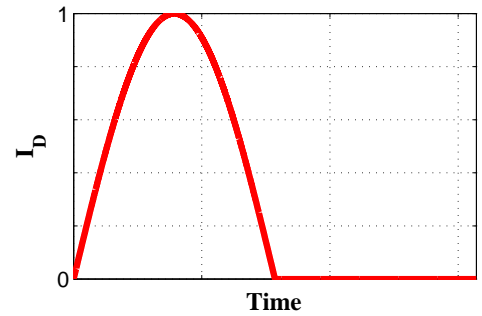

(b)

Figure 1.11: Class D waveform for (a) drain voltage, (b) drain current.

designed such that it meets the conditions given below

$$
\begin{aligned}
\left.v_{C}(t)\right|_{t=\frac{2 \pi}{\omega_{o}}} & =0 \\
\left.\frac{d v_{c}(t)}{d t}\right|_{t=\frac{2 \pi}{\omega_{o}}} & =0
\end{aligned}
$$

The (1.10a) ensures no losses occur due to the discharging of the drain capacitance at off to on switching instance, whereas $(1.10 \mathrm{~b})$ ensures that no current flows through the transistor at off to on switching instance. As a result, the practical Class E PAs may have a higher efficiency compared to Class D PAs. However the disadvantage of Class E PA is a lower power utilization factor, which is 0.098. A typical implementation of the Class E PA is shown in Fig. 1.12 and its corresponding waveforms are shown in Fig 1.13. 


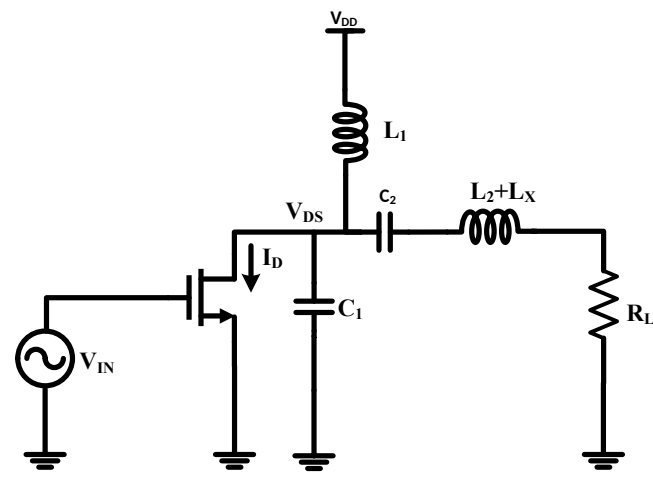

Figure 1.12: Schematic of a Class E PAs.

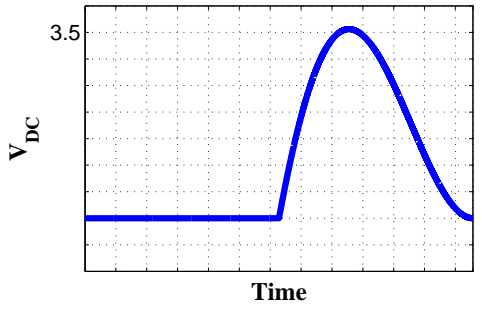

(a)

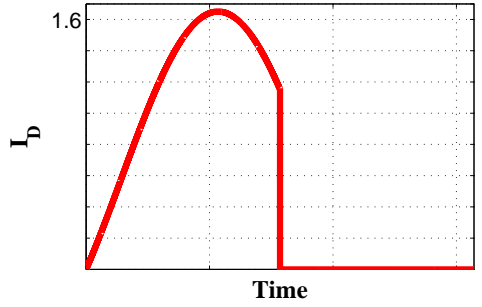

(b)

Figure 1.13: Class E waveform for (a) drain voltage, (b) drain current.

\subsubsection{Class F}

Class F PAs also use a tuning network to reduce the transistor switching losses by shaping the drain voltage and current waveforms. A typical implementation of the Class F PA is shown in Fig. 1.14, where a tuned network consisting of a $\lambda / 4$ transmission line and a parallel tank circuit is used The tuning network only allows the fundamental frequency to pass to the load, while the odd harmonics are terminated by the infinite resistance and even harmonics are terminated by zero resistance. As a result, the transistor drain voltage is a square waveform and drain current is a half-wave sinusoid, as shown in Fig.1.15. It can be seen that the drain current and voltage do not occur simultaneously at the switching instance hence this class of PAs have a higher efficiency. The normalized power output capability of a Class F PA is 0.16 which is higher than Class E PA. However, on-chip implementation of a Class F PA is difficult due to the tuned network. [24, 25] 


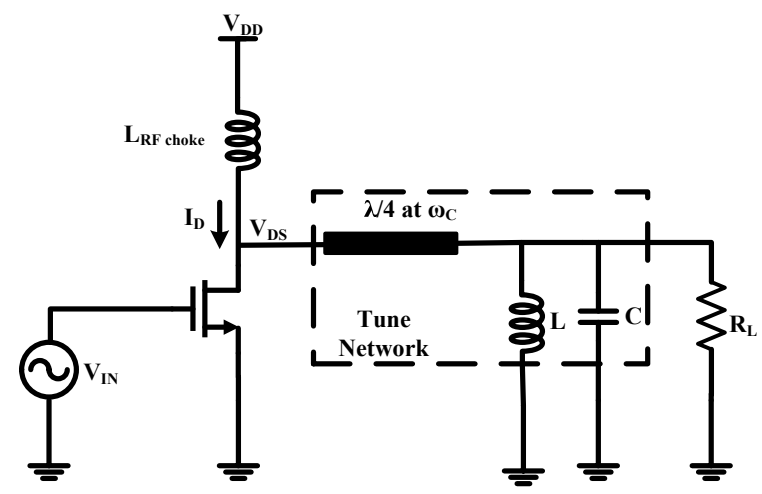

Figure 1.14: Schematic of Class F PAs.

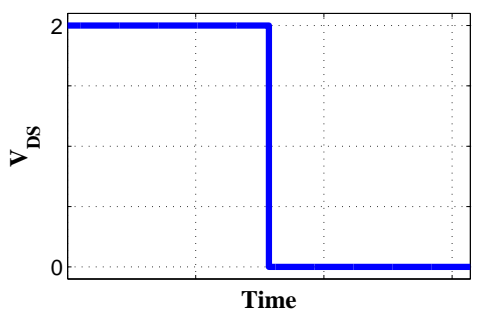

(a)

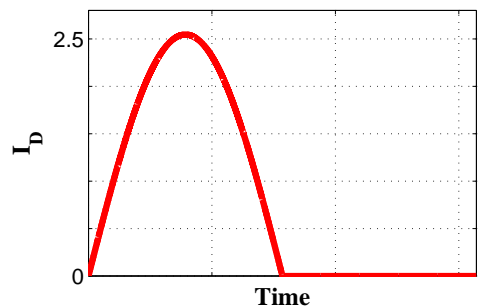

(b)

Figure 1.15: Class F waveform for (a) drain voltage, (b) drain current.

\subsection{Fabrication Technology for RF PAs}

Many of the RF PAs are used in combination with digital circuits used for pre-distortion to maintain their linearity and efficiency. Typically, RF circuits were fabricated using bipolar devices due to higher performance characteristics whereas CMOS has been favored for the implementation of the supporting digital circuits due to its higher density. This led to the introduction of BiCMOS processes that combined the characteristics of bipolar and CMOS technology. However, the BiCMOS processes are not preferred today due to the added complexity in the fabrication process.

Typically, CMOS processes were not preferred for the fabrication of RF circuits due to low transition frequency and inadequate performance. However, as the transition frequency of CMOS has increased due to process scaling hence its RF performance has also improved. For wireless consumer markets cost, 
product size and power consumption are the main driving parameters, thus making CMOS a technology of choice for these applications. Although the RF performance of semiconductors like GaN and GaAs is very high as compared to CMOS, but they are preferred in high-requirement applications, such as RBS and satellite applications. Fully integrated CMOS wireless transceiver have become quite common for portable devices [26, 27]. 



\section{Chapter 2}

\section{Transmitter Architectures for Linearization of Power-Efficient Amplifiers}

The performance of wireless devices is characterized by data rates and power consumption. High data rates are achieved though spectral-efficient communication standards like 802.11 and LTE, which generate non-constant envelope signals that are amplified using highly efficient PAs, which play an important role in maximizing the battery life by reducing the power losses.

As discussed in chapter 1, PAs are categorized into two broad categories: linear PAs and switch-mode PAs (SMPA). The linear PAs amplify non-constant envelope signals but have low peak efficiency. Moreover, their efficiency further decreases at back-off power. SMPAs on the other hand are highly power-efficient due to on-off operation of the transistors. However, they can only be used to amplify constant-envelope signals.

Several transmission schemes have been developed that are highly power efficient as they allow the amplification of non-constant envelope signals either using SMPAs or linear PAs operating at saturated power. Popular transmission schemes that are efficient for non-constant envelope signals are polar modulation, outphasing and pulse-width modulation.

\subsection{Polar Modulation}

The polar modulation or envelope elimination and restoration (EER) was first introduced by Kahn in 1952 [28], and therefore also referred as Kahn transmitter. 


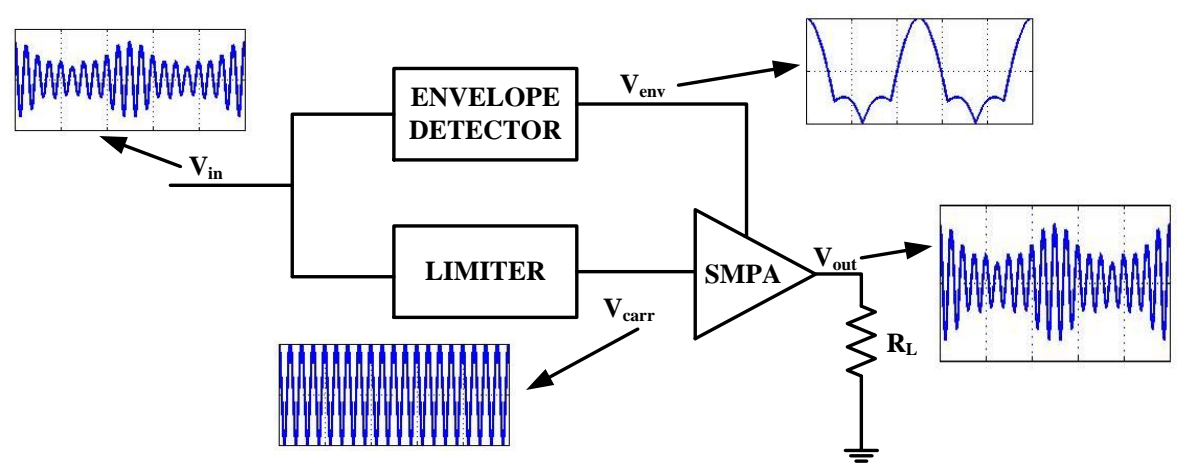

Figure 2.1: Block diagram of a polar modulation transmitter.

The conceptual block diagram is shown in Fig. 2.1. The pass-band signal given in (2.1) is split into a low-frequency envelope signal $v_{e n v}(t)$ and a constant-envelope phase-modulated signal $v_{\text {carr }}(t)$, given in (2.2) using the envelope detector and the limiter respectively. The phase modulated signal is power amplified by an SMPA, where $v_{e n v}(t)$ varies the supply voltage of the SMPA. Hence the final transmitted signal is the amplified version of (2.1) and can be expressed as (2.3). This technique allows the amplification of non-constant envelope signals through SMPAs, resulting in a better power efficiency as compared to conventional transmitters.

$$
v(t)=v_{e n v}(t) \cos \left(\omega_{c} t+\phi(t)\right)
$$

where

$\omega_{c}$ is the carrier frequency in radian/sec

$$
\begin{gathered}
v_{\text {carr }}(t)=\cos \left(\omega_{c} t+\phi(t)\right) \\
v_{\text {out }}(t)=A v_{\text {env }}(t) \cos \left(\omega_{c} t+\phi(t)\right)
\end{gathered}
$$

A common implementation of the polar modulation transmitter [29-32], shown in Fig. 2.2, decomposes the baseband signal into amplitude $\left(v_{e n v}(t)\right)$ and phase $(\phi(t))$ components. The $\phi(t)$ phase modulates the carrier, which is then amplified by an SMPA and its supply voltage is varied by $v_{e n v}(t)$. The major advantage of this implementation is that the envelop detector and the limiter are not required, hence the non-linearity due to the envelope detector and the $\mathrm{AM} / \mathrm{PM}$ conversion due to the limiter are avoided. 


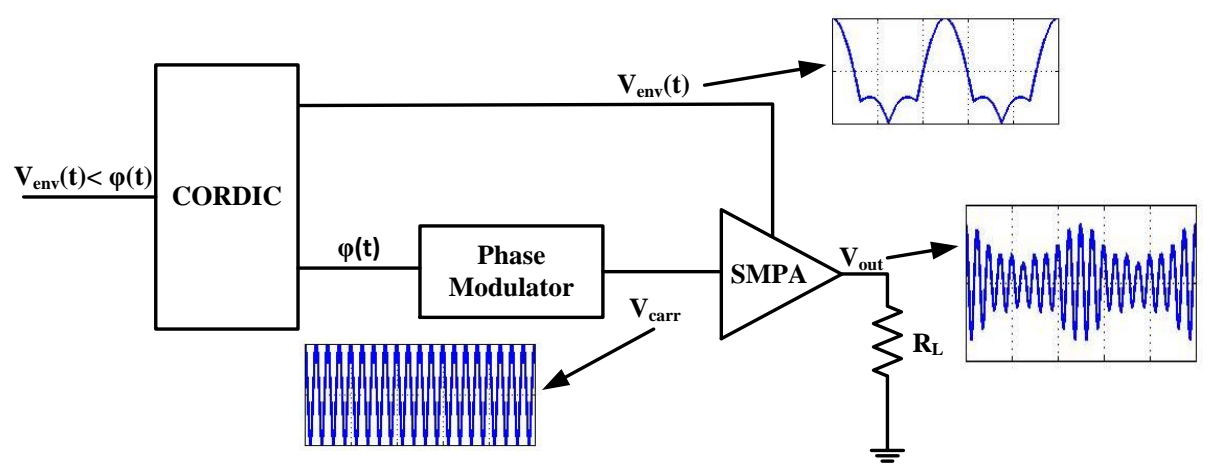

Figure 2.2: Common implementation of a polar modulation transmitter.

However, the performance of polar modulators is affected by the delay mismatch between envelope and phase-modulated carrier paths and varying output capacitance due to the PA supply voltage variations. Apart from these factors, maintaining high efficiency for wide bandwidth signal and achieving large dynamic range in low voltage head room CMOS technology is a challenge.

\subsection{Outphasing}

Outphasing or linear amplification with non-linear components (LINC) [28, 3234] decomposes a non-constant envelope signal into two constant-envelope signals, and allows the use of SMPAs or highly saturated linear PAs operating at their peak efficiency for amplification.

The Fig. 2.3 shows the basic idea of outphasing, in which the non-constant envelope signal, $v_{i n}(t)$ in $(2.4)$, is first decomposed into two phase-shifted constantenvelope signals, $v_{1}(t)$ and $v_{2}(t)$ given in (2.5), where the phase shift $\theta(t)$ (called the outphasing angle hereafter) is determined by the instantaneous envelope signal $a(t)$. The relationship between $\theta(t)$ and $a(t)$ is expressed in (2.6). The constant-envelope signals $v_{1}(t)$ and $v_{2}(t)$ are then amplified by the power-efficient PAs and combined by a passive combiner to generate the amplified version of the input signal.

$$
v_{i n}(t)=a(t) \cos \left(\omega_{c} t+\phi(t)\right)
$$




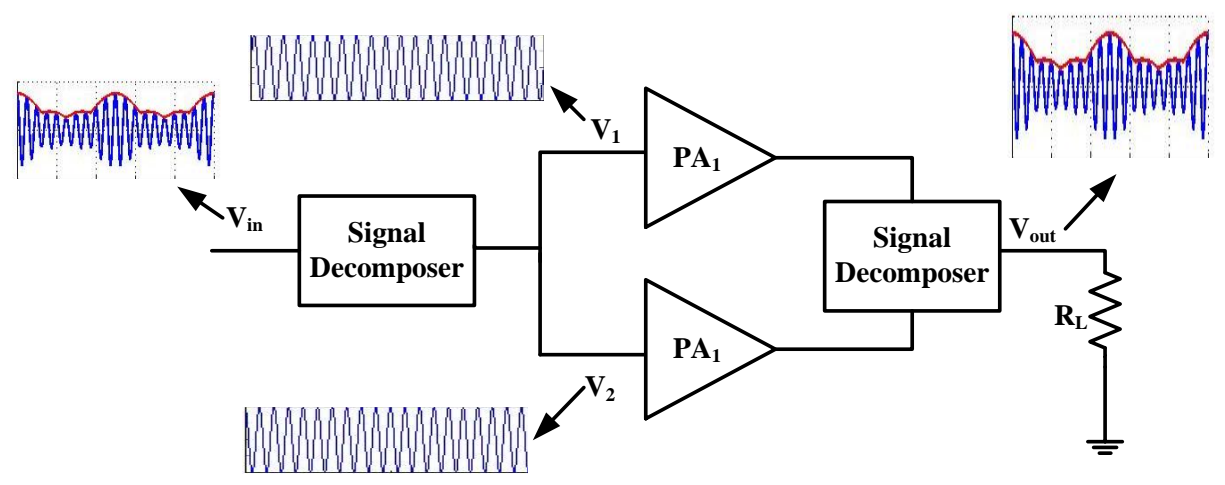

Figure 2.3: Block diagram of an outphasing transmitter.

$$
\begin{aligned}
v_{1}(t)= & \frac{1}{2} \cos \left(\omega_{c} t+\phi(t)+\theta(t)\right) \\
v_{2}(t)= & \frac{1}{2} \cos \left(\omega_{c} t+\phi(t)-\theta(t)\right) \\
& \theta=\cos ^{-1}(a(t))
\end{aligned}
$$

\subsubsection{Outphasing Issues}

For outphasing transmitters, mismatch issues in the amplification path and the combiner design play a critical role in determining the transmitter efficiency and linearity.

\subsubsection{Amplification paths mismatch}

The path mismatch is the gain and phase mismatches between the two amplification paths in Fig. 2.3, which results in signal distortion and spectral regrowth at the output of transmitter [32]. The two mismatches result in an amplitude difference $\Delta A$ and an additional phase difference the $\Delta \theta$ between the two amplified phase-shifted signals, which mathematically can be expressed as (2.7). The combination of the two signals is expressed in (2.8), which shows the signal distortion and spectral regrowth due to the paths mismatches.

$$
\begin{aligned}
& v_{1}(t)=\left(\frac{A}{2}+\Delta A\right) \cos \left(\omega_{C} t+\phi(t)+\theta(t)+\Delta \theta\right) \\
& v_{2}(t)=\frac{A}{2} \cos \left(\omega_{c} t+\phi(t)-\theta(t)\right)
\end{aligned}
$$




$$
\begin{aligned}
v_{\text {out }}(t) & =v_{1}(t)+v_{2}(t) \\
& =\Delta A \cos \left(\omega_{c} t+\phi(t)+\theta(t)+\Delta \theta\right)+A a(t) \cos \left(\omega_{c} t+\phi(t)\right) \\
& -A a(t) \sin ^{2}\left(\frac{\Delta \theta}{2}\right) \cos \left(\omega_{c} t+\phi(t)\right)-\frac{A}{2} a(t) \sin (\Delta \theta) \sin \left(\omega_{c} t+\phi(t)\right) \\
& -\frac{A}{2} \sin (\theta(t)) \sin (\Delta \theta) \cos \left(\omega_{c} t+\phi(t)\right)+A \sin (\theta(t)) \sin \left(\omega_{c} t+\phi(t)\right) \\
& -\sin (\theta(t)) \cos ^{2}\left(\frac{\Delta \theta}{2}\right) \sin \left(\omega_{c} t+\phi(t)\right)
\end{aligned}
$$

\subsubsection{Combiner}

A proper design of the combiner is crucial to ensure the linearity and efficiency of the outphasing transmitter as it determines the interaction of the two amplification paths. Combiners are broadly classified into two types: non-isolated combiners and isolated combiners [35-38].

\section{Non-Isolated Combiner}

The Outphasing transmitters using non-isolated combiners [17, 18, 39] suffer from spectral regrowth and signal corruption at the output, as non-isolated combiners do not stop the signal from one transmission path to interfere with the signal in the other transmission path.

To understand the effect of signal interference between the transmission paths, consider an outphasing transmitter where a transformer is used as combiner, shown in Fig. 2.4a. If the transformer is assumed to be ideal with a turn ratio of $1: 1$, and the power amplifiers are ideal voltage buffers with a unity gain, then the transmitter in Fig. 2.4a can be simplified to Fig. 2.4b.

The current passing through the load resistance is given in (2.9). The impedance seen at the output of $P A_{1}$ is the ratio of $V_{1}$ and $I_{12}$ in phasor form, given in (2.10). Similarly the impedance seen at $P A_{2}$ is determined as the ratio of $V_{2}$ and $I_{12}$, as given in (2.11). From (2.10) and (2.11) it is evident that the load impedances of the PAs depend on the outphasing angle. This results in a time-varying voltage division of the signal in case of a non-ideal voltage buffer (which is the case of practical PA), which results in signal distortion at the output of the transmitter. 


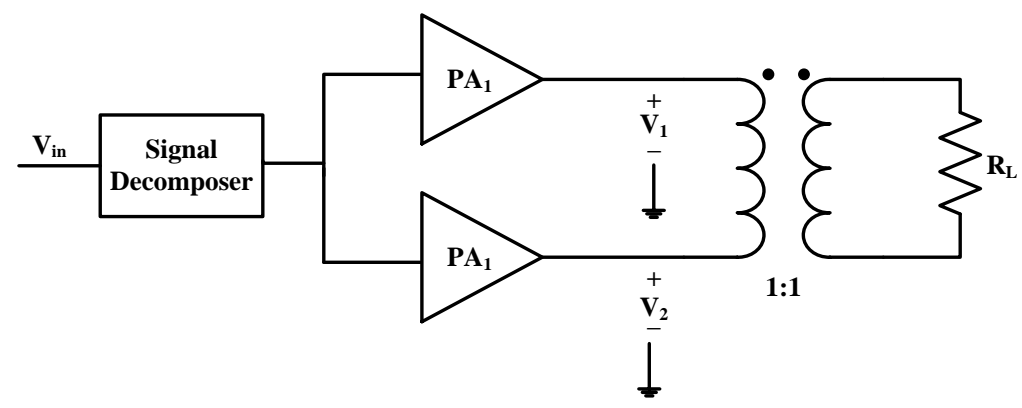

(a)

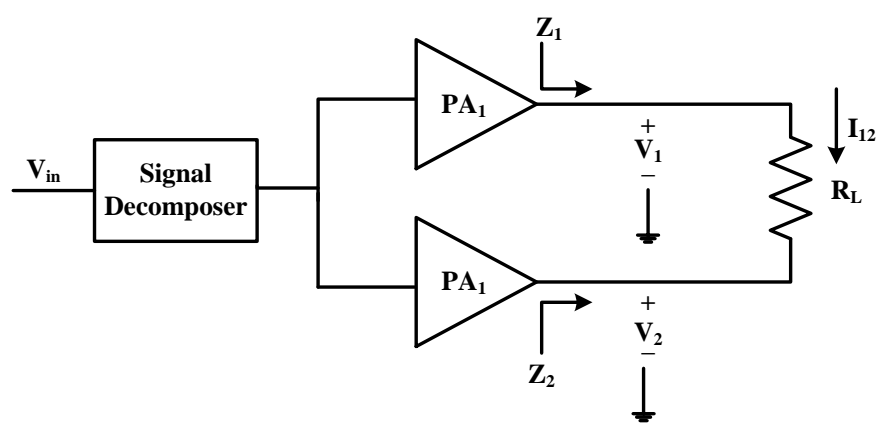

(b)

Figure 2.4: (a) Outphasing transmitter with a transformer (b) simplified circuit.

$$
\begin{aligned}
& I_{12}(t)=\frac{v_{1}(t)-v_{2}(t)}{R_{L}} \\
&=\frac{1}{2} \frac{\sin \left(\omega_{c} t+\phi(t)+\theta(t)\right)-\sin \left(\omega_{c} t+\phi(t)-\theta(t)\right)}{R_{L}} \\
&=\frac{\cos \left(\omega_{c} t+\phi(t)\right) \sin (\theta)}{R_{L}} \\
& Z_{1}=\text { Phasor }\left(\frac{v_{1}(t)}{I_{12}}\right)=\frac{R_{L}}{2}-j \frac{R_{L}}{2} \cot (\theta(t)) \\
& Z_{2}=\frac{R_{L}}{2}+j \frac{R_{L}}{2} \cot (\theta(t))
\end{aligned}
$$


The output signal distortion can be reduced by varying the output capacitance and the power supply such that they compensate the load variations at the PA outputs due to outphasing angle [26, 27].

\section{Isolated Combiner}

Outphasing transmitters using isolated combiners [40, 41] ensure a high amplitude linearity as the combiner provides perfect isolation between the input ports, and as a result no load variation is seen at the output of the PAs. However, the instantaneous efficiency of the outphasing transmitter with isolated combiner decreases as the outphasing angle $\theta$ increases due to power losses in the isolation resistance of the combiner. The relationship between the instantaneous efficiency and the outphasing angle of an outphasing transmitter using a Wilkinson combiner [42] (the one most common type of isolated combiner) is given by (2.12) and is plotted in Fig. 2.5.

$$
\eta_{W}=\cos ^{2}(\theta(t))
$$

Different techniques have been proposed to improve the efficiency of the outphasing transmitters using isolated combiners, among them recycling the $\mathrm{RF}$ power delivered to the isolation port [43, 44], and multilevel outphasing transmitter [45-47].

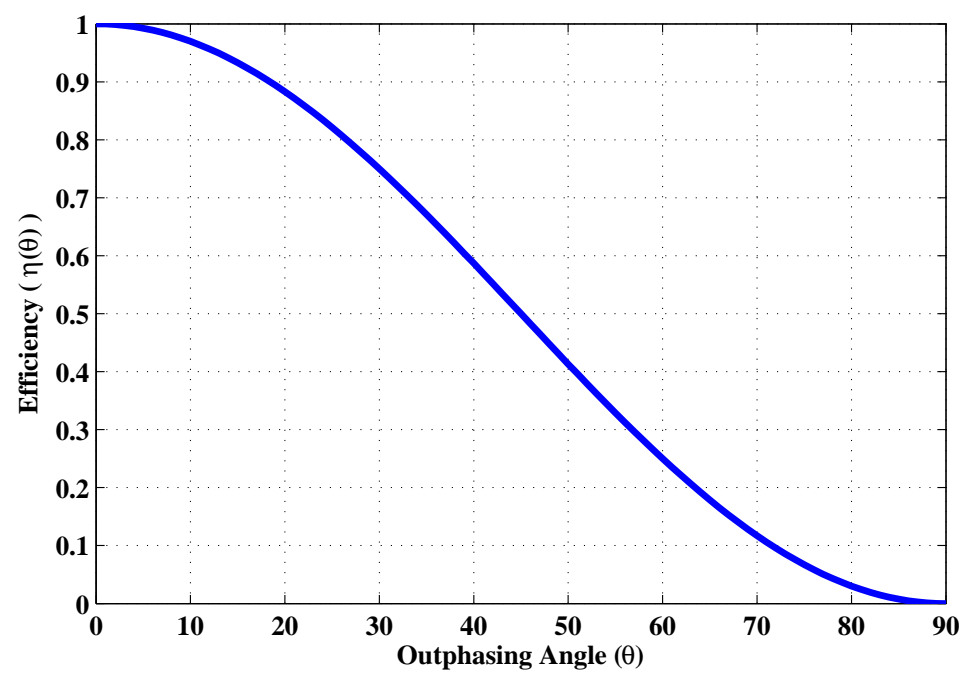

Figure 2.5: Plot of instantaneous efficiency and outphasing angle for an outphasing transmitter using a Wilkinson combiner. 


\subsection{Pulse-Width Modulation}

Pulse-width modulation-based transmitter schemes convert the non-constant envelope signals to constant-envelope signal by translating the envelope information into the width of a pulse train. The advantages of this type of transmitters is an easier implementation in nanometer-CMOS technology and they allow the use of SMPAs for the amplification of non-constant envelope signals. The different variants of pulse-width modulation based transmitters are discussed in chapter 3 . 


\section{Chapter 3}

\section{Pulse-Width Modulation Based Transmitter}

This chapter focuses on the different variants of pulse-width modulation based transmitters used for the amplification of non-constant envelope signals. First, the Radio-Frequency Pulse-Width Modulation Transmitter (RF-PWMT) is discussed, which requires small chip area and does not suffer from spectral regrowth. Next, the polar PWM transmitters (PPWMT), also known as the burst mode transmitter or the carrier based PWM transmitter, are discussed. PPWMT have a better performance characteristics at high frequency and can use either SMPAs or linear PAs operating at saturation power.

\subsection{Radio-Frequency PWM Transmitter}

The radio-frequency pulse-width modulated transmitter (RF-PWMT) [48-51, 51-56] varies the transmitted signal amplitude and phase by varying the width and position of the RF pulse train at a frequency equal to the carrier frequency. Unlike outphasing, the RF-PWMT requires smaller chip area since the combiner is not required [57]. Also there is no spectral regrowth due to mismatch $[32,58]$.

The block diagram of the transmitter is shown in Fig. 3.1, where a CORDIC processor [59] splits the baseband signal into its phase $\phi(t)$ and amplitude $a(t)$ components. The phase component varies the pulse position of a pulse train to generate the pulse-position modulated (PPM) signal, given in (3.1) [60], where the pulse-repetition frequency of a pulse train is equal to the carrier frequency. The amplitude component is first pre-distorted according to (3.2), then the pre-distorted amplitude is used to vary the pulse width of the PPM signal 


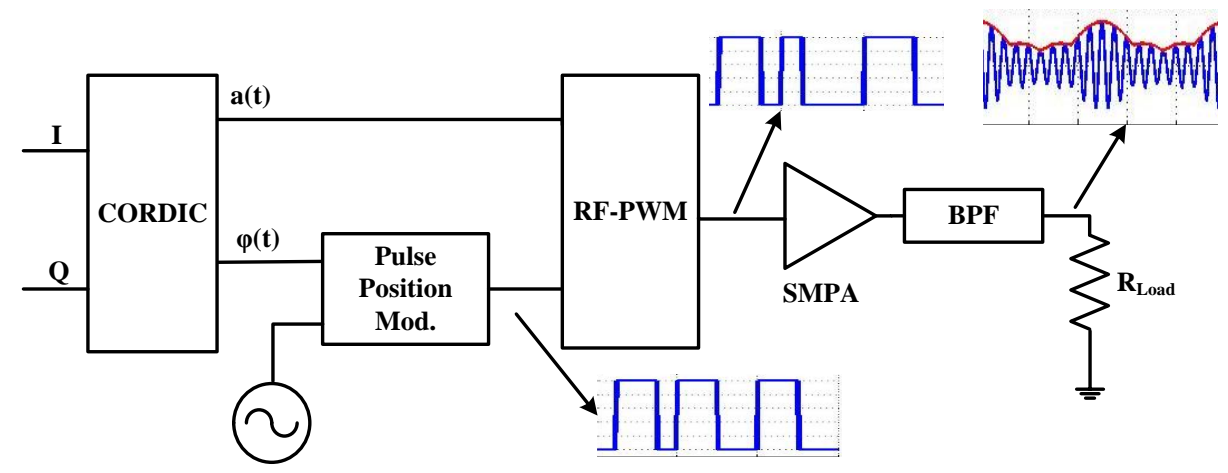

Figure 3.1: Block diagram of an RF-PWM transmitter.

to generate a pulse-width and position-modulated (PWPM) signal, given in (3.3) [50]. The PWPM signal has a constant-envelope and is amplified by an SMPA and finally band-pass filtered to generate a non-constant envelope signal for transmission.

$$
\begin{aligned}
v_{P P M}(t)=\frac{1}{2} & +\frac{2}{\pi} \cos \left(\omega_{c} t+\frac{2 \pi T_{P}(t)}{T_{c}}\right) \\
& +\sum_{k=2}^{\infty} \frac{2}{k \pi} \sin \left(\frac{k \pi}{2}\right) \cos \left(k \omega_{c} t+\frac{2 k \pi T_{P}(t)}{T_{c}}\right)
\end{aligned}
$$

where

$T_{P}(t)=\frac{\phi(t) T_{c}}{2 \pi}$

$$
\begin{gathered}
a^{\prime}(t)=\frac{1}{\pi} \sin ^{-1}(a(t)) \\
v_{P W P M}=a^{\prime}(t)+\frac{2}{\pi} a(t) \cos \left(\omega_{c} t+\frac{2 \pi T_{P}(t)}{T_{c}}\right) \\
+\sum_{k=2}^{\infty} \frac{2}{k \pi} \sin \left(k a^{\prime}(t)\right) \cos \left(k \omega_{c} t+\frac{2 k \pi T_{P}}{T_{c}}\right)
\end{gathered}
$$

However, this transmitter has a small dynamic range at high carrier frequency, as narrow pulses are swallowed by either the driver chain or the SMPA due to their finite switching frequency [48]. Multilevel RF-PWM [61] can be used to address the problem of small dynamic range at the increased cost of several PAs and a combiner. 


\subsection{Polar PWM Transmitter}

\subsubsection{Concept}

The polar PWM transmitter (PPWMT) [62-65] have a larger dynamic range at high carrier frequency as it does not suffer from pulse swallowing in PAs [48]. In the PPWMT, the non-constant envelope signal is converted into carrier bursts of varying duration, which operate the PA in either on state achieving peak efficiency or the off state where no power consumed. These carrier bursts after amplification are band-pass filtered to generate an amplified non-constant envelope signal.

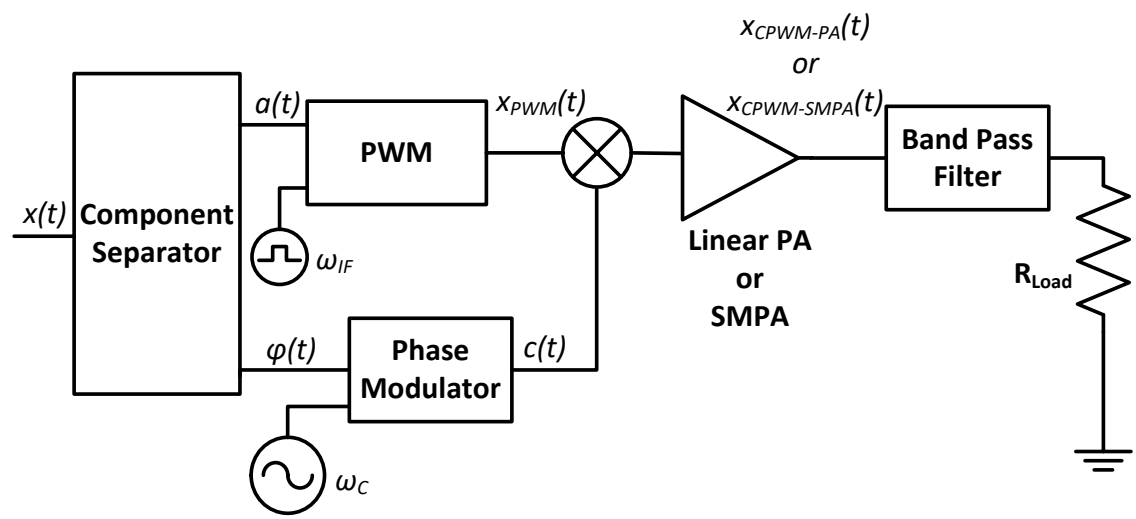

Figure 3.2: Block diagram of a polar PWM transmitter.

The block diagram of a PPWMT is shown in Fig. 3.2, which separate the baseband signal $x(t)$ given in (3.4), to its amplitude $a(t)$ and phase $\phi(t)$ components.

$$
x(t)=a(t) e^{j \phi(t)}
$$

The amplitude component $(a(t))$ varies the pulse width of pulse train to generate a PWM signal having pulse-repetition frequency (PRF) equal to intermediate frequency $[60,66]$, which is expressed as

$$
x_{P W M}=\frac{\tau(t)}{T}+\sum_{k=1}^{\infty} \frac{2}{k \pi} \sin \left(\frac{k \pi \tau(t)}{T}\right) \cos \left(\omega_{I F} k t\right)
$$

where $\tau$ is the pulse width, $T$ is the pulse-repetition period (PRP), $k$ is the harmonic number and $\omega_{I F}$ is the PRF of the PWM signal. The relationship 
between $a(t)$ and $\tau$ is given as

$$
\tau(t)=a(t) T
$$

The pulse-width modulation of the pulse train with respect to a(t) is shown in Fig. 3.3(b).

The phase component varies the phase of the carrier to generate the phasemodulated carrier, given as

$$
c(t)=\cos \left(\omega_{c} t+\phi(t)\right)
$$

Fig. 3.3(d) illustrates the phase modulation of the carrier with respect to $\phi(t)$.

The phase-modulated carrier is then multiplied by the PWM signal to produce the carrier-based PWM signal (C-PWM), which is shown in Fig. 3.3(e) and mathematically expressed as

$$
x_{C P W M}=\left(\frac{\tau(t)}{T}+\sum_{k=1}^{\infty} \frac{2}{k \pi} \sin \left(\frac{k \pi \tau(t)}{T}\right) \cos \left(\omega_{I F} k t\right)\right) \cos \left(\omega_{c} t+\phi(t)\right) .
$$

The C-PWM signal is then amplified by an SMPA or linear PA and finally filtered to generate an amplified non-constant envelope transmitted signal, which is shown in Fig. 3.3(f).

\subsubsection{Efficiency}

In general, the transmitter efficiency is defined as the ratio of the transmitted signal power to the dc power consumed by the transmitter, which is given in (3.9) for constant input signal $x(t)=a$, where $a \in[0,1], \eta$ is the efficiency of the transmitter, $P_{T}$ is the transmitted signal power and $P_{d c_{T}}$ is the dc power consumed by the transmitter [67].

$$
\eta(a)=\frac{P_{T}(a)}{P_{d c_{T}}(a)}
$$

In a transmitter the major power is consumed by the PA and the following passive circuitry, hence a simplified expression of transmitter efficiency is the ratio of the transmitted signal power to the power consumed by the PA [67-69] and is given as

$$
\eta(a)=\frac{P_{T}(a)}{P_{d c_{P A}}(a)}
$$

where $P_{D C_{P A}}$ is the power consumed by the PA. This implies that the efficiency of the PPWMT can be expressed as the product of the PA efficiency and the 
(a)

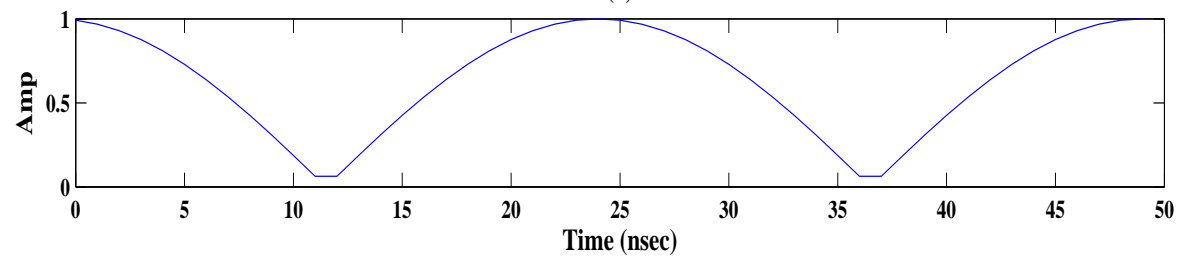

(b)

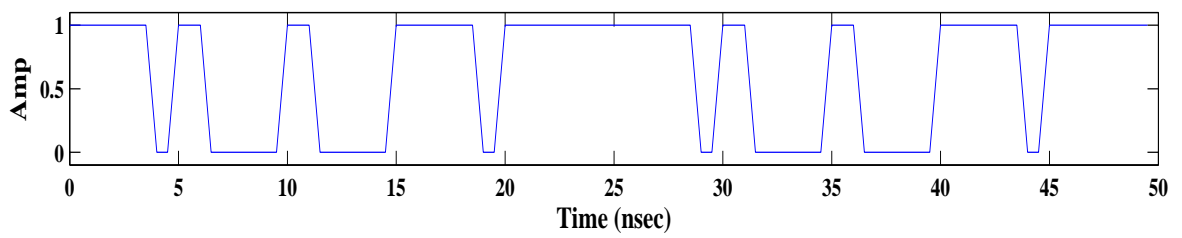

(c)

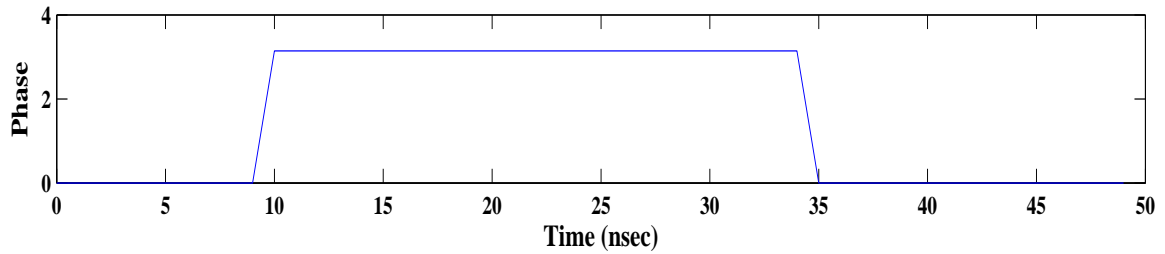

(d)

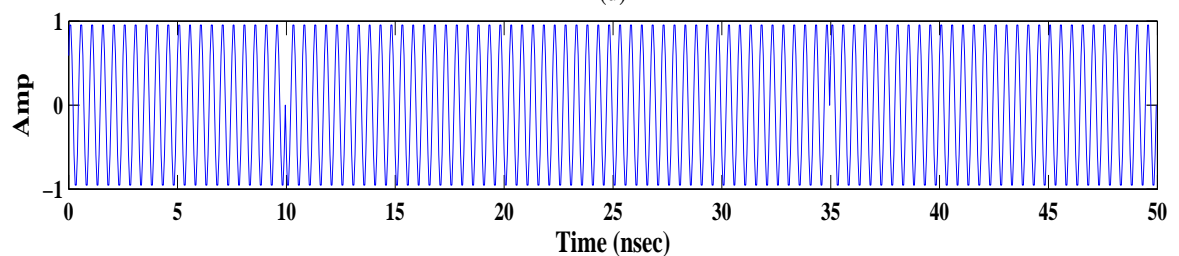

(e)

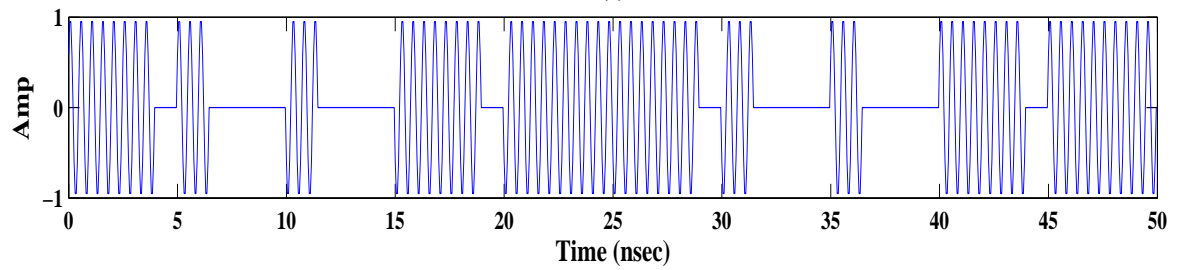

(f)

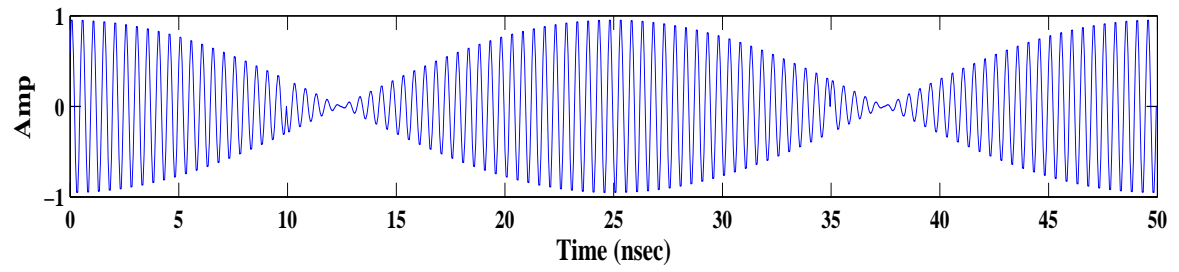

Figure 3.3: (a) Baseband amplitude component, (b) pulse-width modulation of the pulse train, (c) baseband phase component, (d) phase modulation of the carrier, (e) the carrier-based PWM signal, (f) the non-constant envelope transmitted signal. 
coding efficiency $[68,69]$, given as

$$
\eta(a)=\eta_{P A}(a) \eta_{C}(a)
$$

where $\eta_{P A}$ is the efficiency of the PA and $\eta_{C}$ is the coding efficiency which is the measure of the reflected power absorbed by the isolator.

In the PPWMT, the PA remains on for a duration $\tau$ while it is off for duration $(T-\tau)$ during a pulse-repetition period $T$. Hence, the PA efficiency for a constant amplitude $a$ is the average efficiency of the PA determined over the pulse-repetition period $T$, which is given as

$$
\eta_{P A}(A)=\frac{P_{O N} \tau}{P_{D C_{O N}} \tau+P_{D C_{O F F}}(T-\tau)}
$$

where $P_{O N}$ and $P_{D C_{O N}}$ is the output power and the power consumed by the $\mathrm{PA}$ when it is on, respectively, and $P_{D C_{O F F}}$ is the power consumed by the PA when it is OFF. Ideally for Class B/C PAs and SMPAs, there is a peak efficiency when $\mathrm{PA}$ is $\mathrm{ON}$ and there is no power consumption when the PA is OFF, hence (3.12) can be modified as

$$
\eta_{P A}=\frac{P_{O N}}{P_{D C_{O N}}}=\eta_{P A(\text { Peak })} .
$$

The coding efficiency is the ratio of the transmitted signal power to the CPWM signal power at the PA output. For a constant input signal the coding efficiency is given as

$$
\eta_{C}(a)=\frac{P_{T}(a)}{P_{C P W M}(a)}
$$

where $P_{C P W M}(a)$ is the power of the CPWM signal for a constant input signal. The RF transmitted signal for a constant input signal is given as

$$
x_{T}(t)=a \cos \left(\omega_{c} t\right)
$$

Assuming the carrier frequency $\omega_{c}$ is much higher than the PWM frequency $\omega_{I F}$, then the transmitted signal power for a normalized load of $1 \Omega$ can be approximated as [68]

$$
P_{T}(a)=\frac{1}{T} \int_{0}^{T} x_{T}^{2}(t) d t=\frac{1}{2} a^{2} .
$$

Fig. 3.4 shows the CPWM signal for a constant input signal, which is the combination of carrier burst of duration $\tau(a)$ and zero signal of duration $(T-\tau(a))$. 


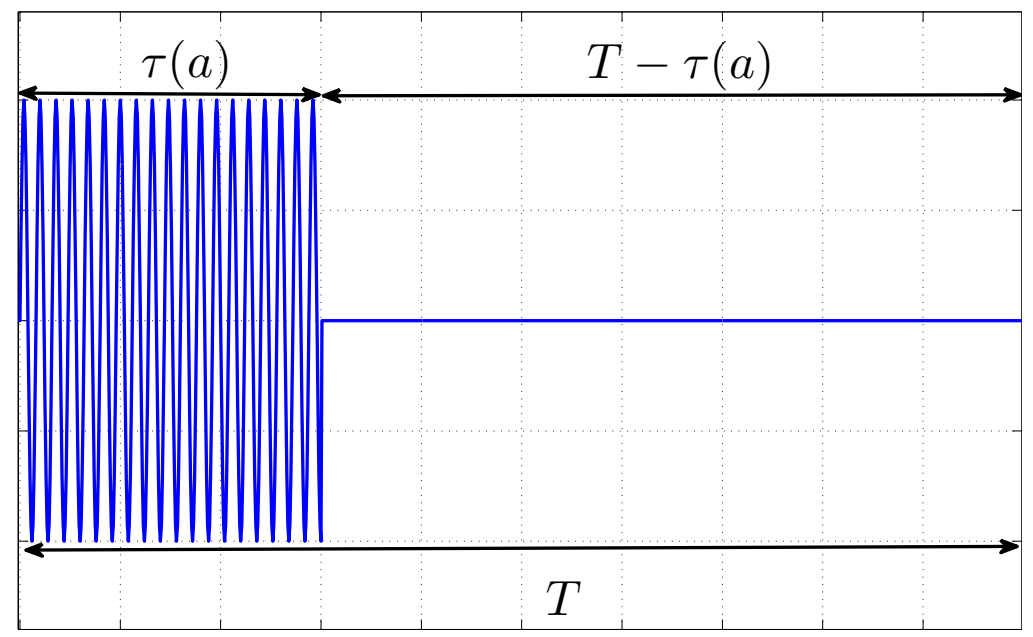

Figure 3.4: CPWM signal for a constant input $a=\tau(a) / T$.

It repeats after a period $T$, hence the power for a normalized load of $1 \Omega$ can be calculated as [68]

$$
P_{T}(a)=\frac{1}{T} \int_{0}^{T}\left(\cos \left(\omega_{c} t\right)\right)^{2} d t=\frac{1}{2} a .
$$

The coding efficiency expression in terms of a constant input signal is obtained by substituting (3.16) and (3.17) into (3.14), which is given as

$$
\eta_{C}(a)=\frac{\frac{1}{2} a^{2}}{\frac{1}{2} a}=a .
$$

The efficiency of the PPWMT for an ideal SMPA and class B PA is shown in Fig. 3.5, which shows a variation in efficiency with respect to input amplitude.

\subsubsection{Polar PWT Transmitter Issue}

The issues that need to be considered when using the PPWMT are the band-pass filtering requirements, the image distortion [70], the amplitude aliasing distortion and the phase aliasing distortion [65]. The last two issues are related to the digital implementation of the PWM and phase modulator.

\subsubsection{Band-Pass Filtering Requirement}

As discussed in Section 3.2.1, the PPWMT converts the amplitude component to a PWM signal. The spectrum of the PWM signal is determined by taking a 


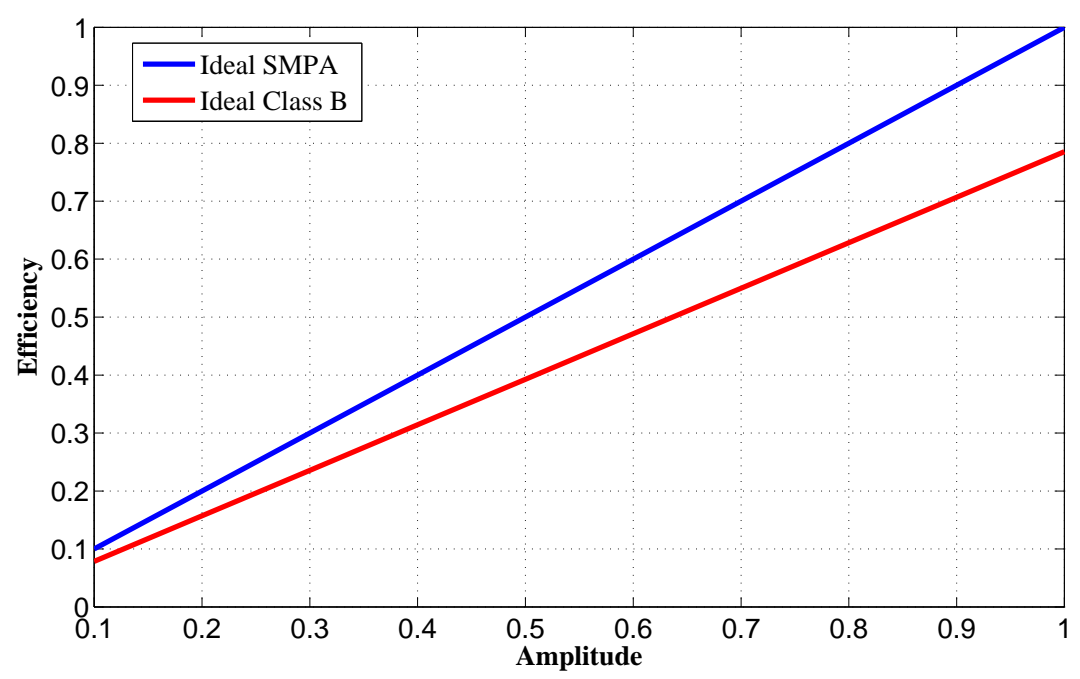

Figure 3.5: Efficiency of the PPWMT for an ideal SMPA and a Class B PA.

Fourier transform of $(3.5)[60,65]$, and is given as

$$
\begin{aligned}
X_{P W M}(\omega) & =A(\omega) \\
& +\sum_{k=0}^{\infty} \sum_{l=0}^{\infty} \frac{2(-1)^{l}(\pi k)^{2 l}}{(2 l+1) !} \times \pi\left[A_{2 l+1}\left(\omega+k \omega_{I F}\right)+A_{2 l+1}\left(\omega-k \omega_{I F}\right)\right]
\end{aligned}
$$

where $A(\omega)=F\{a(t)\}, A_{l}(\omega)=F\left\{a^{l}(t)\right\}$ and $F\{$.$\} denote the Fourier transform.$ The plot of (3.19) is shown in Fig. 3.6 for $\omega=2 \pi \times 200 \mathrm{Mrad} / \mathrm{sec}(200 \mathrm{MHz})$. It can be observed from the spectrum there is a desired amplitude component at DC and infinite harmonic components at both negative and positive multiples of $\omega_{I F}$, which is shifted to the carrier frequency $\omega_{c}$ after up-conversion. The band-pass filter suppress all the harmonic components of the up-converted PWM signal to achieve the desired transmitted signal, hence band-pass filtering requirement depends on $\omega_{I F}$, i.e. smaller value of $\omega_{I F}$ results more stringent band-pass filtering requirements and vice versa. However, a higher the value of $\omega_{I F}$ leads to a smaller dynamic range due to low amplitude resolution, image distortion and amplitude aliasing distortion.

\subsubsection{Image Distortion}

Image distortion [70] occurs due to the infinite spectrum of the PWM signal, which leads to a lower dynamic range and amplitude non-linearity. 


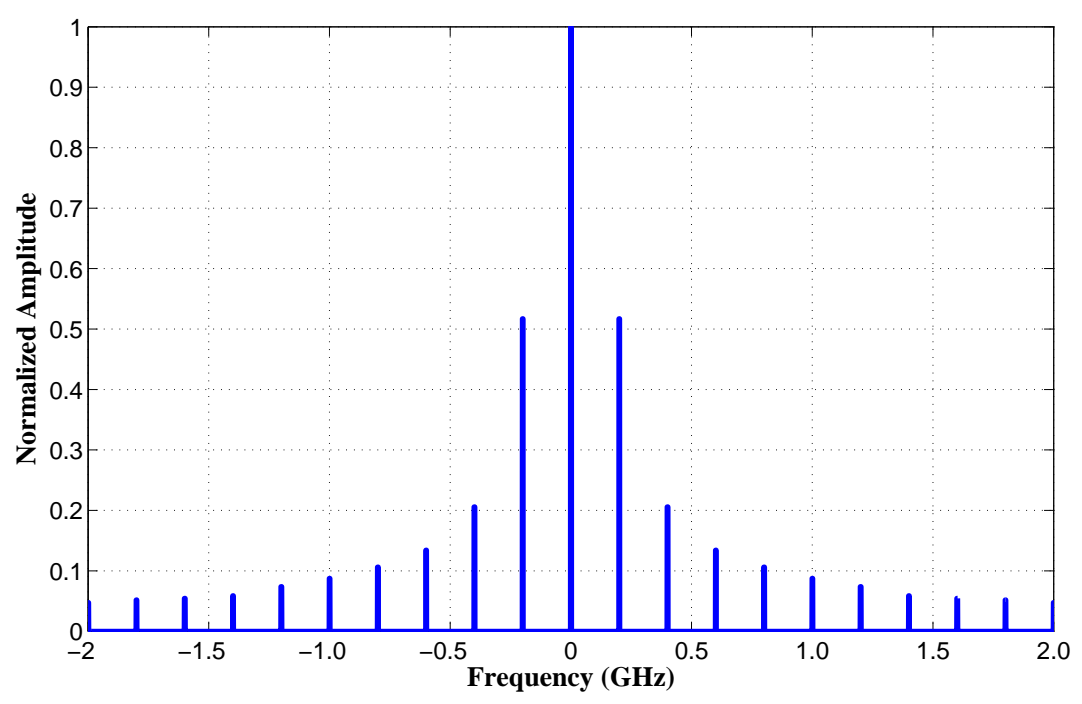

Figure 3.6: Spectrum of a PWM signal.

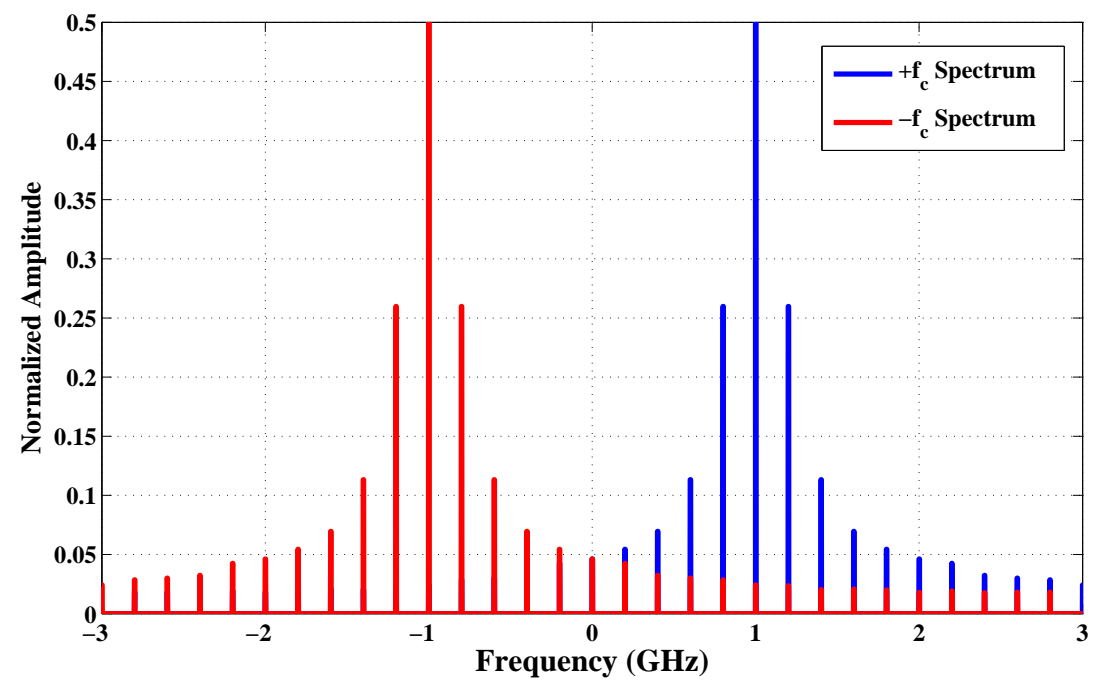

Figure 3.7: Spectrum of a CPWM signal. 
As discussed in Section 3.2.1, the CPWM signal is generated by multiplication of the PWM signal and the phase-modulated carrier, which is given in (3.5). The spectrum of (3.5) is shown in Fig. 3.7 for $\omega_{I F}=2 \pi \times 200 \mathrm{Mrad} / \mathrm{sec}(200 \mathrm{MHz})$, $\omega_{c}=2 \pi \mathrm{Grad} / \mathrm{sec}(1 \mathrm{GHz}), a=0.5$ and $\phi=0$. It is evident from Fig. 3.7 that the spectrum of the PWM signal is shifted to $\pm \omega_{c}$. As the PWM spectrum has infinite harmonic components this causes an intersection of both the shifted PWM spectrums. This leads to an overlap of transmitted signal and $k_{t h}$ harmonic component of shifted PWM signal resulting in a distortion referred as image distortion.

The CPWM signal can be amplified by either a linear PA or SMPA. In case of amplification by a linear PA, there is no increase in image distortion. However, in case of the SMPA, the image distortion is increased compared to the CPWM signal, as the SMPA converts the sinusoid carrier bursts to the square-wave carrier bursts. The expression for square-wave carrier bursts is given as

$$
\begin{aligned}
x_{S M P A}(t)= & \left(\frac{\tau(t)}{T}+\sum_{k=1}^{\infty} \frac{2}{k \pi} \sin \left(\frac{k \pi \tau(t)}{T}\right) \cos \left(\omega_{I F} k t\right)\right) \\
& \left(\frac{1}{2}+\frac{2}{\pi} \cos \left(\omega_{c} t+\phi(t)\right)+\sum_{m=2}^{\infty} \frac{2}{q \pi} \sin \left(\frac{q \pi}{2}\right) \cos \left(q \omega_{c} t+q \phi(t)\right)\right) .
\end{aligned}
$$

The plot of (3.20) and its spectrum is shown in Fig. 3.8 for $\omega_{I F}=2 \pi \times$ $200 \mathrm{Mrad} / \mathrm{sec}(200 \mathrm{MHz})$ and $\omega_{c}=2 \pi \mathrm{Grad} / \mathrm{sec}(1 \mathrm{GHz})$. The spectrum plot shows multiple attenuated PWM spectra at $\pm q \omega_{c}(q=0,1,2, \ldots, \infty)$, hence $q$ harmonic components exist along with the transmitted signal, which results in higher image distortion.

\subsubsection{Amplitude Aliasing Distortion}

The amplitude aliasing distortion $[65,71]$ is due to the digital implementation of the pulse-width modulator. The digital PWM signal is a sampled version of the analog PWM signal, hence the rising and falling edges occur only at integer multiples of the sampling period. The digital PWM signal and its spectrum $[71,72]$ are given as

$$
\begin{gathered}
x_{P W M}\left(n T_{s}\right)=\left(\frac{\tau\left(n T_{s}\right)}{T}+\sum_{k=1}^{\infty} \frac{2}{k \pi} \sin \left(\frac{k \pi \tau\left(n T_{s}\right)}{T}\right) \cos \left(\omega_{I F} k n T_{s}\right)\right) \\
X_{P W M}\left(e^{j \omega}\right)=\frac{1}{T_{s}} \sum_{\rho=-\infty}^{\infty} X_{P W M}\left(j\left(\frac{\omega}{T_{s}}-\frac{2 \pi \rho}{T_{s}}\right)\right)
\end{gathered}
$$


(a)

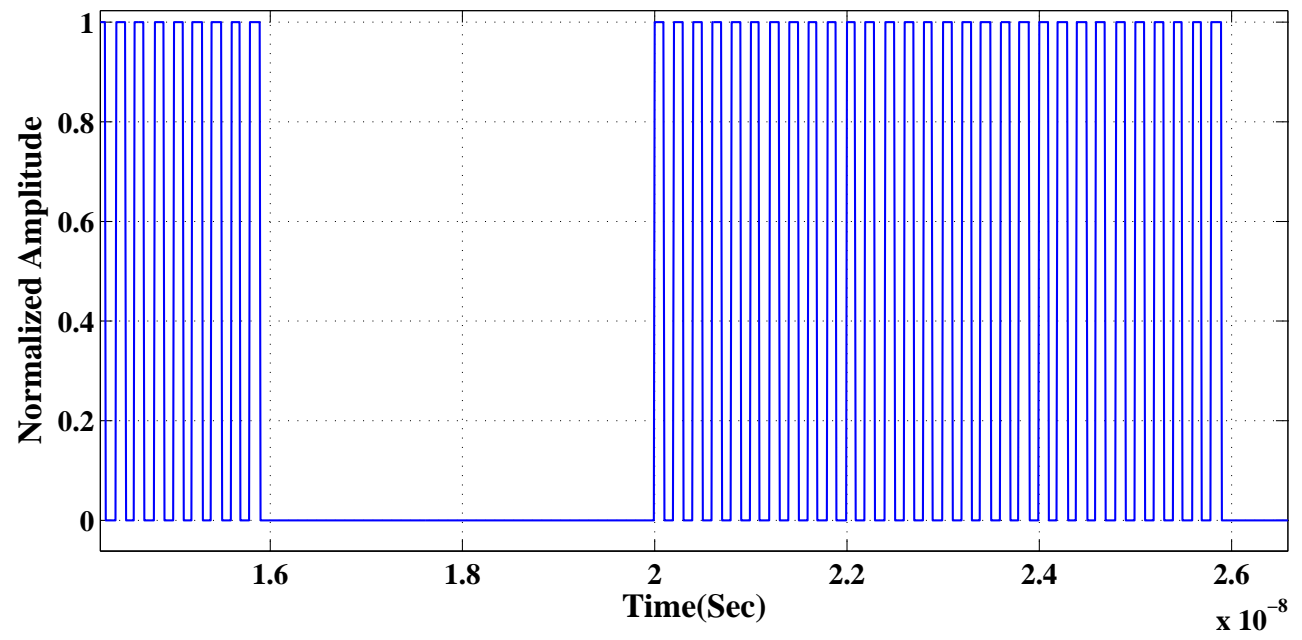

(b)

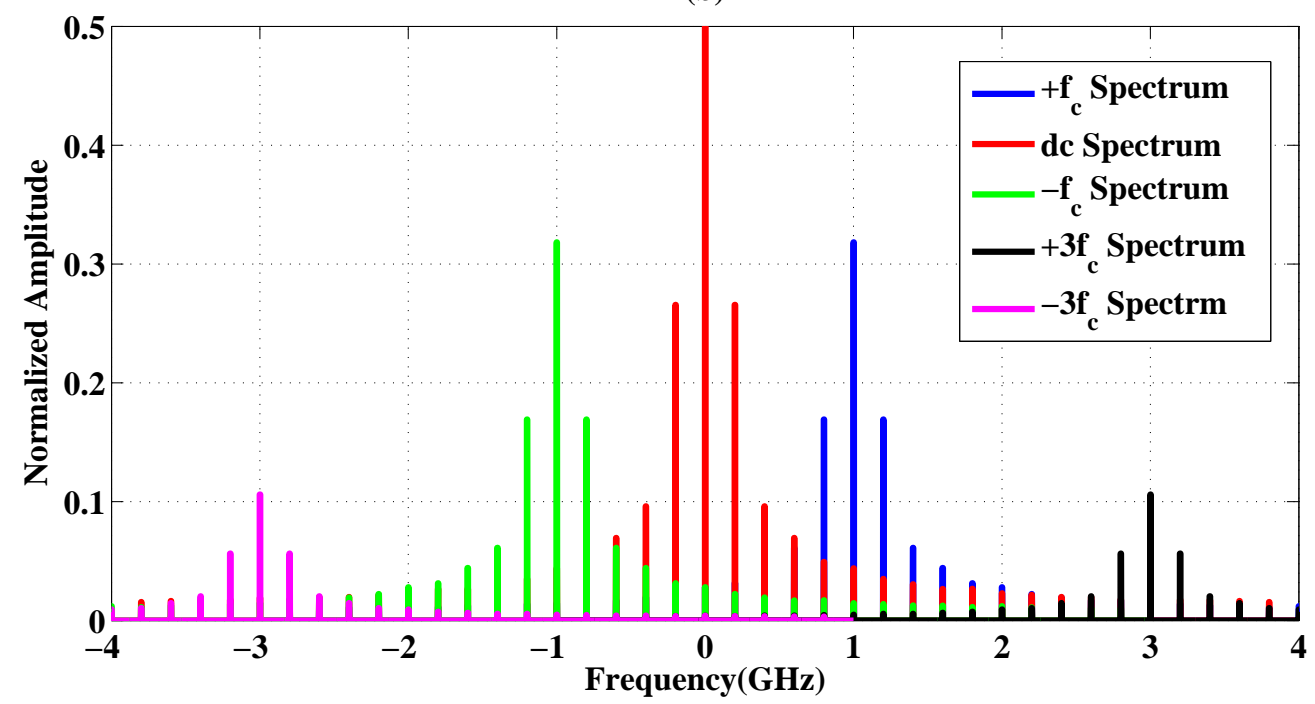

Figure 3.8: (a) The CPWM signal amplified by a SMPA, (b) spectrum of the CPWM signal amplified by a SMPA 
where $n$ is the sampling index and $T_{s}$ is the sampling period. The plot of the digital PWM and its spectrum is shown in Fig. 3.9 for $\omega_{I F}=2 \pi \times 200 \mathrm{Mrad} / \mathrm{s}$ $(200 \mathrm{MHz})$ and $\omega_{s}=2 \pi \mathrm{Grad} / \mathrm{s}(1 \mathrm{GHz})$. The spectrum shows the repetition of the analog PWM spectra at $\pm n \omega_{s}(n=0,1,2, \ldots, \infty)$, which results in an aliasing in the baseband amplitude component due to the harmonic component of the PWM spectra at $\pm n \omega_{s}$. This distortion is referred to as amplitude aliasing distortion of the transmitted signal.

This distortion contributes to lowering the dynamic range and increasing the amplitude non-linearity of the system.

\subsubsection{Phase Aliasing Distortion}

The phase aliasing distortion [65] is due to the digital implementation of the phase modulator, which causes phase non-linearity in the transmitter.

In the digital domain, the phase modulation is achieved by pulse-position modulation (PPM), which can be implemented as a sampled-based system or by synchronous delay lines. In both cases, the time resolution of the PPM is limited by the sampling clock frequency or by the unit delay of the delay lines. As a result, the number of phases of the digital PPM are also limited and is given as

$$
N_{\phi}=\frac{\omega_{r e s}}{\omega_{c}}
$$

where $N_{\phi}$ is the total number of phases, $\omega_{\text {res }}=1 / 2 \pi T_{\text {res }}$ is the sampling frequency in case of sample-based system, or the inverse of the unit delay in case of delay line, and $\omega_{c}=1 / 2 \pi T_{c}$ is the carrier frequency.

The effect of limited time resolution can also be explained from the spectrum of the digital PPM signal. The digital PPM signal and its spectrum [72] are given as

$$
\begin{aligned}
x_{P P M}\left(n T_{s}\right) & =\frac{1}{2}+\frac{2}{l \pi} \cos \left(\omega_{c} n T_{s}+\phi\left(n T_{S}\right)\right) \\
& +\sum_{m=2}^{\infty} \frac{2}{l \pi} \sin \left(\frac{l \pi}{2}\right) \cos \left(l \omega_{c} n T_{s}+l \phi\left(n T_{s}\right)\right) \\
X_{P P M}\left(e^{j \omega}\right) & =\frac{1}{T_{\text {res }}} \sum_{\rho=-\infty}^{\infty} C_{P P M}\left(j\left(\frac{\omega}{T_{r e s}}-\frac{2 \pi \rho}{T_{\text {res }}}\right)\right)
\end{aligned}
$$

The (3.25) shows the repetition of analog PPM spectra at integer multiple of $\omega_{\text {res }}$. The spectrum of the analog PPM has infinite components which cause aliasing in the phase-modulated carrier and is referred to as phase-aliasing distortion. 
(a)

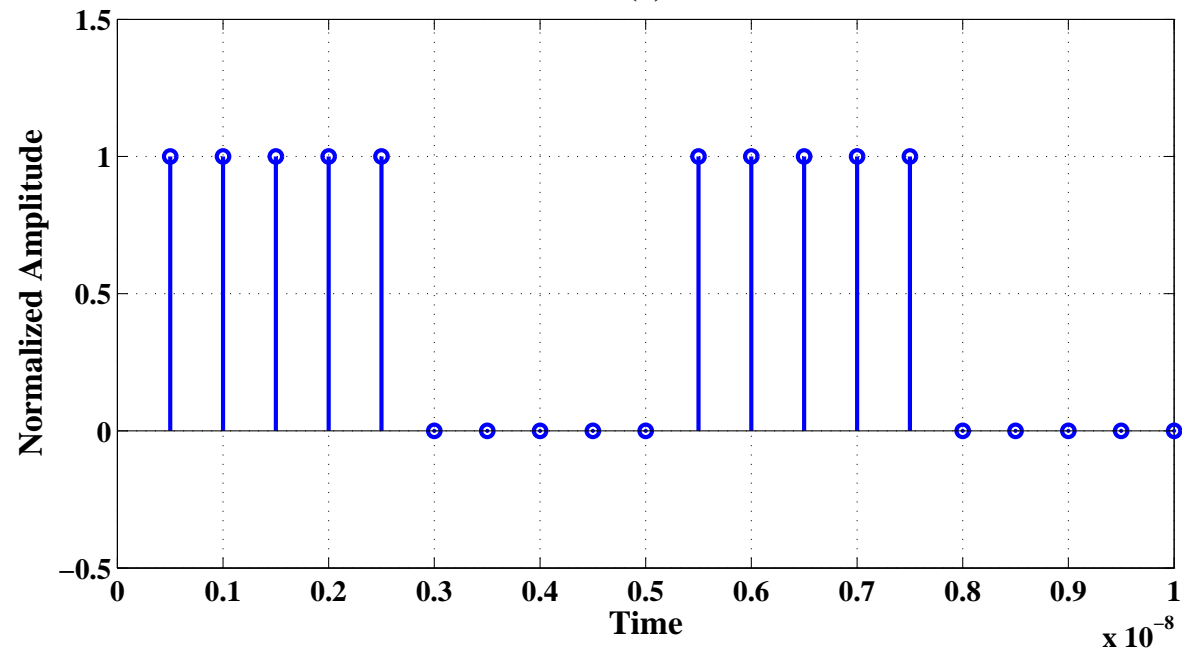

(b)

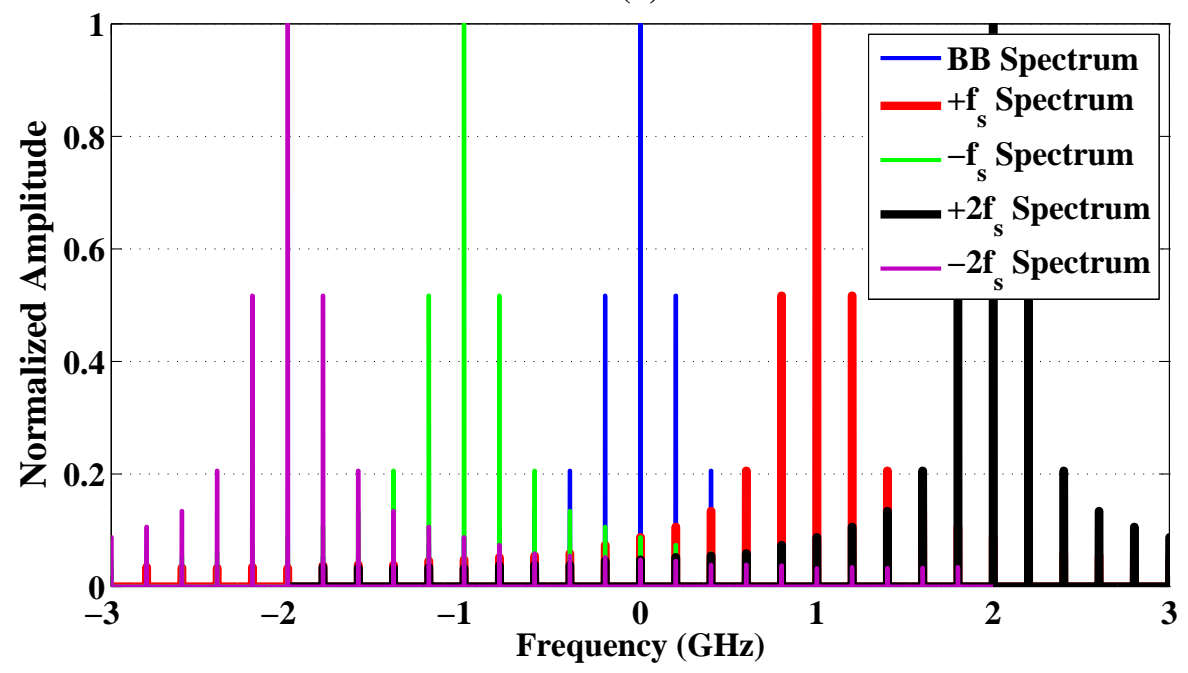

Figure 3.9: (a) Digital PWM signal in time domain, (b) digital PWM spectrum. 



\section{Chapter 4}

\section{Polar PWM Transmitters with Reduce Image and Aliasing Distortion}

Chapter 3 discussed the image, amplitude aliasing and phase aliasing distortions of the PPWMT. The image distortion is due to the up-conversion of the PWM signal to the carrier frequency. The amplitude aliasing distortion occurs due to the digital implementation of the pulse-width modulator and the phase aliasing distortion is due to the digital implementation of the phase modulator. These distortions result in a lower dynamic range of the transmitter and also cause non-linearity in the amplitude and phase of the transmitted signal. The focus of this chapter is on variants of PPWMT that either compensate or eliminate the image and aliasing distortions.

The outline of this chapter is as follows: The first section discusses imagedistortion free PPWMTs. In the second section, the aliasing-free PWM transmitter (AF-PWMT), its efficiency and problems are discussed. The third section briefly discusses the novel combined RF and AF-PWM transmitter (CRFAFPWMT) presented in Paper A. In the fourth section, the aliasing-compensated PWM transmitter (AC-PWMT) presented in Paper B and Paper $\mathbf{C}$ is briefly discussed. The fifth section presents the simulated performance of PPWMT, AFPWMT, CRFAF-PWMT and AC-PWMT. Finally, the enhanced phase-resolution polar PWM transmitter (EP-PPWMT) of Paper D is briefly discussed. 


\subsection{Image-Distortion Free Polar PWM Transmitter}

The image distortion in the polar PWM transmitter can be eliminated or reduced by exploiting the image gap between the transmitted signal and the adjacent harmonics or by the elimination of image harmonic components that distort the transmitted signal.

\subsubsection{Exploiting Image Gap}

The image distortion of the PPWMT can be eliminated or reduced by selecting the PWM frequency $\left(\omega_{I F}\right)$ with respect to the carrier frequency $\left(\omega_{c}\right)$, such that none of the harmonic components of image PWM signal occurs in the transmitted signal band. Instead the image harmonic components occur in frequency bands inbetween the transmitted signal and the adjacent harmonics [70]. Fig. 4.1a shows the spectrum of an up-converted PWM signal with an image distortion due to improper selection of $\omega_{I F}$, whereas the spectrum with no image distortion due to the proper selection of $\omega_{I F}$ is shown in Fig. 4.1b. This technique eliminates the image distortion in case of a linear PA. However, in case of an SMPA, the image distortion is only reduced and not completely eliminated. Although effective, this technique requires strict bandpass filtering to achieve the desired results.

\subsubsection{Elimination of Image Distortion}

An alternative approach is to quantize the amplitude component $a(t)$ of the baseband signal such that the harmonic components of the image PWM spectrum located in the transmitted signal band are eliminated [70]. Although this technique overcomes the image distortion, it results in a higher quantization noise.

The steps to eliminate the image harmonics distorting the transmitted signal are as follows:

1. Determine the order of the highest amplitude image harmonic component located in the transmitted signal band. In the case of a linear PA or differential SMPAs, the order of the image harmonic component in the transmitted signal band is determined as

$$
q=\operatorname{round}\left(\frac{2 \omega_{c}}{\omega_{I F}}\right) .
$$


(a)

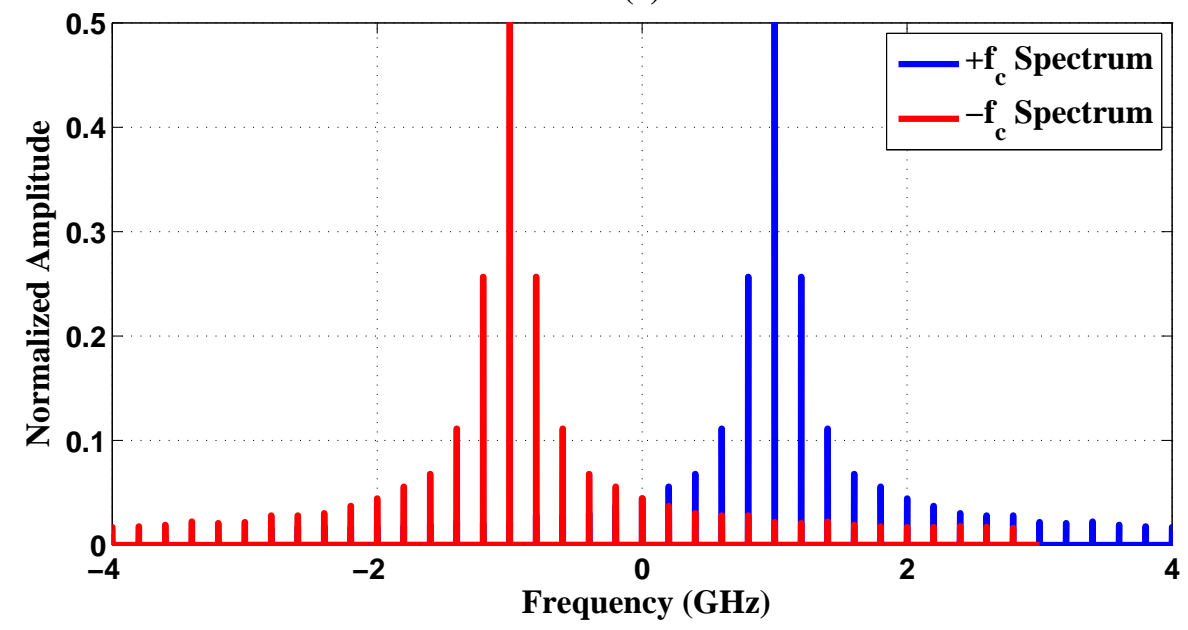

(b)

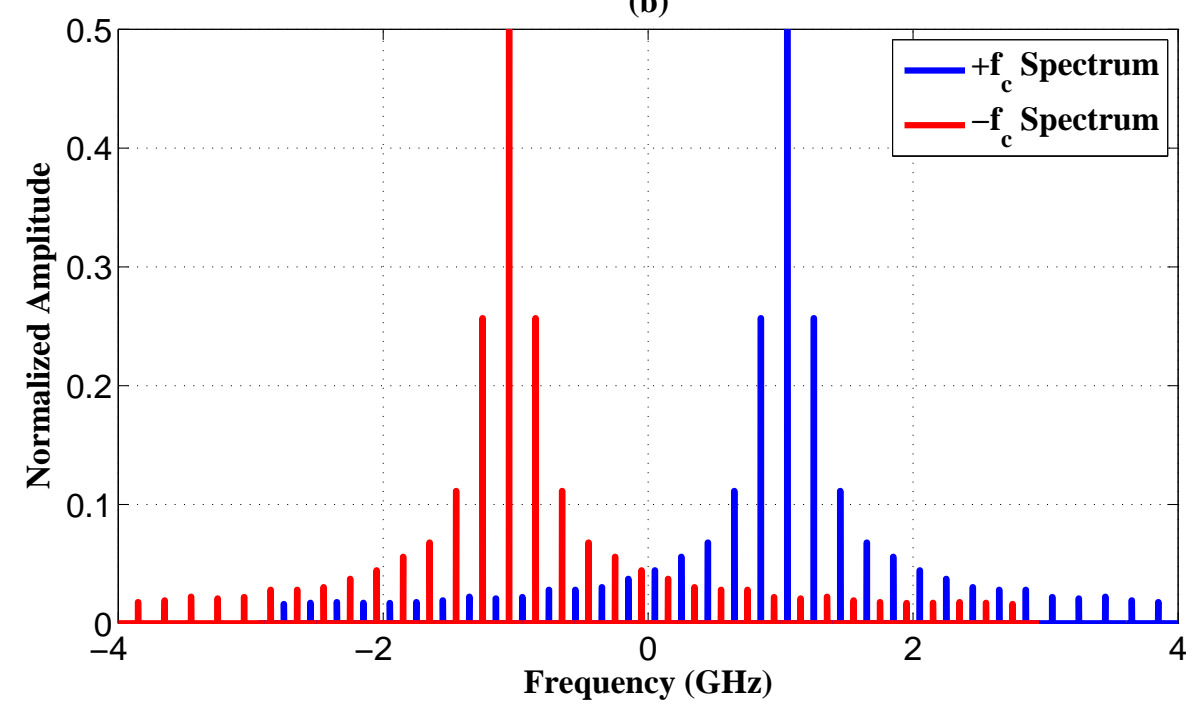

Figure 4.1: Spectra of the up-converted PWM signal (a) image distortion due to improper selection of $\omega_{I F}$, (b) no image distortion due to proper selection of $\omega_{I F}$. 
Whereas in the case of a single ended SMPA, it is determined as

$$
q=\operatorname{round}\left(\frac{\omega_{c}}{\omega_{I F}}\right)
$$

2. Quantize the amplitude component according to following expression

$$
\hat{\mathrm{a}}=\Delta_{q} \cdot \operatorname{round}\left(\frac{a(t)}{\Delta_{q}}\right)
$$

where $\Delta_{q}=1 / q$ is the the quantize interval parameter.

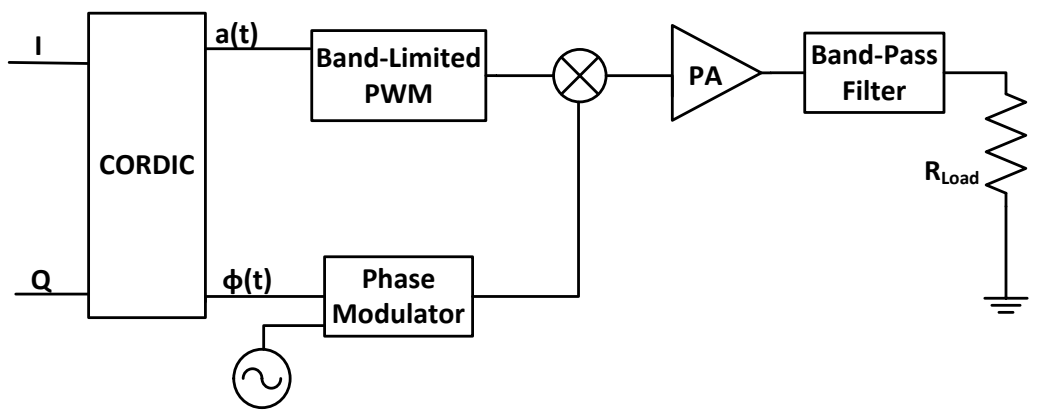

Figure 4.2: Block diagram of the aliasing-free PWM transmitter.

\subsection{Aliasing-Free PWM Transmitter}

\subsubsection{Concept}

The aliasing-Free PWM transmitter [71, 73-75] (AF-PWMT) eliminates the aliasing and image distortion by limiting the number of harmonics of the digital PWM signal.

The block diagram of the AF-PWMT is shown in Fig. 4.2. The transmitter separates the baseband signal $x(t)$ into its amplitude $a(t)$ and phase $\phi(t)$ components. The amplitude component generates a digital PWM signal with finite harmonic components, hereafter referred to as a band-limited PWM (BL-PWM) signal [71], which is given as

$$
x_{B L-P W M}\left(n T_{s}\right)=\frac{\tau\left(n T_{s}\right)}{T}+\sum_{k=1}^{K} \frac{2}{k \pi} \sin \left(\frac{k \pi \tau\left(n T_{s}\right)}{T}\right) \cos \left(\omega_{I F} k n T_{s}\right)
$$


(a)

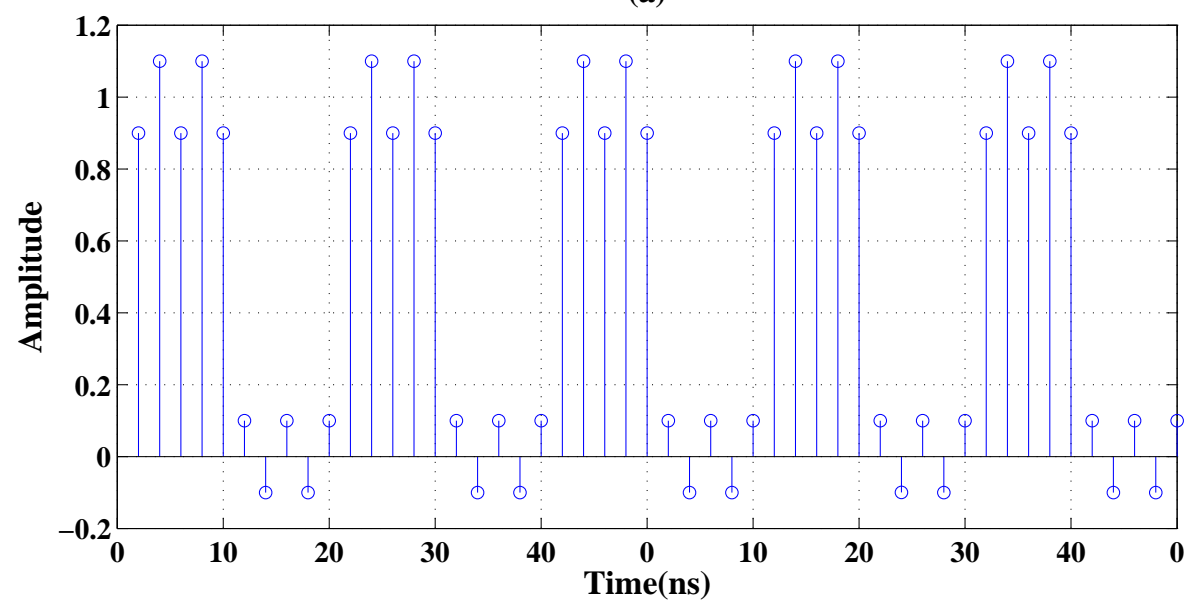

(b)

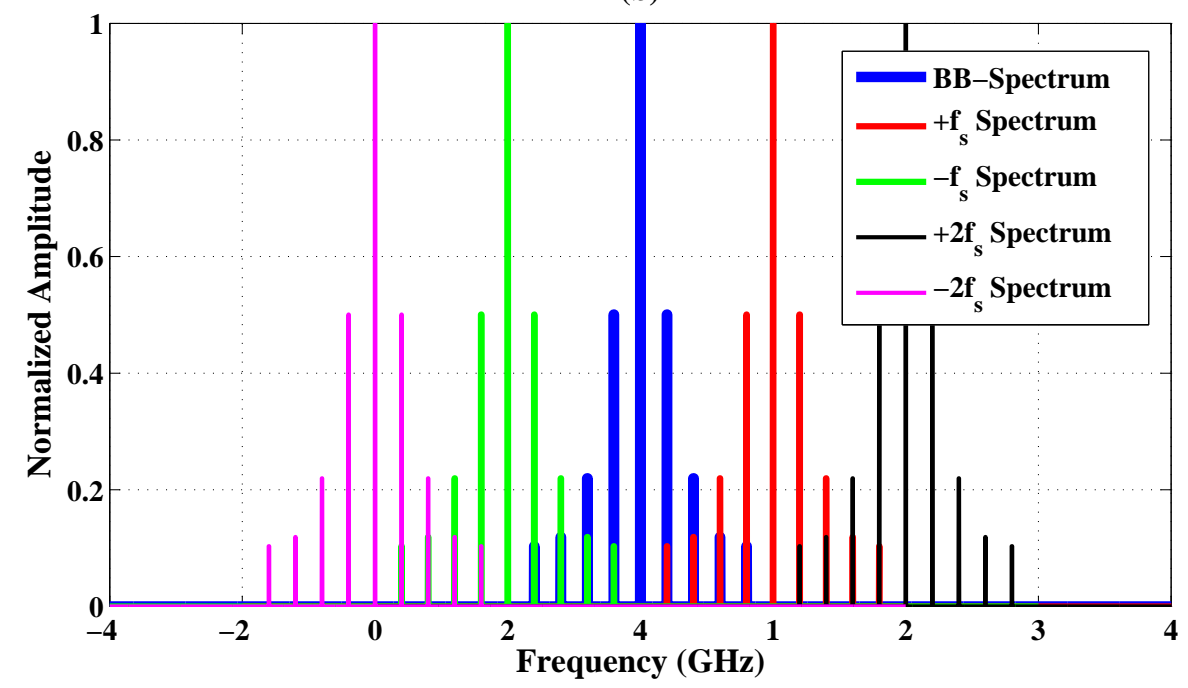

Figure 4.3: (a) BL-PWM signal, (b) BL-PWM spectrum. 
where $\tau\left(n T_{S}\right)=a\left(n T_{S}\right) T, a\left(n T_{S}\right)$ is the baseband signal amplitude at instance $n T_{S}$ and $K$ is the total number of harmonics in the BL-PWM signal. In order to eliminate the aliasing and image distortions, $K$ must ensure the following conditions

$$
\left.\begin{array}{l}
K \omega_{I F}<2 \pi / T_{s} \\
K \omega_{I F}<\omega_{c}
\end{array}\right\}
$$

The BL-PWM signal and its spectrum is shown in Fig. 4.3. This BL-PWM signal is then converted into an analog signal using a digital-to-analog convertor (DAC), which is given as

$$
x_{B L-P W M}(t)=\frac{\tau(t)}{T}+\sum_{k=1}^{K} \frac{2}{k \pi} \sin \left(\frac{k \pi \tau(t)}{T}\right) \cos \left(\omega_{I F} k t\right) .
$$

The phase component $\phi(t)$ varies the phase of the carrier to generate a phase-modulated carrier, which is multiplied by the $x_{B L-P W M}(t)$ to generate a carrier-based BL-PWM (CBL-PWM) signal expressed as

$$
\begin{aligned}
x_{C B L-P W M}(t) & =\frac{\tau(t)}{T} \cos \left(\omega_{c} t+\phi(t)\right) \\
& +\left(\sum_{k=1}^{K} \frac{2}{k \pi} \sin \left(\frac{k \pi \tau(t)}{T}\right) \cos \left(\omega_{I F} k t\right)\right) \cos \left(\omega_{c} t+\phi(t)\right) .
\end{aligned}
$$

The CBL-PWM signal and its spectrum is show in Fig. 4.4. This signal is amplified by the PA and finally filtered to generate the transmitted signal.

The major disadvantage of the AF-PWMT is that it can only use a linear PA operating at low efficiency for the amplification of the CBL-PWM signal.

\subsubsection{Efficiency}

As discussed in chapter 3 the major power consumption in transmitter is due to the PA and the following passive circuitry, which implies that the efficiency of the AF-PWMT is the product of the PA efficiency and the coding efficiency [68], mathematically expressed as

$$
\eta(A)=\eta_{P A}(a, k) \eta_{c}(a)
$$

As discussed earlier, the AF-PWMT converts the amplitude $a$ of the baseband input into a variable amplitude BL-PWM signal, which is mixed with a phasemodulated carrier to generate a non-constant envelope CBL-PWM signal. Since 
(a)

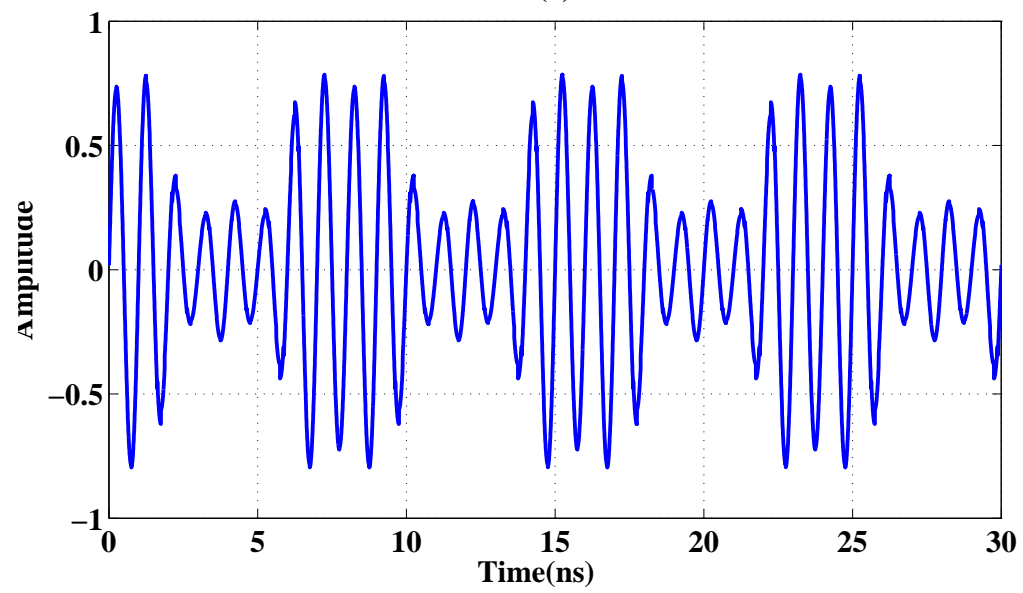

(b)

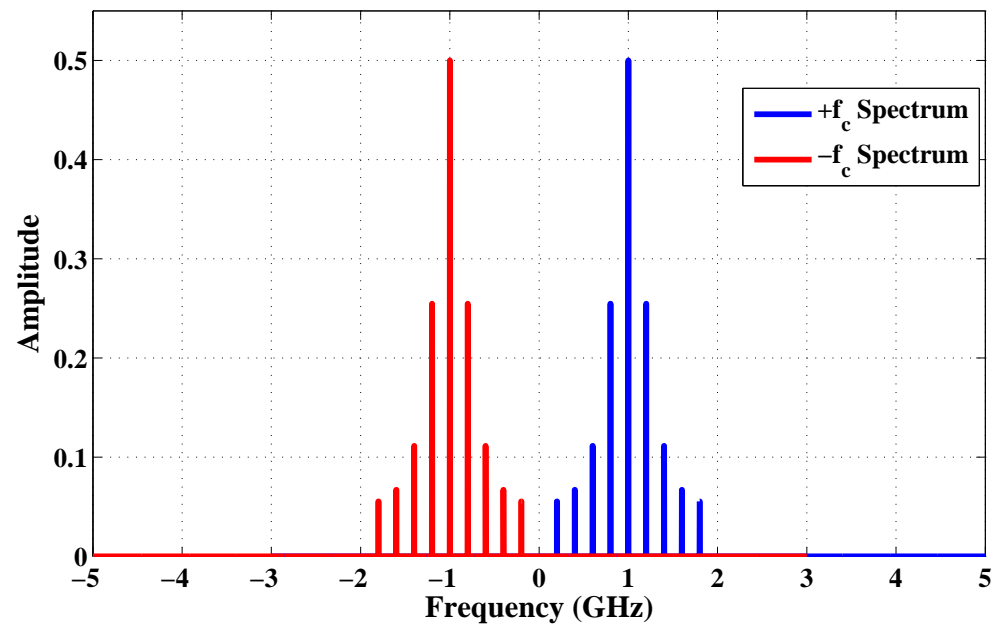

Figure 4.4: . (a) CBL-PWM signal, (b) CBL-PWM spectrum. 
the PA efficiency varies with the envelope of the CBL-PWM, hence $\eta_{P A}$ is the average efficiency, which in case of an ideal class B PA is given as $[76,77]$

$$
\eta_{P A}=\frac{\pi}{4} \frac{\mathbb{E}\left\{x_{B L-P W M}^{2}\right\}}{\mathbb{E}\left\{x_{B L-P W M}\right\}}
$$

The coding efficiency in case of an AF-PWMT is defined as [69]

$$
\eta_{c}(a)=\frac{P_{T}(a)}{P_{C B L-P W M}(a)}
$$

where $P_{T}(a)$ is the power of the RF transmitted signal and $P_{C B L-P W M}$ is the power of the CBL-PWM signal at the PA output. The $P_{T}(a)$ for a normalized load of $1 \Omega$ is approximated in section 3.2 and is given as

$$
P_{T}(a)=\frac{1}{2} a^{2} \text {. }
$$

The $P_{C B L-P W M}$ for a normalized load of $1 \Omega$ is given as

$$
\begin{aligned}
P_{C B L-P W M} & =\frac{1}{T} \int_{0}^{T} x_{C B L-P W M}^{2}(t) d t \\
& =\frac{1}{T} \int_{0}^{T}\left(\frac{\tau(a)}{T}+\sum_{k=1}^{K} \frac{2}{k \pi} \sin \left(\frac{k \pi \tau(a)}{T}\right) \cos \left(\omega_{I F} k t\right)\right)^{2} \cos ^{2}\left(\omega_{c} t\right) \\
& =\frac{1}{2} a^{2}+\frac{1}{T} \int_{0}^{T}\left(\sum_{k=1}^{K} \frac{2}{k \pi} \sin \left(\frac{k \pi \tau(a)}{T}\right) \cos \left(\omega_{I F} k t\right)\right)^{2} \cos ^{2}\left(\omega_{c} t\right) .
\end{aligned}
$$

Substituting the value $P_{T}(a)$ and $P_{C B L-P W M}(a)$ into (4.10), the complete expression for the coding efficiency is given as

$$
\eta_{C}(a, k)=\frac{\frac{1}{2} a^{2}}{\frac{1}{2} a^{2}+\frac{1}{T} \int_{0}^{T}\left(\sum_{k=1}^{K} \frac{2}{k \pi} \sin \left(\frac{k \pi \tau(a)}{T}\right) \cos \left(\omega_{I F} k t\right)\right)^{2} \cos ^{2}\left(\omega_{c} t\right)} .
$$

Equation (4.13) can be simplified as [69]

$$
\eta_{C}(a, k) \approx \frac{1}{1+2 \sum_{k=1}^{K} \operatorname{sinc}^{2}(k A)} .
$$

Substituting the value of $\eta_{P A}$ given in (4.9) and $\eta_{C}(a, k)$ given in (4.14) into (4.8) gives the complete expression for the efficiency of the AF-PWMT, which is

$$
\eta(a, k)=\frac{\pi}{4} \frac{\mathbb{E}\left\{x_{B L-P W M}^{2}\right\}}{\mathbb{E}\left\{x_{B L-P W M}\right\}}\left(\frac{1}{1+2 \sum_{k=1}^{K} \operatorname{sinc}^{2}(k A)}\right) .
$$

The plots for the theoretical efficiency of the AF-PWMT for an ideal class B PA given in Fig. 4.5. 


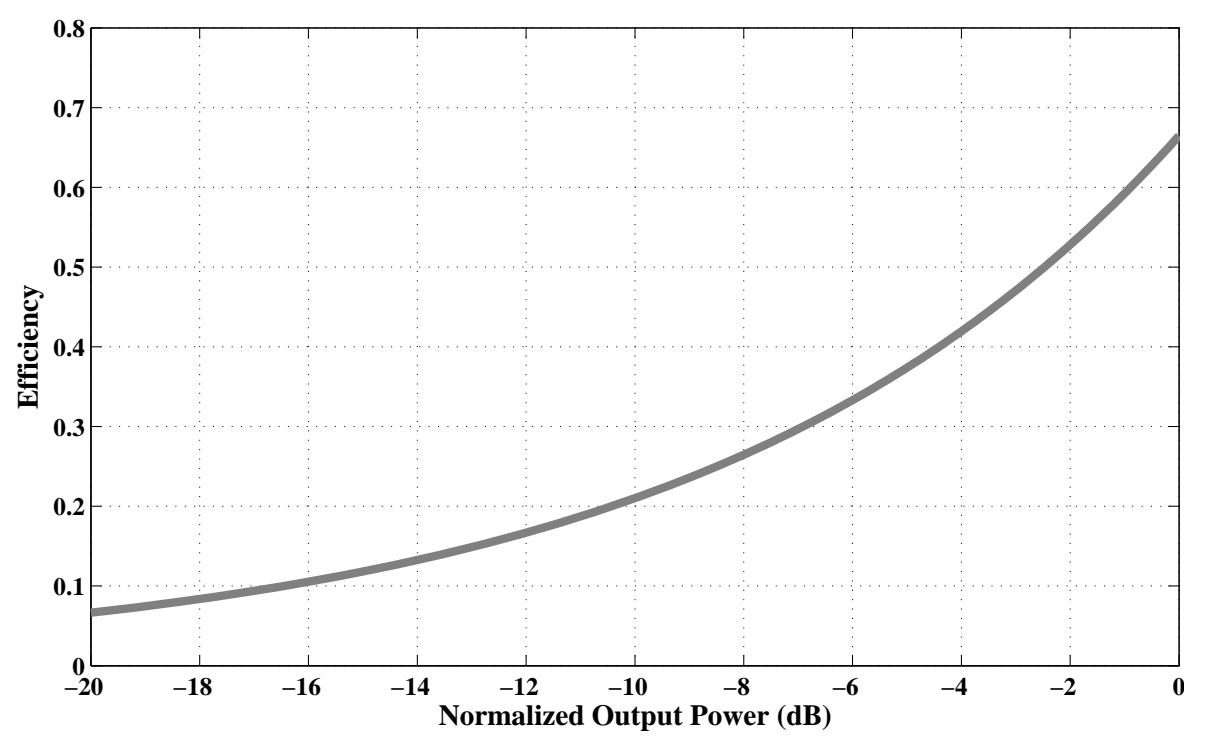

Figure 4.5: The theoretical efficiency of AF-PWMT for ideal class B PA.

\subsection{Combined RF and AF-PWM Transmitter}

The Combined RF and AF-PWM Transmitter (CRFAF-PWMT) is the contribution of Paper A. This section briefly discusses the CRFAF-PWMT along with a comparison of theoretical instantaneous efficiency of the AF-PWMT and the CRFAF-PWMT. The detail concept, analog and digital implementations, efficiency analysis and measurement results are given in Paper A.

This transmitter eliminates the amplitude aliasing and image distortion in the transmitted signal while achieving a high power efficiency as it uses an SMPA for amplification. The advantages of this transmitter over the AF-PWMT is higher power efficiency and its implementation by all-digital circuits. Fig. 4.6 shows the comparison of the instantaneous efficiency for the CRFAF-PWMT using an ideal SMPA (i.e. no loss in switching and impedance matching network for all duty cycles) and AF-PWMT using an ideal class B PA.

The block diagram of the CRFAF-PWMT is shown in Fig. 4.7, which separates the baseband signal into phase $\left(\phi\left(n T_{s}\right)\right)$ and amplitude components $\left(a\left(n T_{s}\right)\right)$. The $\phi\left(n T_{s}\right)$ generates the pulse-position modulated signal by varying the pulse position of a pulse train having a frequency equal to the carrier frequency. The $a\left(n T_{s}\right)$ generates a BL-PWM signal with a repetition frequency equal to the intermediate frequency. This BL-PWM signal varies the pulse width of the 


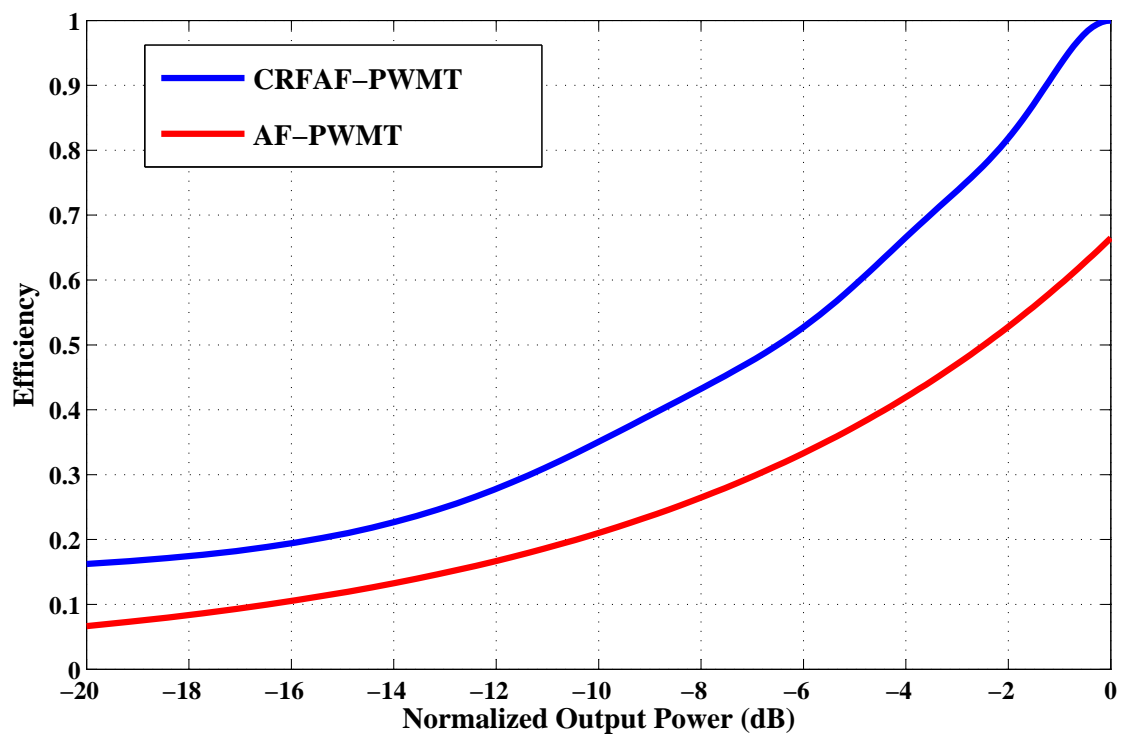

Figure 4.6: The theoretical efficiency of the AF-PWMT and CRFAF-PPWMT.

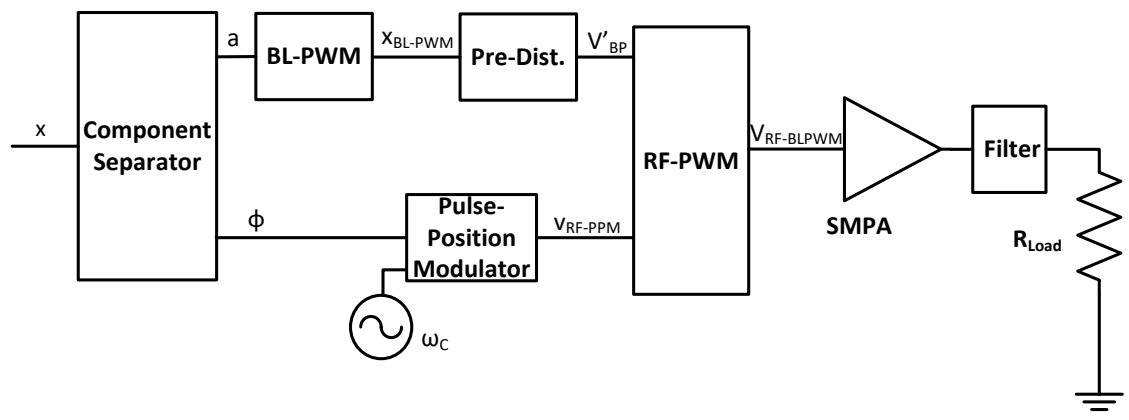

Figure 4.7: Block diagram of the combined RF aliasing-free PWM transmitter. 
pulse-position modulated signal to generate a constant envelope band-limited RF-PWM signal, which is amplified by an SMPA and finally filtered to generate a distortion-free transmitted signal.

\subsection{Aliasing-Compensated PWM Transmitter}

The aliasing-compensated PWM transmitter(AC-PWMT) and its all-digital implementation are the contribution of the Paper B and Paper C. Paper B gives a detailed discussion on the AC-PWMT along with its efficiency analysis, whereas Paper $\mathbf{C}$ gives the all-digital implementation.

This transmitter compensates for amplitude aliasing and image distortion in the transmitted signal by combining the two outphasing PWM signals after the final amplification. The advantage of this transmitter over the AF-PWMT is a higher efficiency as it allows the use of both SMPAs or linear PAs operating at saturation power. The curve for the theoretical efficiency of the AC-PWMT using an ideal SMPA and a class B PA is shown in Fig. 4.8. The figure also shows the theoretical efficiency of the AF-PWMT using an ideal class B PA for comparison.

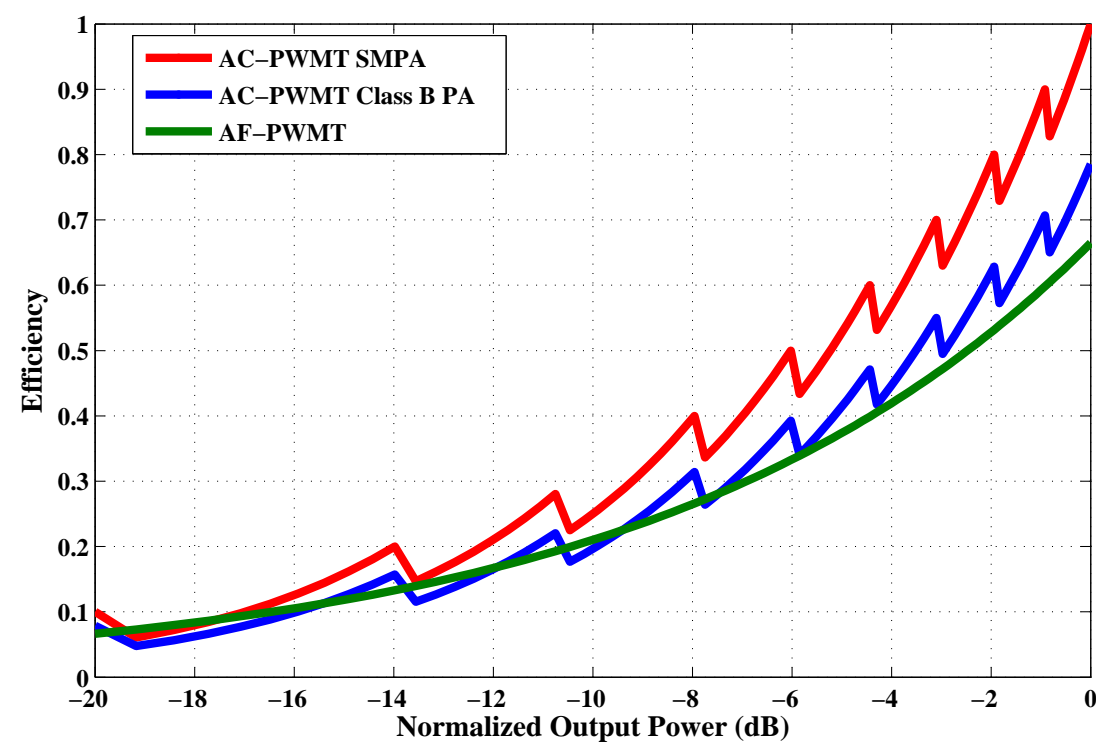

Figure 4.8: The theoretical efficiency of AC-PWMT (for SMPA and class B PA) and AF-PWMT. 


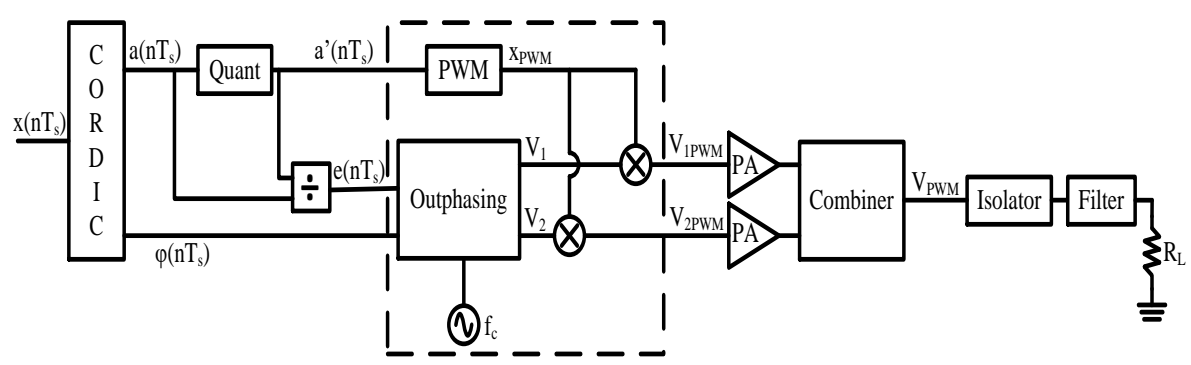

Figure 4.9: Block diagram of the AC-PWMT.

The block diagram of the AC-PWMT is shown in Fig. 4.9, which separates the baseband signal into its amplitude $a\left(n T_{S}\right)$ and phase $\phi\left(n T_{S}\right)$ components. $a\left(n T_{S}\right)$ is then quantized to $a^{\prime}\left(n T_{S}\right)$, which generates an aliasing-free PWM signal $X_{P W M}$. The error ratio $e\left(n T_{S}\right)$ due to quantization is added and subtracted to the phase component $\phi\left(n T_{S}\right)$ to generate two outphasing angles. The carrier is then phase modulated according to the outphasing angles to generate two outphasing carriers which are multiplied by $X_{P W M}$ to generate two carrier-based PWM signals. These carrier-based PWM signals are amplified by PAs, then combined and finally filtered to generate the aliasing and image distortion free transmitted signal.

\subsection{Simulation Results}

This section presents the performance of the PPWMT, AF-PWMT, CRFAFPPWMT and AC-PWMT. The simulations are done using Cadence and ADS using a standard $130 \mathrm{~nm}$ CMOS technology for a carrier frequency of $1 \mathrm{GHz}$. The PPWMT and CRFAF-PWMT are simulated using a 1 Watt class D PA, the AF-PWMT using a 1 Watt class AB PA and the AC-PWMT using a pair of 0.5 watt class D PAs.

The amplitude linearity of the transmitters is shown in Fig. 4.10, where the normalized output amplitude is plotted against the normalized input amplitude. It can be observed that the PPWMT has a staircase-like characteristics due to the aliasing distortion of the pulse-width modulator. The AF-PWMT and the CRFAF-PWMT show a near linear behavior, with the CRFAF-PWMT showing a better linearity. The distortion in amplitude linearity of AF-PWMT is due to the AM-AM distortion of the class AB PA, whereas for the CRAF-PPWMT it is due to the limited switching speed of the MOS devices. Finally, the AC-PWMT 


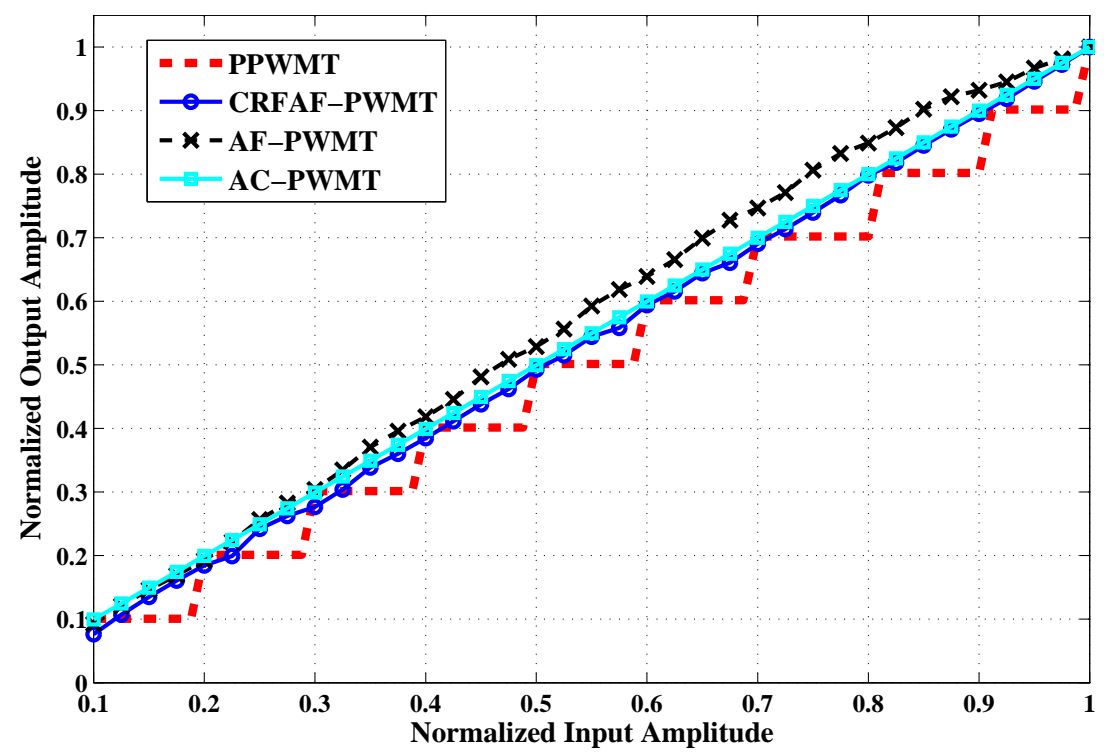

Figure 4.10: Amplitude linearity plot of the PPWMT, CRFAF-PPWMR, AFPWMT and AC-PWMT.

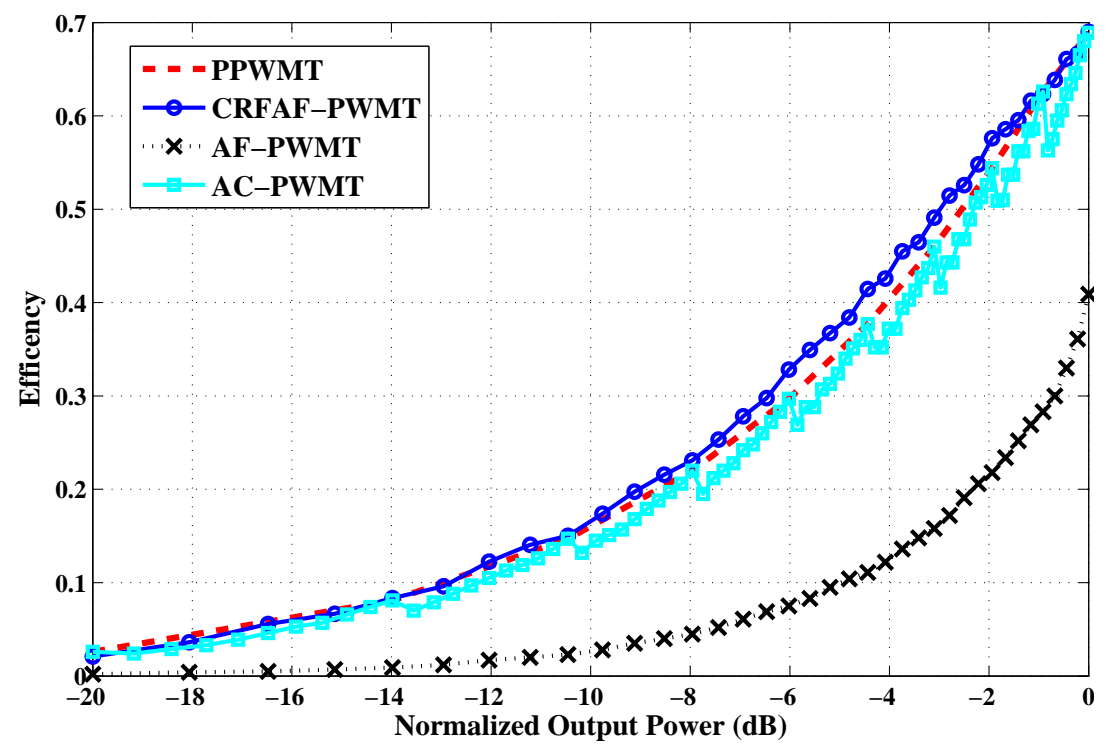

Figure 4.11: Instantaneous efficiency plot of the PPWMT, CRFAF-PWMT, AF-PWMT and AC-PWMT. 
Table 4.1: Specification and performance of PPWMT, AF-PWMT, CRFAFPWMT and AC-PWMT

\begin{tabular}{|c|c|c|c|c|}
\hline & PPWMT & AF-PWMT & CRFAF-PWMT & AC-PWMT \\
\hline $\begin{array}{c}\text { Dynamic } \\
\text { Range }\end{array}$ & $28 \mathrm{~dB}$ & $33.4 \mathrm{~dB}$ & $45 \mathrm{~dB}$ & $35 \mathrm{~dB}$ \\
\hline $\begin{array}{c}\text { Average } \\
\text { Efficiency }\end{array}$ & $33 \%$ & $8.3 \%$ & $34 \%$ & $31.5 \%$ \\
\hline $\begin{array}{c}\text { PA } \\
\text { Type } \\
\text { Quantity } \\
\text { Peak Power } \\
\text { Peak } \\
\text { Efficiency }\end{array}$ & $\begin{array}{c}\text { Class D } \\
1 \\
30 \mathrm{dBm} \\
69 \%\end{array}$ & $\begin{array}{c}\text { Class AB } \\
1 \\
30 \mathrm{dBm} \\
60 \%\end{array}$ & $\begin{array}{c}\text { Class D } \\
1 \\
30 \mathrm{dBm} \\
69 \%\end{array}$ & $\begin{array}{c}\text { Class D } \\
2 \\
27 \mathrm{dBm} \\
69 \%\end{array}$ \\
\hline $\begin{array}{c}\text { Carrier } \\
\text { Frequency }\end{array}$ & $1 \mathrm{GHz}$ & $1 \mathrm{GHz}$ & $1 \mathrm{GHz}$ & $1 \mathrm{GHz}$ \\
\hline $\begin{array}{l}\text { Baseband } \\
\text { Input }\end{array}$ & $\begin{array}{l}\text { LTE-UL } \\
1.4 \mathrm{MHz}\end{array}$ & $\begin{array}{l}\text { LTE-UL } \\
1.4 \mathrm{MHz}\end{array}$ & $\begin{array}{l}\text { LTE-UL } \\
1.4 \mathrm{MHz}\end{array}$ & $\begin{array}{l}\text { LTE-UL } \\
1.4 \mathrm{MHz}\end{array}$ \\
\hline
\end{tabular}

shows the best linearity among all the compared transmitters.

The instantaneous efficiency of the transmitters is shown in Fig. 4.11. The CRFAF-PWMT outperforms the other transmitters, whereas the AC-PWMT has a better efficiency compared to the AF-PWMT.

Table 4.1 shows the performance of the PPWMT, AF-PWMT, CRAF-PWMT and AC-PWMT for a $1.4 \mathrm{MHz}$ LTE up-link signal. It can be seen that the CRFAF-PPWMT has the highest efficiency and dynamic range as compared to all other transmitters. The AC-PWMT has a higher dynamic range and similar efficiency compared to the PPWMT. The AF-PWMT has the lowest efficiency among all transmitters.

\subsection{Enhanced Phase Resolution All-Digital PWM Trans- mitter}

An enhanced phase resolution PWM transmitter (EP-PWMT) is presented in Paper D. The EP-PWMT increases the phase resolution of an all-digital PPWMT by using asymmetric outphasing. The limited phase resolution in the all-digital PPWMT is caused by the phase-aliasing distortion due to the digital phase modulator. 


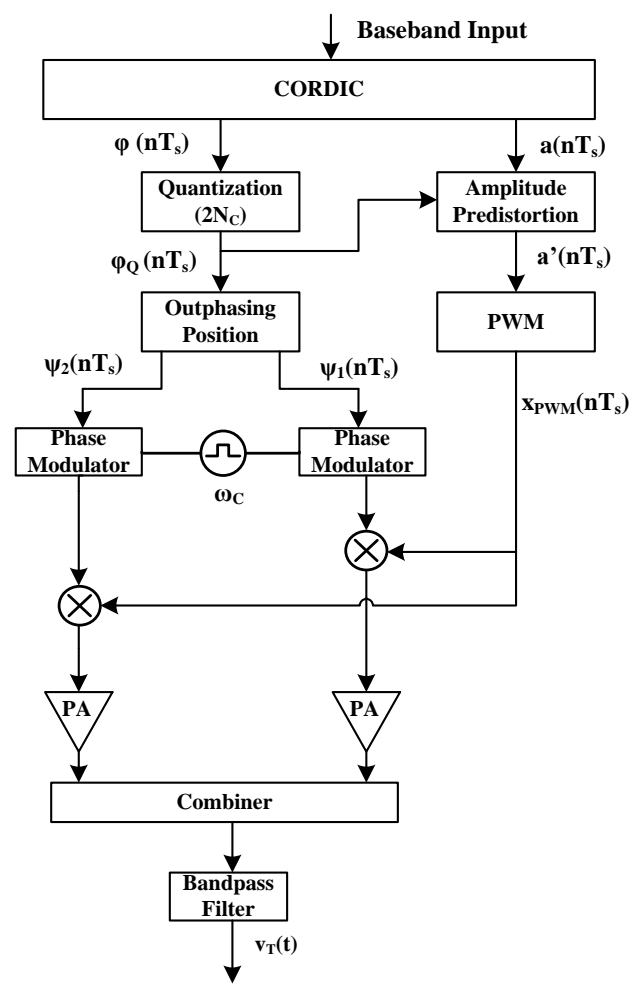

Figure 4.12: Block diagram of the EP-PWMT.

The block diagram of the EP-PWMT is shown in Fig. 4.12. It uses a CORDIC to separate the baseband input signal into its phase and amplitude components. The phase component is quantized into $2 N$ levels for a digital phase modulator of resolution $N$. Depending on the value of the quantized phase, both phase modulators either generate symmetrical phase-modulated carriers or asymmetrical phase-modulated carriers shifted by the minimum phase resolution of the phase modulator. The amplitude component is first pre-distorted to overcome the mismatch in the transmitted signal amplitude due to outphasing and then converted into a PWM signal. This PWM signal is then multiplied by phase-modulated carriers to generate carrier-based PWM signals, which are combined, amplified and then filtered to generate the final transmitted signal.

The simulated performance of the EP-PMWT and the all-digital PPWMT for a class D PAs designed in $130 \mathrm{~nm}$ CMOS is shown in table 4.2. The simulation results show that the EP-PWMT has a better EVM and dynamic range as 
Table 4.2: Performance of the all-digital PPWMT and EP-PWMT.

\begin{tabular}{ccc}
\hline \hline & PPWMT & EP-PWMT \\
\hline \hline Peak Power & $30 \mathrm{dBm}$ & $30 \mathrm{dBm}$ \\
Average Efficiency & $33 \%$ & $32.8 \%$ \\
Dynamic Range & $29.8 \%$ & $33 \%$ \\
EVM & $6.9 \%$ & $3.8 \%$ \\
\hline \hline
\end{tabular}

compared to the all-digital PPWMT, whereas the efficiencies of the transmitters are similar. 


\section{Chapter 5}

\section{Polar PWM Transmitters with Relaxed Band-Pass Filtering}

Chapter 3 discussed the band-pass filtering requirements and the amplitude resolution of the PPWMT. The band-pass filter requirements for the PPWMT are dependent on the PWM pulse-repetition frequency (PRF), i.e., with higher $\mathrm{PRF}$, a more relaxed band-pass filter is required but on the other side the transmitter has a lower amplitude resolution. This chapter discusses PWM transmitters that enhance the amplitude resolution while relaxing the band-pass filtering requirements.

The outline of this chapter is as follows: The first section discusses the multilevel PWM transmitter. In the second section, the multiphase PWM transmitter is discussed. The third section gives a brief overview of the combined RF and multi-level PWM transmitter (CRF-ML-PWMT) presented in Paper E. The last section discusses the combined RF and multiphase PWM transmitter (CRF-ML-PWMT) presented in Paper F.

\subsection{Multi-Level PWM Transmitter}

\subsubsection{Concept}

The multi-level PWM transmitter (ML-PWMT) [68, 69, 78, 79] uses multiple PWM signals in order to improve the amplitude resolution, which results in an improved dynamic range. However, the major issue for the transmitter is the 


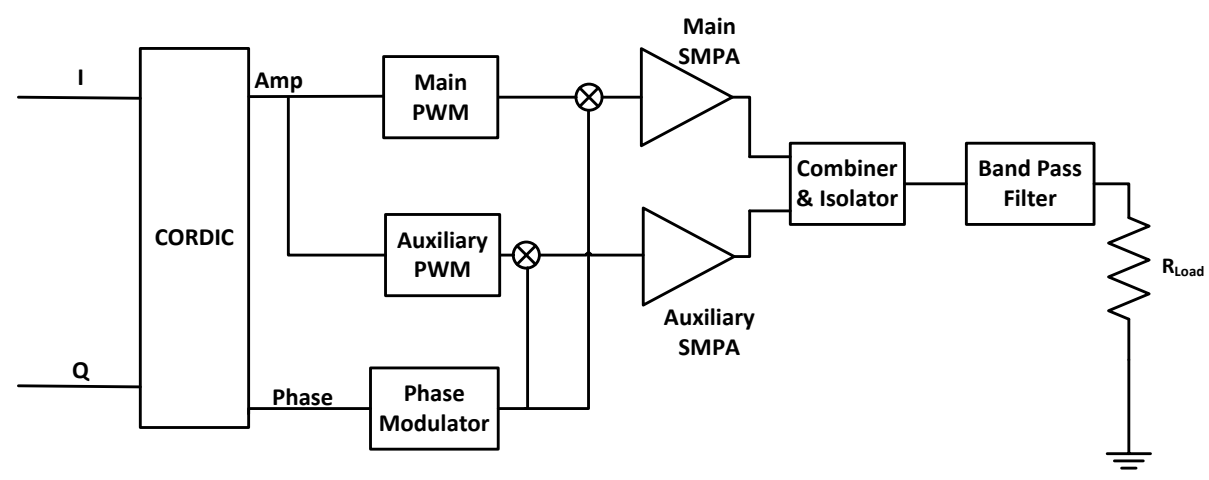

Figure 5.1: Block diagram of the 2 level PWM Transmitter.

larger chip area, which is due to the requirement of multiple PAs followed by a power combiner.

The block diagram of a two-level PWM transmitter is shown in Fig. 5.1. The transmitter separates the baseband signal $x(t)$ into its amplitude $a(t)$ and phase $\phi(t)$ components. The amplitude component generates two PWM signals. For $a(t) \leq V_{1}$, only the main PWM signal is generated with a duty-cycle proportional to $a(t)$, whereas for $V_{1}<a(t) \leq 1$ an auxiliary PWM signal is generated along with the main PWM signal, such that the duty cycle of the auxiliary PWM is proportional to $a(t)-V_{1}$ and the main PWM signal has $100 \%$ duty cycle. The generation of PWM signals is expressed as (5.1), where $V_{1}$ is the threshold voltage.

$$
\left.\begin{array}{c}
x_{P W M_{\text {main }}}=a(t) \\
+V_{1} \sum_{k=1}^{\infty} \frac{2}{k \pi} \sin \left(k \pi a(t) / V_{1}\right) \cos \left(\omega_{I F} k t\right) \\
x_{P W M_{a u x}}=0
\end{array}\right\} a(t) \leq V_{1}
$$

The phase component $\phi(t)$ on the other hand generates a phase-modulated carrier, which is multiplied by the PWM signals to generate the main and auxiliary carrier-based PWM (CPWM) signals. These signals are expressed as

$$
\left.\begin{array}{rl}
x_{C P W M_{\text {main }}} & =x_{P W M_{\text {main }}} \times \cos \left(\omega_{c} t+\phi(t)\right) \\
x_{C P W M_{\text {aux }}} & =x_{P W M_{\text {aux }}} \times \cos \left(\omega_{c} t+\phi(t)\right)
\end{array}\right\} .
$$


These CPWM signals are amplified by separate PAs and then combined to generate a two-level composite signal, given as

$$
x_{2 l e v e l-C P W M}\left\{\begin{array}{l}
A x_{C P W M_{\text {main }}} \\
A x_{C P W M_{\text {main }}}+A x_{C P W M_{\text {aux }}}
\end{array}\right.
$$

where $A$ is the gain of PAs. It is evident from (5.3) that the two-level PWMT has twice the amplitude resolution compared to the PPWMT. The two-level composite signal is finally filtered to generate the amplified transmitted signal.

In case of a generalized M-level PWMT, there are M pulse-width modulated signals, which are multiplied by a phase-modulated carrier to generate M CPWM signals. These M CPWM signals are power amplified and combined to generate an M-level composite signal, which is filtered to generate the transmitted signal. The M-level PWMT has an amplitude resolution that is M times that of the PPWMT, however it requires M SMPAs followed by a power combiner.

\subsubsection{Efficiency}

As discussed in chapter 3 and 4, the major power consumption of a transmitter is due to the PAs and the circuitry following it, so the efficiency of an ML-PWMT for a constant input amplitude $a$ is given as

$$
\eta(a)=\eta_{P A}(a) \eta_{c o m b}(t) \eta_{C}(a)
$$

where $\eta_{P A}$ is the efficiency of PAs, $\eta_{c o m b}$ is the efficiency of the combiner and $\eta_{C}$ is the coding efficiency. In case where all the PAs are switch-mode and have the same efficiency, then $\eta_{P A}(a)$ for all amplitudes is given as

$$
\eta_{P A}=\eta_{P A(\text { Peak })}
$$

The $\eta_{c o m b}(a)$ depends on the type of the combiner. In case of an ideal combiner it is given as

$$
\eta_{\text {comb }}(a)=1 \text {. }
$$

The $\eta_{C}(a)$ for the ML-PWMT is the ratio of the transmitted signal power to the output power at the combiner, hence it depends on the number of PAs used. In case of a two-level PWMT, either only a single PA is operational or both PAs are operational. The coding efficiency when only the main PA is operational is determined in a similar manner as the coding efficiency of the PWMT and is expressed as $[68,70]$

$$
\eta_{C_{1}}(a)=\frac{\frac{1}{2} a^{2}}{\frac{1}{T} \int_{0}^{\tau_{\operatorname{main}}(a)}\left(V_{1} \cos \left(2 \pi f_{c} t\right)\right)^{2} d t}=\frac{a}{V_{1}} \quad \in\left(0, V_{1}\right]
$$


where $\tau_{\text {main }}(a)$ is the duty cycle of $x_{P W M_{\text {main }}}, V_{1}$ is its peak amplitude (threshold voltage) and $T$ is its pulse-repetition period. The relationship between $\tau_{\text {main }}(a)$ and $\mathrm{a}$ is given as

$$
\tau_{\text {main }}(a)=\frac{a}{V_{1}} T \text {. }
$$

The coding efficiency, when both main PA and auxiliary PA are operational, is determined as follows

$$
\eta_{C_{1}}(a)=\frac{P_{T}(a)}{P_{P W M_{\text {main }}}(a)+P_{P W M_{a u x}}(a)} .
$$

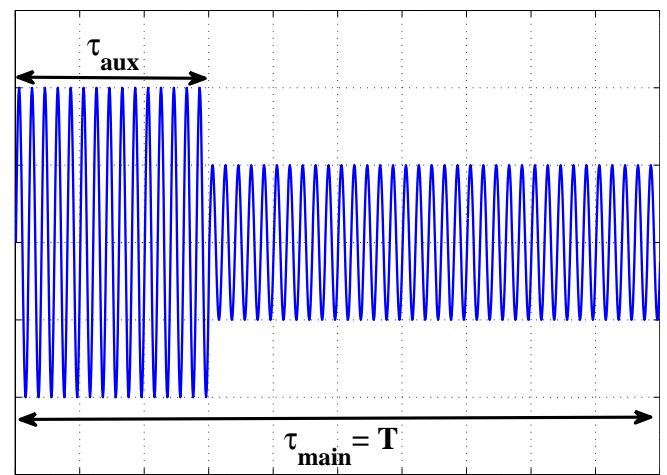

Figure 5.2: The waveform at the output of combiner when both main and auxiliary PAs are operational.

Fig. 5.2 shows the waveform at the output of the combiner, when both main and auxiliary PAs are operational, where $\tau_{a u x}$ is the pulse-width of the $x_{P W M_{a u x}}$ and $\tau_{\text {main }}=T$ is the pulse-width of the $x_{P W M_{\text {main }}}$, thus $\eta_{C_{2}}$ (a) is further elaborated as $[68,70]$

$$
\begin{aligned}
\eta_{C_{2}(a)} & =\frac{\frac{1}{2} a^{2}}{\frac{1}{T} \int_{0}^{\tau_{a u x(a)}}\left(\cos \left(2 \pi f_{c} t\right)\right)^{2} d t+\frac{1}{T} \int_{0}^{1-\tau_{a u x(a)}}\left(V_{1} \cos \left(2 \pi f_{c} t\right)\right)^{2} d t} \\
& =\frac{a^{2}}{a\left(V_{1}+1\right)-V_{1}} \quad \in\left(V_{1}, 1\right] .
\end{aligned}
$$

The generalized coding efficiency for an M-level PWMT is determined in a similar manner as the two-level PWMT and it is represented as [68, 70]

$$
\eta_{C}(a) \begin{cases}0 & \text { for } a=0 \\ \frac{a^{2}}{a\left(V_{m-1}+V_{m}\right)-V_{m-1} V_{m}} & \text { for } a \in\left(V_{m-1}, V_{m}\right] ; m \in[1, M]\end{cases}
$$

where $M$ represents the total number of PWM signals, $V_{M}$ is $1 V$ and $V_{0}$ is $0 \mathrm{~V}$. 


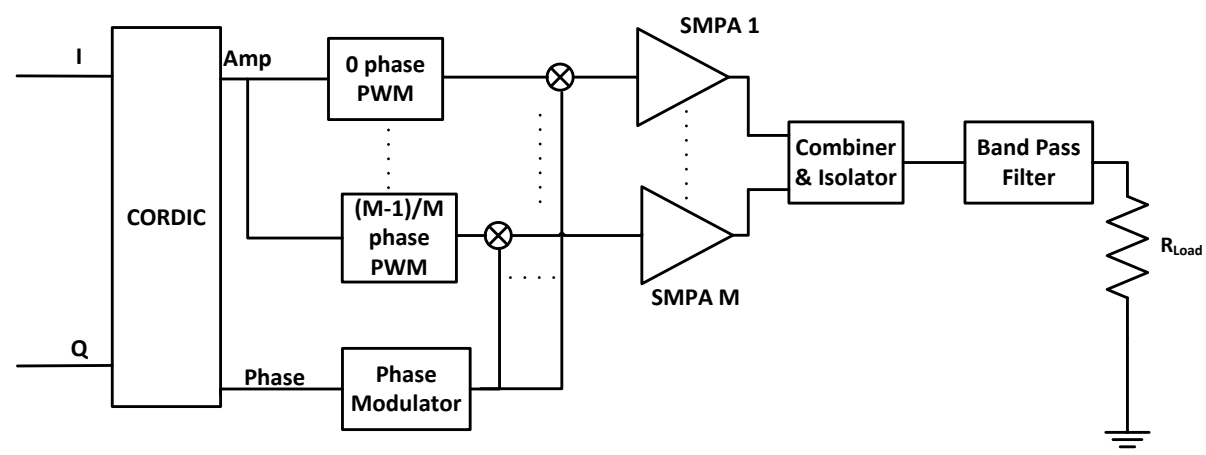

Figure 5.3: Block diagram of the M-phase PWM transmitter.

\subsection{Multi-Phase PWM Transmitter}

\subsubsection{Concept}

The multi-phase PWM transmitter (MP-PWMT) [80, 81] uses multiple timeshifted PWM signals in order to relax the final band-pass filtering requirements while achieving a similar amplitude resolution as the PPWMT. However, like the ML-PWMT it also requires multiple PAs and a combiner, hence its implementation needs a larger chip area.

The block diagram of the M-phase PWMT is shown in Fig. 5.3. The transmitter separates the baseband signal $x(t)$ into phase $\phi(t)$ and amplitude $a(t)$ components. The $\phi(t)$ generates the phase modulated carrier. The $a(t)$ generates M PWM signals that are time shifted by a factor $T / M$. The M PWM signals are expressed as

$$
\begin{aligned}
& v_{1 P W M}=\frac{a(t)}{M}+\sum_{k=1}^{\infty} \frac{2}{M k \pi} \sin (k \pi a(t)) \cos \left(\omega_{I F} k t\right) \\
& v_{2 P W M}=\frac{a(t)}{M}+\sum_{k=1}^{\infty} \frac{2}{M k \pi} \sin (k \pi a(t)) \cos \left(\omega_{I F} k t+\frac{2 k \pi}{M}\right) \\
& - \\
& - \\
& v_{M P W M}=\frac{a(t)}{M}+\sum_{k=1}^{\infty} \frac{2}{M k \pi} \sin (k \pi a(t)) \cos \left(\omega_{I F} k t+\frac{2 k \pi}{M-1}\right)
\end{aligned}
$$

The M PWM signals are multiplied by the phase-modulated carrier to 
generate M CPWM signals, which are given as

$$
\left.\begin{array}{l}
v_{1 C P W M}=\left(\frac{a(t)}{M}+\sum_{k=1}^{\infty} \frac{2}{M k \pi} \sin (k \pi a(t)) \cos \left(\omega_{I F} k t\right)\right) \cos \left(\omega_{c} t+\phi(t)\right) \\
v_{2 C P W M}=\left(\frac{a(t)}{M}+\sum_{k=1}^{\infty} \frac{2}{M k \pi} \sin (k \pi a(t)) \cos \left(\omega_{I F} k t+\frac{2 k \pi}{M}\right)\right) \cos \left(\omega_{c} t+\phi(t)\right) \\
- \\
v_{M C P W M}=\left(\frac{a(t)}{M}+\sum_{k=1}^{\infty} \frac{2}{M k \pi} \sin (k \pi a(t)) \cos \left(\omega_{I F} k t+\frac{2 k \pi}{M-1}\right)\right) \cos \left(\omega_{c} t+\phi(t)\right)
\end{array}\right\} .
$$

The CPWM signals are power amplified and combined to generate the M-phase CPWM signal (MP-CPWM), which is given as

$$
\begin{aligned}
& v_{M P-C P W M}=A a(t) \cos \left(\omega_{c} t+\phi(t)\right) \\
& A \sum_{m=0}^{M-1} \sum_{k=1}^{\infty} \frac{2}{M k \pi} \sin (k \pi a(t)) \cos \left(\omega_{I F} k t+\frac{2 m k \pi}{M}\right) \cos \left(\omega_{c} t+\phi(t)\right) .
\end{aligned}
$$

The transmitter then finally filters the $v_{M P-C P W M}$ to generate the final transmitted signal. It is evident from (5.14) the nearest harmonic for the MPhase PPWMT occurs at $M \times \omega_{I F}$, which relaxes the final band-pass filter requirements as compared to the PPWMT where the nearest harmonic occurs at $\omega_{I F}$.

\subsubsection{Efficiency}

The derivation of efficiency for MP-PWMT is similar to the ML-PWMT, so the efficiency of the multi-phase transmitter is given as

$$
\eta(a)=\eta_{P A}(a) \eta_{c o m b}(a) \eta_{C}(a)
$$

where $\eta_{P A}=\eta_{P A(P e a k)}$ for the case of switch-mode PA, $\eta_{c o m b}=1$ for case of an ideal combiner and $\eta_{C}$ is the ratio of the transmitted signal power to the combiner output power. The coding efficiency for the MP-PPWMT is expressed as

$$
\eta_{C}(a)=\frac{P_{T}(a)}{P_{M P-C P W M}(a)}=\frac{\frac{1}{2} a^{2}}{\frac{1}{T} \int_{0}^{T} v_{M P-C P W M}^{2} d t} .
$$




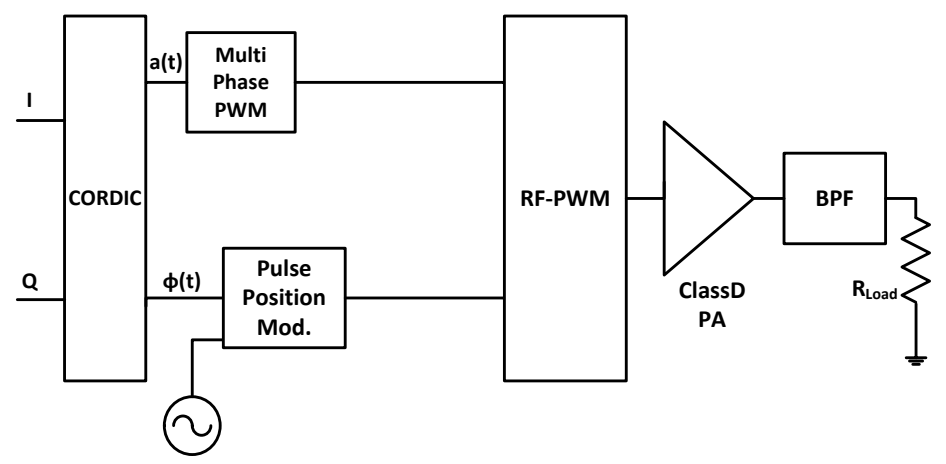

Figure 5.4: Block diagram of the CRF-ML-PWMT.

The (5.16) is simplified as [80]

$$
\eta_{C}=\left\{\begin{array}{cl}
\frac{a}{\left(\frac{1}{M}\right)} & a \in\left(0, \frac{1}{M}\right] \\
\frac{a^{2}}{a\left(\frac{1}{M}+\frac{2}{M}\right)-\frac{2}{M^{2}}} & a \in\left(\frac{1}{M}, \frac{2}{M}\right] \\
- & \\
- & a \in\left(\frac{M-1}{M}, 1\right]
\end{array} .\right.
$$

\subsection{Combined RF and ML-PWM Transmitter}

The combined RF and ML-PWM transmitter (CRF-ML-PWMT) is the contribution of the Paper E. This section briefly discusses the concept of the CRF-ML-PWMT and its simulated efficiency for an ideal SMPA. The detailed discussion on the transmitter along with a possible implementation is given in Paper E.

The CRF-ML-PPWMT combines the RF-PWM and ML-PWM to eliminate multiple PAs and a combiner, hence resulting in a smaller chip area. The transmitter also shows a better efficiency compared to the ML-PWMT and a larger dynamic as compared to the RF-PWMT.

The block diagram of CRF-ML-PWMT is shown in Fig. 5.4. The transmitter separates the baseband signal into amplitude and phase component. The amplitude component generates the multilevel PWM signal, whereas the phase component generates the pulse-position modulated signal. These pulseposition modulated and multi-level PWM signals are input to the RF pulse-width modulator to generate an RF pulse-width and pulse-position modulated sig- 
nal (RF-PWPM), which is amplified by an SMPA and filtered to generate the transmitted signal.

The simulation results of instantaneous efficiency of the combined RF and three-level PWM transmitter using an ideal SMPA is shown in Fig. 5.5.

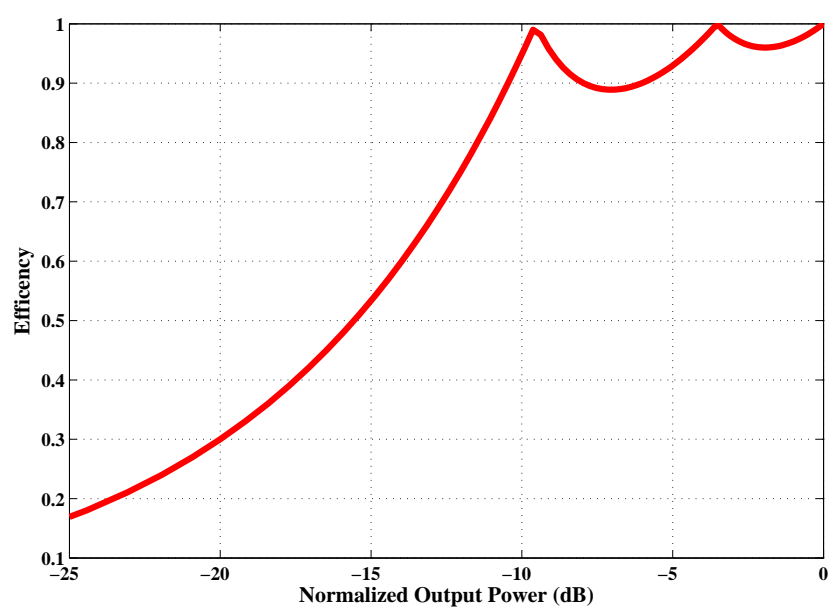

Figure 5.5: Instantaneous efficiency of the combined RF and three-level PWM transmitter using an ideal SMPA.

\subsection{Combined RF and MP-PWM Transmitter}

The combined RF and MP-PWM transmitter(CRF-MP-PWMT) is the contribution of the Paper F. This section briefly discusses the concept of the polar and quadrature CRF-MP-PWMT and its simulated efficiency for an ideal SMPA. The detailed description along with mathematical expressions are given in Paper F.

The CRF-MP-PWMT has a smaller chip area compared to the multiphase PPWMT as it does not require multiple PAs and a combiner. The transmitter combines RF-PWM and multiphase PWM to achieve a larger dynamic range and better amplitude resolution at a higher frequency compared to the RF-PWMT and a better efficiency compared to the MP-PWMT.

The block diagram of the polar CRF-MP-PWMT is shown in Fig. 5.6. The transmitter first decomposes the baseband signal into phase and amplitude components. The phase component generates the pulse-position modulated 


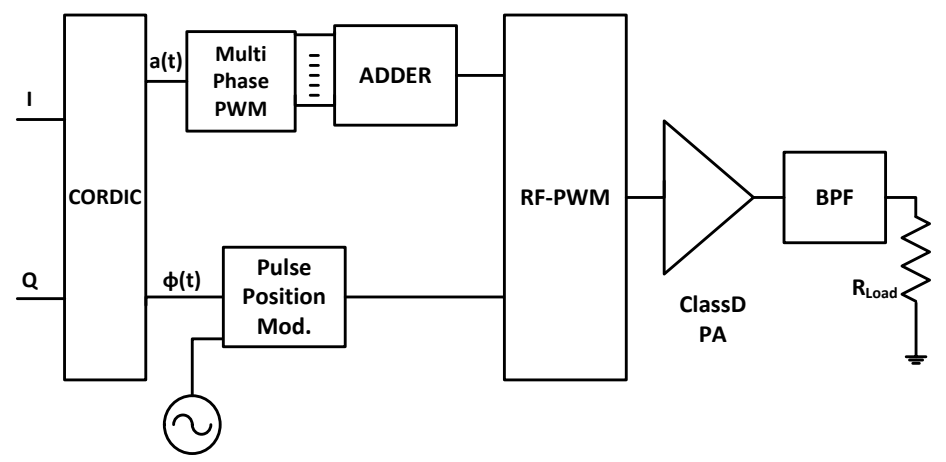

Figure 5.6: Block diagram of the polar CRF-MP-PWMT.

signal. The amplitude component generates the multiphase PWM signals which are combined to generate the composite signal. This composite PWM signal varies the pulse width of the pulse-position modulated signal to generate the RF pulse-width and pulse-position modulated signal, which is amplified by an SMPA and filtered to generate the transmitted signal.

The block diagram of the quadrature CRF-MP-PWMT is shown in Fig. 5.7. This architecture decomposes the baseband signal into four components, two positive components $I_{P}$ and $Q_{P}$, and two negative components $I_{N}$ and $Q_{N}$. These components generate their respective composite signals, which pulse-width modulate the time-shifted RF carriers. These pulse-width modulated RF carriers have a maximum pulse width of a quarter of the pulse-repetition period of the carrier and they are input to a MUX to generate a single combined RF multiphase PWM carrier signal. This signal is then power amplified by an SMPA and finally filtered to generate the transmitted signal.

The simulation results of instantaneous efficiency of the combined RF twophase PWM transmitter using an ideal SMPA is shown in Fig. 5.8. 


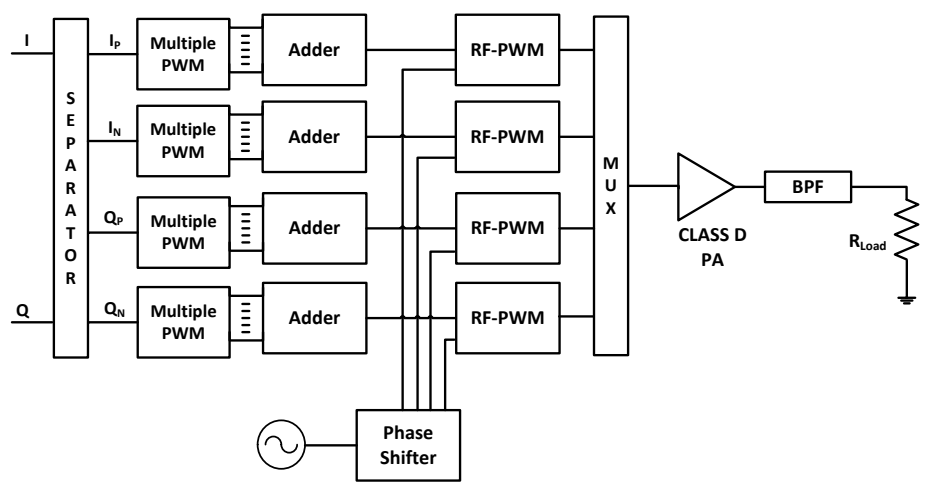

Figure 5.7: Block diagram of the quadrature CRF-MP-PWMT.

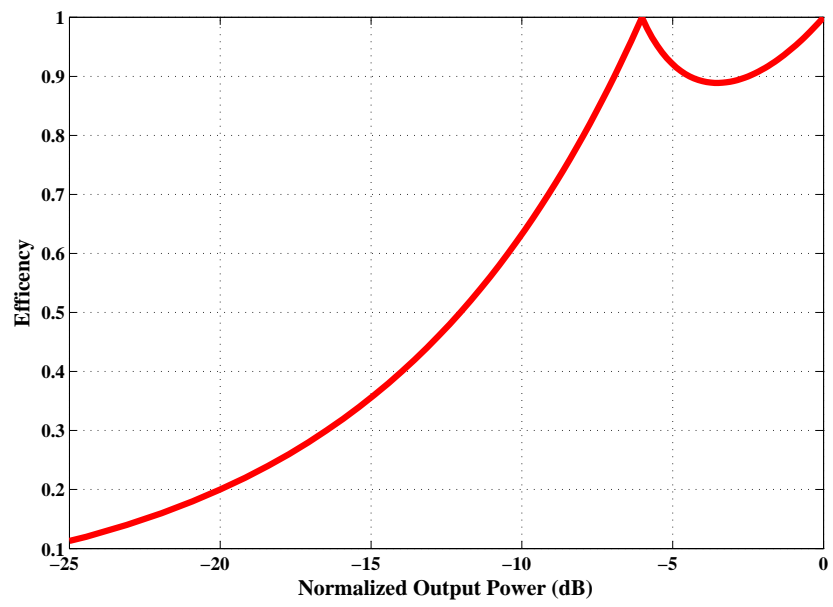

Figure 5.8: Instantaneous efficiency of the combined RF and two-phase PWM transmitter using an ideal SMPA. 


\section{Chapter 6}

\section{Conclusions and Future Trends}

The linearity and efficiency are important parameters in determining the performance of wireless transmitters. By using PWM techniques we can make a trade-off between these parameters while allowing all-digital implementation. However, the PWM-based transmitters suffer from aliasing and image distortions. This thesis focuses on techniques to reduce the effects of these distortions by modifying the architectures of conventional PWM transmitters.

Multiple transmitters have been proposed in this thesis that use PWM along with other linearization techniques to improve the spectral performance characteristics and efficiency. The focus has been to make use of SMPAs, which have a higher efficiency as compared to linear PAs. To emphasize the digital nature of the proposed architectures, one of the transmitter is completely implemented using an FPGA followed by SMPAs for power amplification.

The transmitter proposed in Paper A eliminates amplitude aliasing and image distortion by combining RF-PWM and band-limited PWM. Class-D SMPAs fabricated in $130 \mathrm{~nm}$ CMOS have been used to verify the performance of the proposed transmitter which shown an improvement of $10.2 \mathrm{~dB}$ in the dynamic range.

The PWM transmitters proposed in Paper B and Paper C compensate for the amplitude aliasing and image distortion due to PWM by using outphasing. The concept is verified using linear PAs in Paper $\mathbf{B}$, whereas in Paper $\mathbf{C}$, an all-digital implementation using an FPGA and Class-D SMPAs is presented. The measurements clearly show an improvement in the linearity of proposed transmitter as compared to the other PWM based transmitters. 
In Paper D, a technique to improve the phase linearity of all-digital PWM based transmitters is presented. An asymmetric outphasing technique is used to effectively double the phase resolution. The measurement results show an improvement of $2.8 \mathrm{~dB}$ in the adjacent channel leakage ratio with a $3.3 \%$ reduction in the EVM.

Paper E and Paper F present area-efficient implementations for multiphase and multilevel PWM transmitters by eliminating the need for a combiner. From the simulations improvements in dynamic range and efficiency are observed as compared to conventional PWM transmitters.

For battery-powered wireless devices with multiple transceivers, the linearity and efficiency of the transmitters are important performance parameters. In recent years, PWM-based wireless transmitters have been gaining popularity due to their higher efficiency at the cost of increased distortion. This thesis presents techniques to reduce the distortion in PWM-based transmitters. As the demand for data rates increase it would be interesting to study the use of PWM transmitters for simultaneous multi-band transmission. Another interesting area to explore is the feasibility of using PWM based transmitters in the $60 \mathrm{GHz}$ band. 
References 



\section{References}

[1] F. Raab, "Radio frequency pulsewidth modulation," IEEE Trans. Commun., vol. 21, no. 8, pp. 958-966, Aug 1973.

[2] F. H. Raab, P. Asbeck, S. Cripps, P. B. Kenington, Z. B. Popovic, N. Pothecary, J. F. Sevic, and N. O. Sokal, "RF and microwave power amplifier and transmitter technologies-Part 5," High Frequency Electronics, pp. 46-54, Jan 2004.

[3] B. Razavi, RF microelectronics, Chapter 4, 2nd ed. Prentice Hall, 2011.

[4] Q. Gu, RF system design of transceivers for wireless communications, Chapter 3. Springer Science \& Business Media, 2005.

[5] F. H. Raab, P. Asbeck, S. Cripps, P. B. Kenington, Z. B. Popovic, N. Pothecary, J. F. Sevic, and N. O. Sokal, "RF and microwave power amplifier and transmitter technologies-Part 1," High Frequency Electronics, vol. 2, no. 3, pp. 22-36, May 2003.

[6] P. A. Dal Fabbro and M. Kayal, Linear CMOS RF Power Amplifiers for Wireless Applications: Efficiency Enhancement and Frequency-tunable Capability. Springer Science \& Business Media, 2010.

[7] A. Raghavan, N. Srirattana, and J. Laskar, Modeling and design techniques for RF power amplifiers. John Wiley \& Sons, 2008.

[8] T. Johansson and J. Fritzin, "A review of Watt-level CMOS RF power amplifiers," IEEE Trans. Microw. Theory Tech., vol. 62, no. 1, pp. 111-124, Jan 2014.

[9] F. H. Raab, P. Asbeck, S. Cripps, P. B. Kenington, Z. B. Popovic, N. Pothecary, J. F. Sevic, and N. O. Sokal, "RF and microwave power amplifier and transmitter technologies-Part 2," High Frequency Electronics, 2003. 
[10] S. C. Cripps, RF power amplifiers for wireless communications, Chapter 2. Artech House, 1999.

[11] A. Grebennikov, N. O. Sokal, and M. J. Franco, Switchmode RF and microwave power amplifiers, Chapter 1. Academic Press, 2012.

[12] T. H. Lee, The design of CMOS radio-frequency integrated circuits, Chapter 13, 1st ed. Cambridge Univ. Press, 1998.

[13] S. C. Cripps, RF power amplifiers for wireless communications, Chapter 6. Artech House, 1999.

[14] A. Afsahi, A. Behzad, and L. E. Larson, "A 65nm CMOS 2.4GHz 31.5dBm power amplifier with a distributed LC power-combining network and improved linearization for WLAN applications," in Proc. ISSCC, Feb 2010, pp. $452-453$.

[15] O. Degani, F. Cossoy, S. Shahaf, D. Chowdhury, C. D. Hull, C. Emanuel, and R. Shmuel, "A 90nm CMOS power amplifier for 802.16e (WiMAX) applications," in Proc. RFIC, Jun 2009, pp. 373-376.

[16] D. Chowdhury, C. D. Hull, O. B. Degani, Y. Wang, and A. M. Niknejad, "A fully integrated dual-mode highly linear $2.4 \mathrm{GHz}$ CMOS power amplifier for 4G WiMax applications," IEEE J. Solid-State Circuits, vol. 44, no. 12, pp. 3393-3402, Dec 2009.

[17] J. Fritzin, C. Svensson, and A. Alvandpour, "Analysis of a 5.5-V class-D stage used in + 30-dBm outphasing RF PAs in 130 and 65-nm CMOS," IEEE Trans. Circuits Syst. II, vol. 59, no. 11, pp. 726-730, Nov 2012.

[18] — - "A +32 dBm 1.85 GHz class-D outphasing RF PA in 130nm CMOS for WCDMA/LTE," in Proc. ESSCIRC, Sep 2011, pp. 127-130.

[19] - "Design and analysis of a class-d stage with harmonic suppression," IEEE Trans. Circuits Syst. I, vol. 59, no. 6, pp. 1178-1186, Jun 2012.

[20] S. C. Cripps, RF power amplifiers for wireless communications, Chapter 6. Artech House, 1999.

[21] A. Grebennikov, N. O. Sokal, and M. J. Franco, Switchmode RF and microwave power amplifiers, Chapter 2. Academic Press, 2012. 
[22] Y. Song, S. Lee, E. Cho, J. Lee, and S. Nam, "A CMOS class-E power amplifier with voltage stress relief and enhanced efficiency," IEEE Trans. Microw. Theory Tech., vol. 58, no. 2, pp. 310-317, Feb 2010.

[23] C. Park, D. H. Lee, Y. Lee, J. Han, S. H. Baek, Y. Kim, and S. Hong, "1.8-GHz CMOS power amplifier with stage-convertible structure using differential line inductor," in Proc. RFIC, Jun 2007, pp. 741-744.

[24] H. Lee, C. Park, and S. Hong, "A quasi-four-pair class-E CMOS RF power amplifier with an integrated passive device transformer," IEEE Trans. Microw. Theory Tech., vol. 57, no. 4, pp. 752-759, Apr 2009.

[25] A. Grebennikov, N. O. Sokal, and M. J. Franco, Switchmode RF and microwave power amplifiers, Chapter 2. Academic Press, 2012.

[26] S. Moloudi, K. Takinami, M. Youssef, M. Mikhemar, and A. Abidi, "An outphasing power amplifier for a software-defined radio transmitter," in Proc. ISSCC, Feb 2008, pp. 568-636.

[27] M. E. Heidari, M. Lee, and A. A. Abidi, "All-digital outphasing modulator for a software-defined transmitter," IEEE J. Solid-State Circuits, vol. 44, no. 4, pp. 1260-1271, Apr 2009.

[28] F. H. Raab, P. Asbeck, S. Cripps, P. B. Kenington, Z. B. Popovic, N. Pothecary, J. F. Sevic, and N. O. Sokal, "RF and microwave power amplifier and transmitter technologies-Part 3," High Frequency Electronics, pp. 34-48, Sep 2003.

[29] W. B. Sander, S. V. Schell, and B. L. Sander, "Polar modulator for multimode cell phones," in Proc. CICC, Sep 2003, pp. 439-445.

[30] M. R. Elliott, T. Montalvo, B. P. Jeffries, F. Murden, J. Strange, A. Hill, S. Nandipaku, and J. Harrebek, "A polar modulator transmitter for GSM/EDGE," IEEE J. Solid-State Circuits, vol. 39, no. 12, pp. 2190-2199, Dec 2004.

[31] K. Onizuka, S. Saigusa, and S. Otaka, "A 1.8 GHz linear CMOS power amplifier with supply-path switching scheme for WCDMA/LTE applications," in Proc. ISSCC, Feb 2013, pp. 90-91.

[32] B. Razavi, RF microelectronics, Chapter 12, 2nd ed. Prentice Hall, 2011. 
[33] H. Chireix, "High power outphasing modulation," Proc. IRE, vol. 23, no. 11, pp. 1370-1392, Nov 1935.

[34] D. Cox, "Linear amplification with nonlinear components," IEEE Trans. Commun., vol. 22, no. 12, pp. 1942-1945, Dec 1974.

[35] M. Özen, "Advanced transmitter architectures based on switch mode power amplifiers," Ph.D. dissertation, Chalmers University of Technology, 2014.

[36] A. Grebennikov, "Power combiners, impedance transformers and directional couplers-Part 1," High Freq. Electronics, pp. 20-38, Dec 2007.

[37] — - "Power combiners, impedance transformers and directional couplersPart 2," High Freq. Electronics, pp. 42-53, Jan 2008.

[38] — - "Power combiners, impedance transformers and directional couplersPart 3," High Freq. Electronics, pp. 42-52, Feb 2008.

[39] J. Fritzin, "CMOS RF power amplifiers for wireless communications," Ph.D. dissertation, Linköping University, 2011.

[40] C. P. Conradi, R. H. Johnston, and J. G. McRory, "Evaluation of a lossless combiner in a LINC transmitter," in Proc. CCECE, vol. 1, May 1999, pp. $105-110$.

[41] A. Birafane and A. B. Kouki, "On the linearity and efficiency of outphasing microwave amplifiers," IEEE Trans. Microw. Theory Tech., vol. 52, no. 7, pp. 1702-1708, Jul 2004.

[42] Z. Abou-Chahine, T. Felgentreff, G. Fischer, and R. Weigel, "Efficiency analysis of the asymmetric 2-level outphasing PA with Rayleigh enveloped signals," in Proc. PAWR, Jan 2012, pp. 85-88.

[43] X. Zhang, L. E. Larson, P. M. Asbeck, and R. A. Langridge, "Analysis of power recycling techniques for $\mathrm{RF}$ and microwave outphasing power amplifiers," IEEE Trans. Circuits Syst. II, vol. 49, no. 5, pp. 312-320, May 2002.

[44] J. Xu and D. S. Ricketts, "An efficient, watt-level microwave rectifier using an impedance compression network (ICN) with applications in outphasing energy recovery systems," IEEE Microw. Wireless Compon. Lett., vol. 23, no. 10 , pp. 542-544, Oct 2013. 
[45] P. Godoy, S. Chung, T. Barton, D. Perreault, and J. Dawson, "A 2.4-GHz, 27-dBm asymmetric multilevel outphasing power amplifier in 65-nm CMOS," IEEE J. Solid-State Circuits, vol. 47, no. 10, pp. 2372-2384, Oct 2012.

[46] A. F. Aref, A. Askar, A. A. Nafe, M. M. Tarar, and R. Negra, "Efficient amplification of signals with high PAPR using a novel multilevel linc transmitter architecture," in Proc. EuMC, Oct 2012, pp. 1035-1038.

[47] K. Y. Jheng, Y. J. Chen, and A. Y. Wu, "Multilevel linc system designs for power efficiency enhancement of transmitters," IEEE Journal of Selected Topics in Signal Processing, vol. 3, no. 3, pp. 523-532, Jun 2009.

[48] J. Walling and D. Allstot, "Pulse-width modulated CMOS power amplifiers," IEEE Microw. Mag., vol. 12, no. 1, pp. 52-60, Feb 2011.

[49] M. Özen, R. Jos, C. Andersson, M. Acar, and C. Fager, "High-efficiency RF pulsewidth modulation of class-E power amplifiers," IEEE Trans. Microw. Theory Tech., vol. 59, no. 11, pp. 2931-2942, Nov 2011.

[50] S. Rosnell and J. Varis, "Bandpass pulse-width modulation (BP-PWM)," in Proc. IMS, Jun 2005.

[51] S. Kulkarni, I. Kazi, D. Seebacher, P. Singerl, F. Dielacher, W. Dehaene, and P. Reynaert, "Multi-standard wideband OFDM RF-PWM transmitter in 40nm CMOS," in Proc. ESSCIRC, Sep 2015, pp. 88-91.

[52] B. Shi and M. Chia, "On the performance of class-D power amplifiers with RF pulse-width modulation," in Proc. APMC, Dec 2011, pp. 1550-1553.

[53] N. Singhal, N. Nidhi, R. Patel, and S. Pamarti, "A zero-voltage-switching contour-based power amplifier with minimal efficiency degradation under back-off," IEEE Trans. Microw. Theory Tech., vol. 59, no. 6, pp. 1589-1598, Jun 2011.

[54] H. Song and R. Gharpurey, "Digitally intensive wireless transmitter architecture employing RF pulse width modulation," presented at DCAS, Oct 2014 .

[55] D. Seebacher, P. Singerl, C. Schuberth, F. Dielacher, Y. Papananos, N. Alexiou, K. Galanopoulos, M. E. Gadringer, and W. Bösch, "Predistortion of digital RF PWM signals considering conditional memory," IEEE Trans. Circuits Syst. I, vol. 62, no. 9, pp. 2342-2350, Sep 2015. 
[56] D. Seebacher, P. Singerl, C. Schuberth, F. Dielacher, P. Reynaert, and W. Bösch, "Reduction of aliasing effects of RF PWM modulated signals by cross point estimation," IEEE Trans. Circuits Syst. I, vol. 61, no. 11, pp. 3184-3192, Nov 2014.

[57] M. Haque, T. Johansson, and D. Liu., "Combined RF and multiphase PWM transmitter," presented at ECCTD, Aug 2015.

[58] M. Haque, T. Johansson, and D. Liu, "Combined RF and multilevel PWM switch mode power amplifier," presented at NORCHIP, Nov 2013.

[59] J. E. Volder, "The CORDIC trigonometric computing technique," Electronic Computers, IRE Trans on, vol. 8, no. 3, pp. 330-334, Sep 1959.

[60] A. Carlson, P. Crilly, and J. Rutledge, Communication systems: an introduction to signals and noise in electrical communication, Chapter 6. McGraw-Hill, 2002.

[61] B. Francois, P. A. J. Nuyts, W. Dehaene, and P. Reynaert, "Extending dynamic range of RF PWM transmitters," Electronics Letters, vol. 49, no. 6, pp. 430-432, Mar 2013.

[62] M. Taromaru, N. Ando, T. Kodera, and K. Yano, "An EER transmitter architecture with burst-width envelope modulation based on triangle-wave comparison PWM," presented at PIMRC, Sep 2007.

[63] P. Nuyts, B. Francois, W. Dehaene, and P. Reynaert, "A CMOS burstmode transmitter with watt-level RF PA and flexible fully digital front-end," IEEE Trans. Circuits Syst. II, vol. 59, no. 10, pp. 613-617, Oct 2012.

[64] P. Nuyts, P. Singerl, F. Dielacher, P. Reynaert, and W. Dehaene, "A fully digital delay line based $\mathrm{GHz}$ range multimode transmitter front-end in 65-nm CMOS," IEEE J. Solid-State Circuits, vol. 47, no. 7, pp. 1681-1692, Jul 2012.

[65] P. Nuyts, P. Reynaert, and W. Dehaene, "Frequency-domain analysis of digital PWM-based RF modulators for flexible wireless transmitters," IEEE Trans. Circuits Syst. I, vol. 61, no. 1, pp. 238-246, Jan 2014.

[66] H. Enzinger and C. Vogel, "Analytical description of multilevel carrier-based PWM of arbitrary bounded input signals," in Proc. ISCAS, Jun 2014, pp. 1030-1033. 
[67] Y.-S. Jeon and S. Nam, "A discrete-amplitude pulse width modulation for a high-efficiency linear power amplifier," ETRI Journal, vol. 33, no. 5, pp. 679-688, 2011.

[68] S. Chi, P. Singerl, and C. Vogel, "Efficiency optimization for burst-mode multilevel radio frequency transmitters," IEEE Trans. Circuits Syst. I, vol. 60, no. 7, pp. 1901-1914, Jul 2013.

[69] S. Chi, K. Hausmair, and C. Vogel, "Coding efficiency of bandlimited PWM based burst-mode RF transmitters," in Proc. ISCAS, May 2013, pp. $2263-2266$.

[70] S. Chi, C. Vogel, and P. Singerl, "The frequency spectrum of polar modulated PWM signals and the image problem," in Proc. ICECS, Dec 2010, pp. 679682.

[71] K. Hausmair, S. Chi, P. Singerl, and C. Vogel, "Aliasing-free digital pulsewidth modulation for burst-mode RF transmitters," IEEE Trans. Circuits Syst. I, vol. 60, no. 2, pp. 415-427, Feb 2013.

[72] A. Oppenheim and R. Schafer, Discrete-time Signal Processing. Pearson, 2013.

[73] K. Hausmair, P. Singerl, and C. Vogel, "Multiplierless implementation of an aliasing-free digital pulsewidth modulator," IEEE Trans. Circuits Syst. II, vol. 60, no. 9, pp. 592-596, Sep 2013.

[74] K. F. Liang, H. S. Yang, C. W. Chang, and J. H. Chen, "A wideband pulsemodulated polar transmitter using envelope correction for LTE applications," IEEE Trans. Microw. Theory Tech., vol. 63, no. 8, pp. 2603-2608, Aug 2015.

[75] J. H. Chen, C. W. Chang, and H. S. Yang, "Linearity enhanced widebandwidth pulse-modulated polar transmitters for LTE femtocell applications," IEEE Trans. Microw. Theory Tech., vol. 64, no. 1, pp. 219-225, Jan 2016.

[76] K. H.Enzinger and C.Vogel, "A joint linearity-efficiency model of radio frequency power amplifiers," in Proc. ISCAS, May 2016, pp. 281-284.

[77] H. Ochiai, "An analysis of band-limited communication systems from amplifier efficiency and distortion perspective," IEEE Trans. Commun., vol. 61, no. 4, pp. 1460-1472, Apr 2013. 
[78] J.-H. Chen, H.-S. Yang, and Y.-J. Chen, "A multi-level pulse modulated polar transmitter using digital pulse-width modulation," IEEE Microw. Wireless Compon. Lett., vol. 20, no. 5, pp. 295-297, May 2010.

[79] P. Singerl, C. Schuberth, M. Mataln, D. Seebacher, F. Dielacher, and T. Magesacher, "A 2.7-GHz multi-level PWM carrier-bursting RF transmitter," in Proc. EuMIC, Sep 2015, pp. 273-276.

[80] J.-H. Chen, H.-S. Yang, H.-C. Lin, and Y.-J. Chen, "A polar-transmitter architecture using multiphase pulsewidth modulation," IEEE Trans. Circuits Syst. I, vol. 58, no. 2, pp. 244-252, Feb 2011.

[81] M. Park and M. H. Perrott, "A multiphase PWM RF modulator using a VCO-based opamp in 45nm CMOS," in Proc. RFIC, May 2010, pp. 39-42. 


\section{Publications}

The articles associated with this thesis have been removed for copyright reasons. For more details about these see:

http://urn.kb.se/resolve?urn=urn:nbn:se:liu:diva-134023 


\section{Recent Dissertations \\ Division of Computer Engineering \\ Department of Electrical Engineering \\ Linköping University, Sweden}

A. Nilsson, Design of programmable multi-standard baseband processors, Linköping Studies in Science and Technology, Diss., No. 1084, May 2007.

A. Ehliar, Performance driven FPGA design with an ASIC perspective, Linköping Studies in Science and Technology, Diss., No. 1237, Feb. 2009.

D. Wu, Scalable Multi-Standard Radio Baseband for Modern Wireless Communications, Linköping Studies in Science and Technology, Diss., No. 1298, Nov. 2009 .

J. Eilert, ASIP for Wireless Communication and Media, Linköping Studies in Science and Technology, Diss., No. 1298, Feb. 2010.

R. Asghar, Flexible Interleaving Sub-systems for FEC in Baseband Processors, Linköping Studies in Science and Technology, Diss., No. 1312, May 2010.

P. A. Karlström, NoGAP: Novel Generator of Accelerators and Processors, Linköping Studies in Science and Technology, Diss., No. 1347, Nov. 2010.

J. Wang, Low Overhead Memory Subsystem Design for a Multicore Parallel DSP Processor, Linköping Studies in Science and Technology, Diss., No. 1532, May 2014 .

J. Sohl, Efficient Compilation for Application Specific Instruction set DSP Processors with Multi-bank Memories, Linköping Studies in Science and Technology, Diss., No. 1641, Feb. 2015.

S. A. Alam, Techniques for Efficient Implementation of FIR and Particle Filtering, Linköping Studies in Science and Technology, Diss., No. 1716, Feb. 2016.

A. Karlsson, Design of Energy-Efficient High-Performance ASIP-DSP Platforms, Linköping Studies in Science and Technology, Diss., No. 1772, Sep. 2016. 